Louisiana State University

LSU Digital Commons

2012

\title{
Measurement of interfacial tension in hydrocarbon/water/ dispersant systems at deepwater conditions
}

Mohamed Abdelrahim

Louisiana State University and Agricultural and Mechanical College

Follow this and additional works at: https://digitalcommons.Isu.edu/gradschool_theses

Part of the Petroleum Engineering Commons

\section{Recommended Citation}

Abdelrahim, Mohamed, "Measurement of interfacial tension in hydrocarbon/water/dispersant systems at deepwater conditions" (2012). LSU Master's Theses. 394.

https://digitalcommons.Isu.edu/gradschool_theses/394

This Thesis is brought to you for free and open access by the Graduate School at LSU Digital Commons. It has been accepted for inclusion in LSU Master's Theses by an authorized graduate school editor of LSU Digital Commons. For more information, please contact gradetd@lsu.edu. 


\title{
MEASUREMENT OF INTERFACIAL TENSION IN HYDROCARBON/WATER/DISPERSANT SYSTEMS AT DEEPWATER CONDITIONS
}

\author{
A Thesis \\ Submitted to the Graduate Faculty of the \\ Louisiana State University and \\ Agricultural and Mechanical College \\ in partial fulfillment of the \\ requirements for the degree of \\ Master of Science in Petroleum Engineering
}

In

The Craft \& Hawkins Department of Petroleum Engineering

by

Mohamed Abdelrahim

B.S. in Petroleum Engineering, Louisiana State University, 2008

May 2012 


\section{DEDICATION}

This work is dedicated to my parents and beloved family members... 


\section{ACKNOWLEDGEMENTS}

I thank Almighty God for giving me the strength, good health and drive to complete this work.

I am grateful to my advisor, Dr. Dandina Rao, for the guidance, encouragement and support he has provided throughout this work. I thank Dr. Rao for believing in me and giving me the opportunity to fulfill my dreams in achieving this degree.

I would also like to thank Dr. Seung Kam and Dr. Mileva Radonjic who served as members on my examination committee.

This work was made possible by a grant from BP/The Gulf of Mexico Research Initiative.

I am also grateful to Dr. Kalliat Valsaraj of the Department of Chemical Engineering at LSU for his valuable suggestions and recommendations. I thank Mr. Paul Rodriguez and Mr. Joe Bell of the Chemical Engineering Shop at LSU for all the diligent effort they have put in fabricating the high pressure optical cell.

I would like to specially thank Mauricio Toscano for his help with setting up the experimental apparatus. The support of Mr. Fenelon Nunes is greatly acknowledged as well. I also thank Dayanand Saini, Yu Zheng, and Ruiz Paidin for their technical assistance.

I would also like to express my gratitude to all the graduate faculty members and students of the Craft \& Hawkins Department of Petroleum Engineering for all the support I received throughout my studies.

I sincerely thank my family and friends for their moral support. 


\section{TABLE OF CONTENTS}

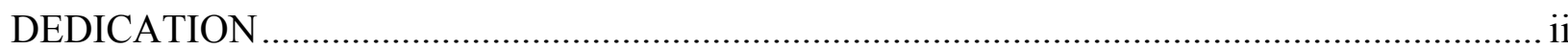

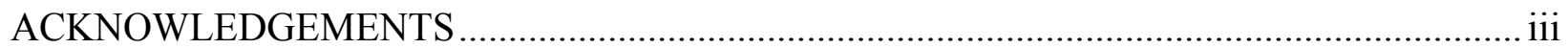

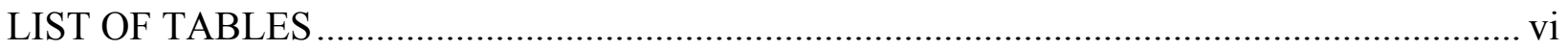

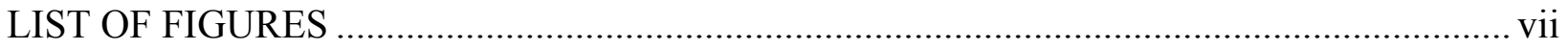

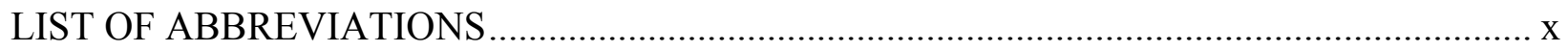

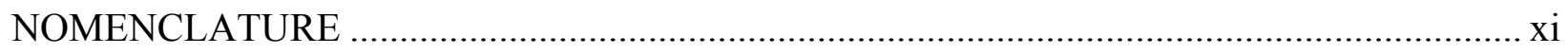

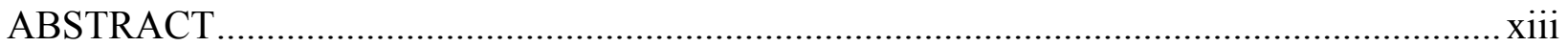

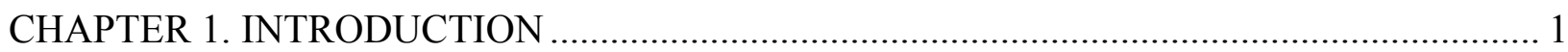

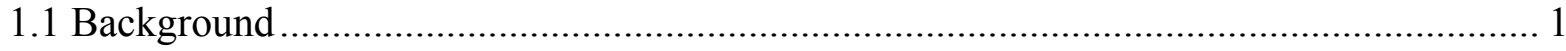

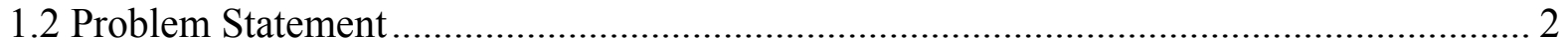

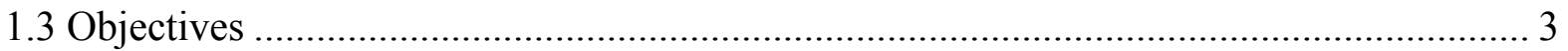

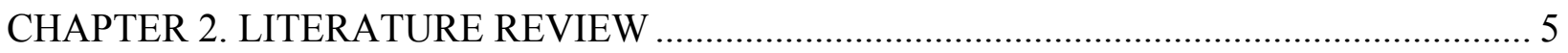

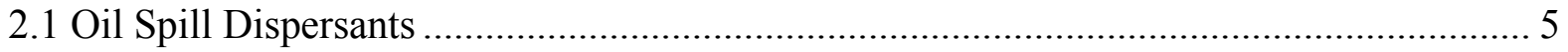

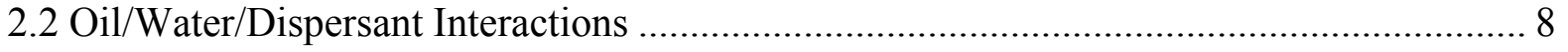

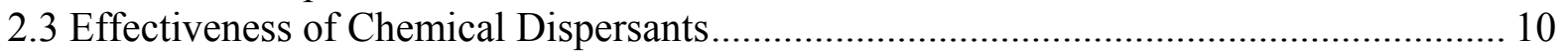

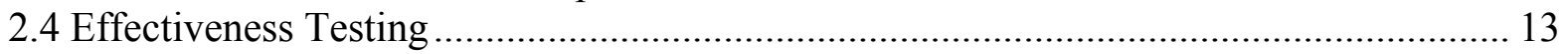

2.4.1 The Drop-Weight Test ..................................................................................... 14

2.4.2 The Spinning Drop Technique......................................................................... 17

2.5 Factors Affecting the Chemical Dispersion of Spilled Oil .............................................. 19

2.5.1 Properties and Composition of Oil .................................................................... 20

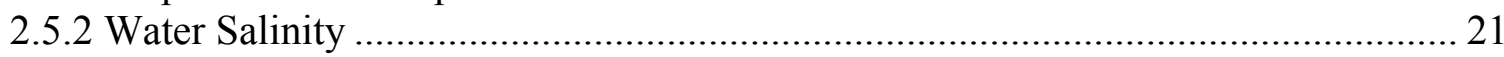

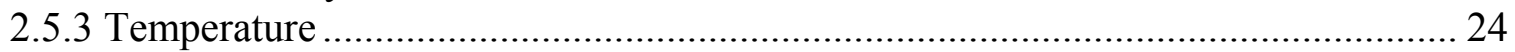

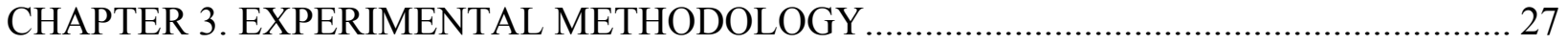

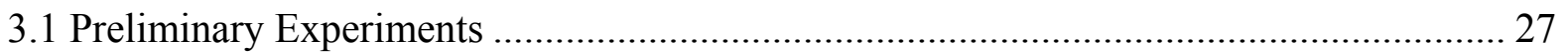

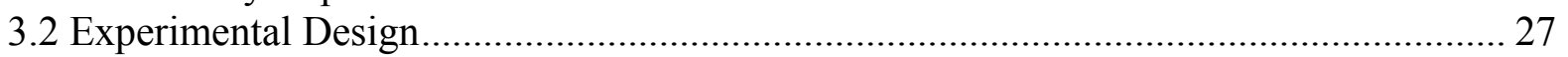

3.2.1 Experiment Set 1: Water Depth Variation .......................................................... 29

3.2.2 Experiment Set 2: Temperature Variation ............................................................ 30

3.2.3 Experiment Set 3: Pressure Variation............................................................... 31

3.2.4 Experiment Set 4: Water Salinity Variation ………………………...................... 32

3.2.5 Experiment Set 5: Dispersant-in-Oil Concentration Variation................................. 32

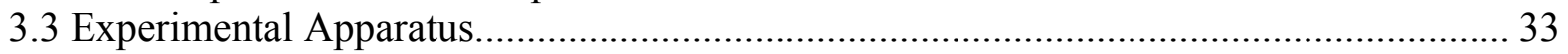

3.3.1 The Low Temperature/High Pressure Optical Cell Apparatus ................................. 33

3.3.2 The Ambient Optical Cell Apparatus .................................................................. 35

3.3.3 Preparation and Cleaning of the Optical Cell Apparatus......................................... 37

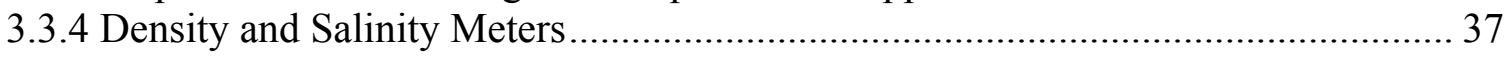




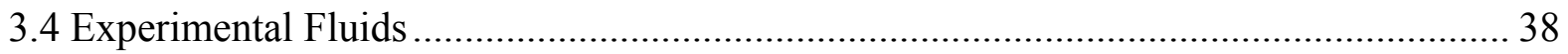

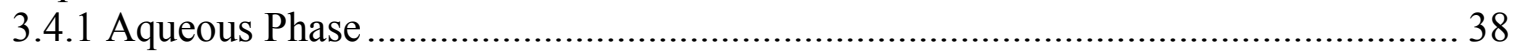

3.4.2 Oleic Phase

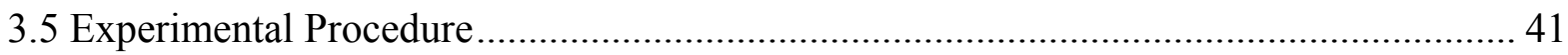

3.5.1 The Pendant Drop Method...................................................................................... 41

3.5.2 The Axisymmetric Drop Shape Analysis (ASDA) Technique .................................. 43

3.5.3 Previous Use of the Pendant Drop Method................................................................ 46

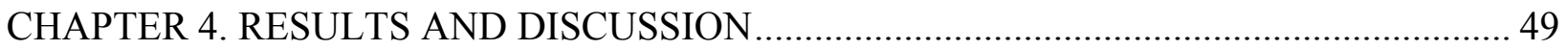

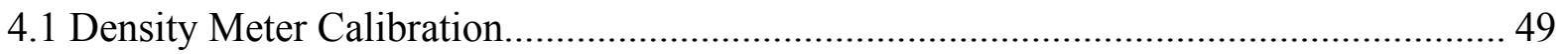

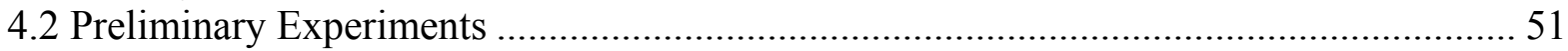

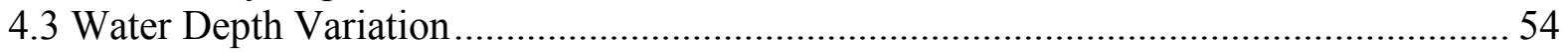

4.3.1 n-Octane/Water/Dispersant System .................................................................... 54

4.3.2 Crude Oil/Water/Dispersant System.................................................................. 56

4.3.3 Comparison of n-Octane and Crude Oil Systems ................................................ 58

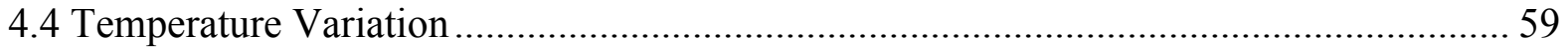

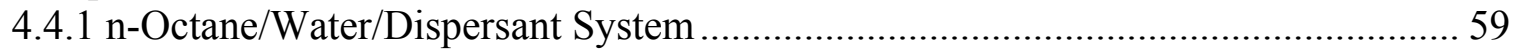

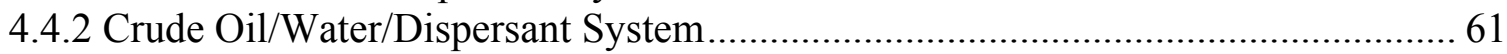

4.4.3 Comparison of n-Octane and Crude Oil Systems ...................................................... 63

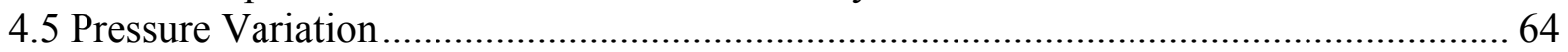

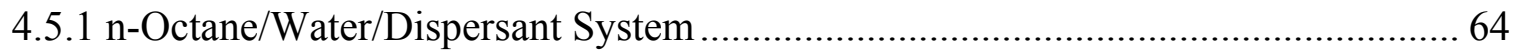

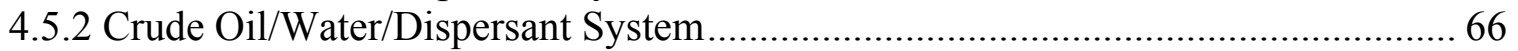

4.5.3 Comparison of n-Octane and Crude Oil Systems ..................................................... 68

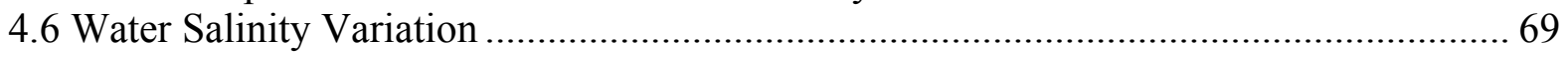

4.6.1 n-Octane/Water/Dispersant System ..................................................................... 70

4.6.2 Crude Oil/Water/Dispersant System.................................................................. 71

4.6.3 Comparison of n-Octane and Crude Oil Systems ……………………………..... 73

4.7 Dispersant-in-Oil Concentration Variation....................................................................... 74

CHAPTER 5. CONCLUSIONS AND RECOMMENDATIONS ………………….................. 78

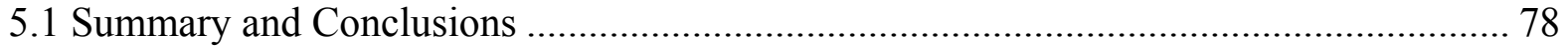

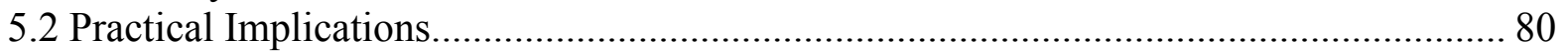

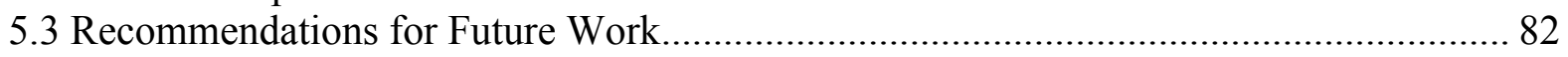

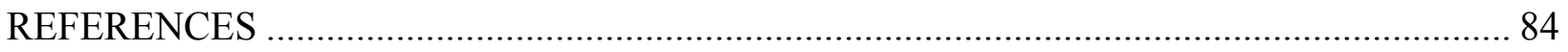

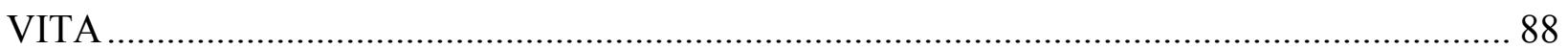




\section{LIST OF TABLES}

Table 1: Overview of the conditions of the first set of preliminary experiments ...................... 27

Table 2: Overview of the conditions of the second set of preliminary experiments .................. 27

Table 3: Pressure and temperature values corresponding to various water depths.................... 28

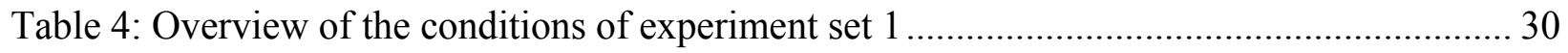

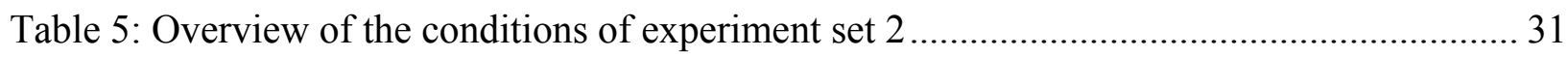

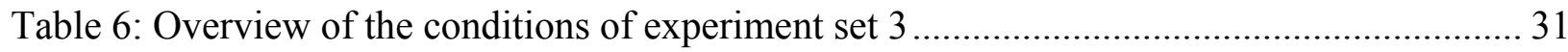

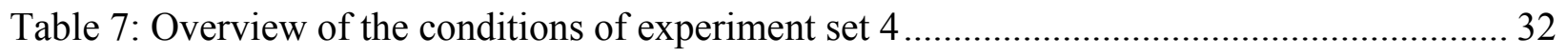

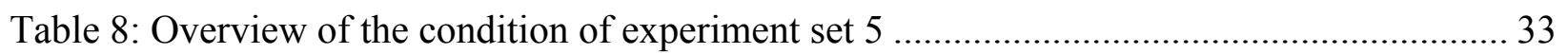

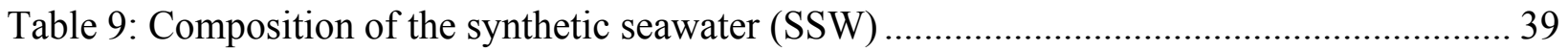

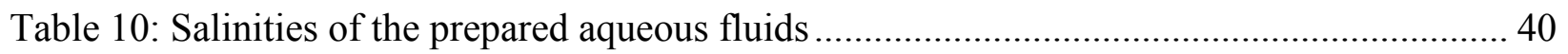

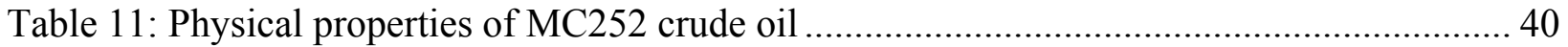

Table 12: Comparison of the measured n-octane/de-ionized water IFT with values reported by Cai et al. (1996) and Al-Shahhaf et al. (2005) at $76^{\circ} \mathrm{F}$ and various pressures........................... 52

Table 13: Comparison of the measured n-octane/water IFT with values reported by Motomura et al. (1983) at atmospheric pressure and various temperatures ................................................ 53 


\section{LIST OF FIGURES}

Figure 1: Fire-fighting vessels combat the flames on the Deepwater Horizon rig ...................... 1

Figure 2: An illustration of the underwater oil plume ....................................................... 2

Figure 3: Orientation of surfactants at the oil/water interface in dispersed oil droplets............... 7

Figure 4: Mechanism of chemical dispersion ...................................................................... 10

Figure 5: Relationship between the oil/water IFT and the dispersant concentration.................. 11

Figure 6: Illustration of surfactant packing efficiency at the interface ................................... 13

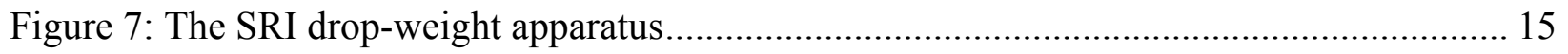

Figure 8: Typical CMC curves for light Arabian crude oil versus dispersant in seawater.......... 16

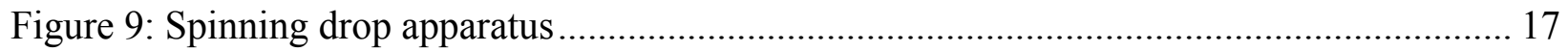

Figure 10: Plot of interfacial tension function versus water volume for Murban crude oil and

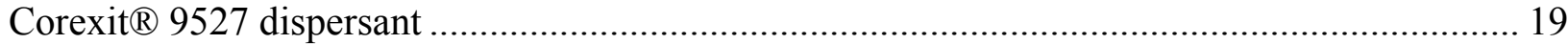

Figure 11: Effect of water salinity and temperature on the interfacial tension of Alberta crude oil-

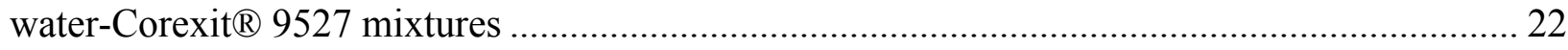

Figure 12: Effect of water salinity on the $\mathrm{CMC}$, the initial slope of the CMC curve, and the drop

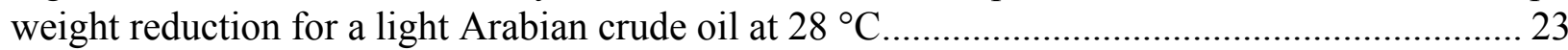

Figure 13: Effect of temperature on the CMC, the initial slope of the CMC curve, and the drop weight reduction for a light Arabian crude oil ................................................................... 25

Figure 14: Mean annual water temperature of the Gulf of Mexico waters versus water depth.... 28

Figure 15: Representation of the conditions of pressure and temperature as a function of water

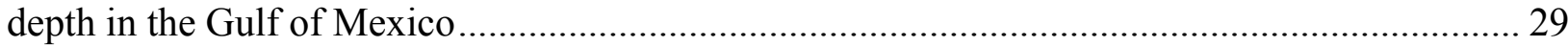

Figure 16: A picture of the low temperature/high pressure optical cell apparatus ..................... 34

Figure 17: A schematic of the low temperature/high pressure experimental set-up.................. 35

Figure 18: A picture of the ambient optical cell apparatus ................................................. 36

Figure 19: A simplified sketch of the ambient optical cell apparatus..................................... 36

Figure 20: A picture of the DMA HP density meter............................................................. 37 
Figure 21: The HACH® Sension ${ }^{\mathrm{TM}} 5$ conductivity meter. 38

Figure 22: Illustration of the shape of a pendant drop. 42

Figure 23: Implementation of the Pendant Drop method in the laboratory .................................. 43

Figure 24: Geometrical consideration of the ASDA technique .................................................... 45

Figure 25: Illustration of a measured curve and a calculated interface curve ............................. 46

Figure 26: Measured water density compared to NIST values at 2,225 psi and as a function of temperature 50

Figure 27: Measured water density compared to NIST values at $40{ }^{\circ} \mathrm{F}$ and as a function of

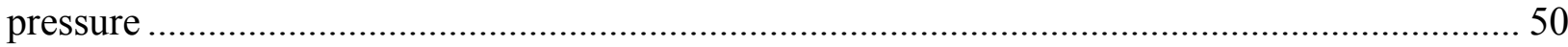

Figure 28: Measured n-octane/de-ionized water IFT at $76^{\circ} \mathrm{F}$ and various pressures ................... 51

Figure 29: Measured n-octane/de-ionized water IFT at atmospheric pressure and various

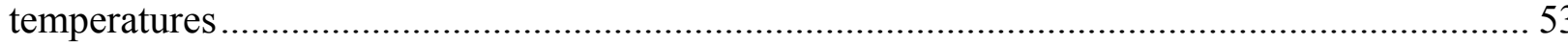

Figure 30: n-Octane and $2.5 \mathrm{wt} \%$ salt water densities at pressure and temperature conditions corresponding to various water depths 55

Figure 31: Average IFT between n-octane and $2.5 \mathrm{wt} \%$ salt water at pressure and temperature conditions corresponding to various water depths. 56

Figure 32: Crude oil and $2.5 \mathrm{wt} \%$ salt water densities at pressure and temperature conditions corresponding to various water depths

Figure 33: Average IFT between crude oil and $2.5 \mathrm{wt} \%$ salt water at pressure and temperature conditions corresponding to various water depths 58

Figure 34: Dispersant-induced reduction in the hydrocarbon/water IFT at pressure and temperature conditions corresponding to various water depths.

Figure 35: $\mathrm{n}$-Octane and $2.5 \mathrm{wt} \%$ salt water densities at 2,225 psi and as a function of temperature

Figure 36: Average IFT between n-octane and $2.5 \mathrm{wt} \%$ salt water at 2,225 psi and as a function of temperature......

Figure 37: Crude oil and $2.5 \mathrm{wt} \%$ salt water densities at 2,225 psi and as a function of temperature 62

Figure 38: Average IFT between crude oil and $2.5 \mathrm{wt} \%$ salt water at 2,225 psi and as a function 
of temperature 63

Figure 39: Dispersant-induced reduction in the hydrocarbon/water IFT at 2,225 psi and as a function of temperature

Figure 40: n-Octane and $2.5 \mathrm{wt} \%$ salt water densities at $40{ }^{\circ} \mathrm{F}$ and as a function of pressure ..... 65

Figure 41: Average IFT between n-octane and $2.5 \mathrm{wt} \%$ salt water at $40^{\circ} \mathrm{F}$ and as a function of pressure

Figure 42: Crude oil and $2.5 \mathrm{wt} \%$ salt water densities at $40{ }^{\circ} \mathrm{F}$ and as a function of pressure..... 67

Figure 43: Average IFT between crude oil and $2.5 \mathrm{wt} \%$ salt water at $40^{\circ} \mathrm{F}$ and as a function of pressure

Figure 44: Dispersant-induced reduction in the hydrocarbon/water IFT at $40^{\circ} \mathrm{F}$ and as a function of pressure 69

Figure 45: n-Octane and water densities at $2,225 \mathrm{psi}$ and $40^{\circ} \mathrm{F}$ 70

Figure 46: Average IFT between n-octane and water samples of various salinities at 2,225 psi and $40^{\circ} \mathrm{F}$

Figure 47: Crude oil and water densities at $2,225 \mathrm{psi}$ and $40^{\circ} \mathrm{F}$

Figure 48: Average IFT between crude oil and water samples of various salinities at 2,225 psi and $40{ }^{\circ} \mathrm{F}$

Figure 49: Dispersant-induced reduction in the hydrocarbon/water IFT at 2,225 psi and $40^{\circ} \mathrm{F}$ and at various water salinities

Figure 50: Average IFT between crude oil and $2.5 \mathrm{wt} \%$ salt water at $2,225 \mathrm{psi}$ and $40^{\circ} \mathrm{F}$ and as a function of the dispersant concentration in the oil 75

Figure 51: Photograph of the crude oil emerging from the tip of the capillary tube at 2,225 psi, 40 ${ }^{\circ} \mathrm{F}$ and 10,000 ppm dispersant-in-oil concentration 76

Figure 52: Dispersant-induced reduction in the crude oil/water IFT as a percentage of the dispersant-free IFT at 2,225 psi and $40^{\circ} \mathrm{F}$..... 76 


\section{LIST OF ABBREVIATIONS}

NOAA $=$ National Oceanic and Atmospheric Administration

WHOI $=$ Woods Hole Oceanographic Institute

IFT $=$ Interfacial tension

HLB $=$ Hydrophile-lipophile balance

$\mathrm{CMC}=$ Critical micelle concentration

MNS $=$ Mackay $/$ Nadeau/Steelman

SRI $=$ Stanford Research Institute

ppt $=$ Parts per thousand

NODC $=$ National Oceanographic Data Center

$\mathrm{ppm}=$ Parts per million

$\mathrm{wt} \%=$ Percentage by weight

NIST $=$ National Institute of Standards and Technology

SSW $=$ Synthetic sea water

DIW $=$ De-ionized water

$\mathrm{MC}=$ Mississippi Canyon

DSA $=$ Drop Shape Analysis

ASDA $=$ Axisymmetric Drop Shape Analysis 


\section{NOMENCLATURE}

$\mathrm{W}_{\mathrm{k}}=$ Mixing energy

$\gamma_{\mathrm{o} / \mathrm{w}}=$ Oil/water interfacial tension

$\mathrm{A}_{\mathrm{o} / \mathrm{w}}=$ Oil/water interfacial area

$\mathrm{S}_{\mathrm{o}}=$ Oil spreading coefficient

$\gamma_{\mathrm{o} / \mathrm{a}}=$ Oil/air interfacial tension, or oil surface tension

$\gamma_{\mathrm{w} / \mathrm{a}}=$ Water/air interfacial tension, or water surface tension

$\Delta \mathrm{wt}=$ Difference in drop weight

$\omega=$ Rotational velocity

$\gamma=$ Interfacial tension

$\mathrm{X}=$ Semi-major drop axis

$\Delta \rho=$ Density difference between the two phases

$\mathrm{r}=$ Radius of a drop sphere of equivalent volume

$\gamma_{0}=$ Dispersant-free interfacial tension

$\mathrm{E}=$ Dimensionless constant

$\mathrm{y}=$ Volumetric ratio of dispersant to oil

$\mathrm{K}=\mathrm{Oil} /$ water partition coefficient

$\mathrm{D}=$ Dispersant volume

$\mathrm{H}=$ Oil volume

$\mathrm{g}=$ Gravitational acceleration

$\mathrm{d}_{\mathrm{e}}=$ Equatorial diameter of a pendant drop

$\mathrm{S}=$ Pendant drop shape factor

$d_{s}=$ Diameter of a pendant drop measured at a specific height above the bottom of the drop 
$\Delta \mathrm{P}=$ Pressure difference across the interface, or capillary pressure

$\mathrm{R}_{1}, \mathrm{R}_{2}=$ Principal radii of curvature

$\mathrm{R}_{0}=$ Radius of curvature at the origin of the $\mathrm{x}-\mathrm{z}$ coordinate

$\mathrm{z}=$ Vertical height measured from the datum plane

$\Phi=$ Turning angle

$\mathrm{s}=$ Arc length

$\mathrm{u}_{\mathrm{n}}=\mathrm{A}$ set of experimental points on a physically observed (measured) curve

$\mathrm{v}=\mathrm{A}$ theoretically calculated curve

$d\left(u_{n}, v\right)=$ Normal distance between $u_{n}$ and the curve $v$

$\Delta \gamma=$ Dispersant-induced reduction in the IFT 


\begin{abstract}
The events of the Deepwater Horizon oil spill in the Gulf of Mexico were associated with great water depths that made it difficult to understand the behavior of the spilled oil as it came in contact with the seawater. The remedial subsea application of chemical dispersants draws interest to evaluate the interfacial interactions between the oil and water at such great water depths. Most importantly, a quantification of the interfacial tension (IFT) between the spilled oil and seawater at deepwater conditions can provide insight into the effectiveness of the chemical dispersion of spilled oil.

In this study, Macondo crude oil and synthetic seawater samples were used to measure the oil/water IFT by the Pendant Drop method at deepwater conditions of pressure and temperature. A laboratory apparatus capable of representing such conditions was designed and established to enable IFT and density measurements. Reagent grade n-octane was also used to compare its behavior to that of crude oil. The effectiveness of a commercial dispersant, Corexit ${ }^{\circledR}$ 9500, was assessed through the evaluation of the magnitude of the reduction in the hydrocarbon/water IFT. The influence of pressure, temperature, water salinity and dispersant concentration on the IFT was each studied independently as well.
\end{abstract}

The measured oil/water IFT decreased from 25.69 to $22.55 \mathrm{mN} / \mathrm{m}$ as both pressure and temperature were changed from water surface to seafloor conditions. The dispersant was capable of reducing the IFT by $70 \%$ from its original value at the water surface while only a $50 \%$ reduction was observed at seafloor conditions. The low temperature associated with the seafloor was determined as the main factor responsible for deteriorating the dispersant effectiveness as pressure had a relatively smaller effect on the IFT. The dispersant was also observed to perform better when dissolved in the crude oil as compared to the time it was dissolved in the water. 
However, at 10,000 ppm dispersant-in-oil concentration, the oil adopted the shape of a continuous stream instead of breaking up into small droplets. Accordingly, ultra-low oil/water IFT was not achieved, despite such a high dispersant concentration, indicating ineffective chemical dispersion at seafloor conditions. 


\section{CHAPTER 1. INTRODUCTION}

\subsection{Background}

The Deepwater Horizon was an offshore drilling rig operated by BP in the Macondo prospect located in the Gulf of Mexico. As a result of well control equipment failure, methane gas blew out of an exploratory well being drilled at 5,000 ft of water depth and a recorded total vertical depth of 35,000 ft. On April 20, 2010, the rig exploded after the gas expanded onto the platform and ignited (Figure 1). After three days of burning, the rig sank into the water. As a result of the explosion, an estimated 53,000 barrels per day were being released into the seawater from a seafloor oil gusher at the wellhead before the well was capped on July 15 [www.uscg.mil]. On September 19, the relief well process was successfully completed and the federal government declared the well "effectively dead" after the spill had amounted to a total of 4.9 million barrels [www.oilspillcommission.gov].

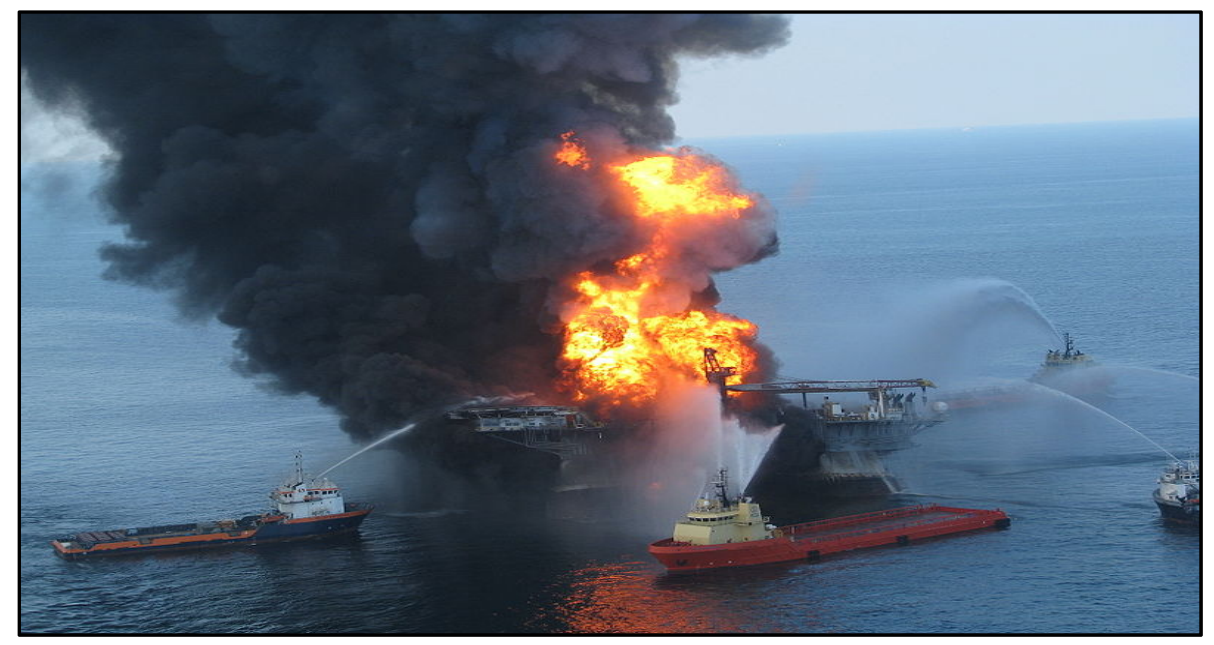

Figure 1: Fire-fighting vessels combat the flames on the Deepwater Horizon rig [www.uscg.mil]

Due to the unprecedented nature of the spill, BP along with the U.S. Coast Guard and the Environmental Protection Agency decided to try the first subsea injection of chemical dispersants directly at the source. Over 700,000 gallons [www.oilspillcommission.gov] of 
chemical dispersants were sprayed directly onto the gushing oil at the wellhead in an attempt to keep some of the oil under the water surface. The dispersant use was intended to facilitate the digestion of the spilled oil by microbes to ultimately mitigate the shoreline impacts of the spilled oil on fisheries, wetlands and other sensitive environments. The National Oceanic and Atmospheric Administration (NOAA) estimated that over 400,000 barrels of the spilled oil were dispersed underwater in the form of oil plumes and small oil droplets [www.noaa.gov]. In June 2010, scientists from the Woods Hole Oceanographic Institute (WHOI) indicated that a 22 milelong hydrocarbon plume emanating from the Deepwater Horizon oil spill does exist at a water depth of 3,600 ft (Figure 2). Using an autonomous underwater vehicle instrumented with a mass spectrometer, the scientists were able to report that the plume was 1.6 miles wide and $600 \mathrm{ft}$ thick.

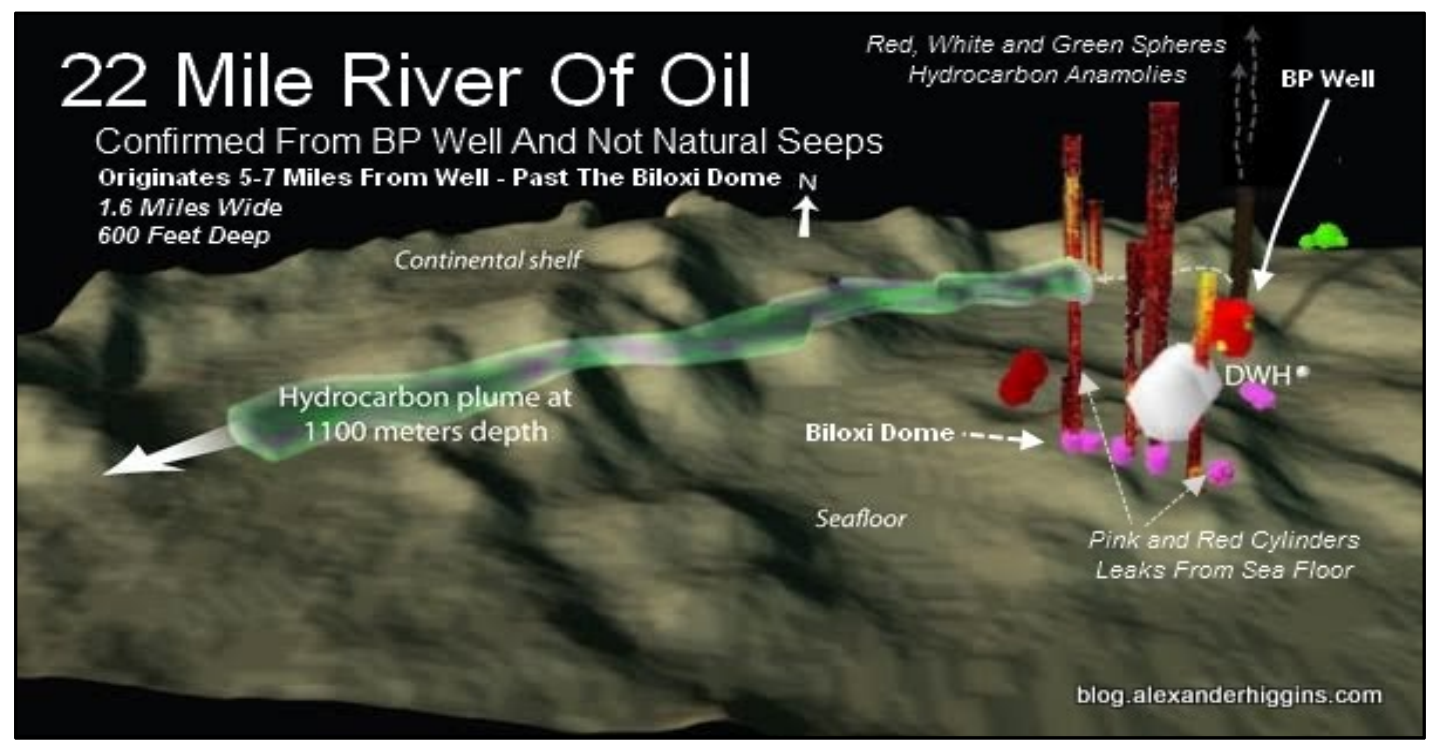

Figure 2: An illustration of the underwater oil plume [www.whoi.edu]

\subsection{Problem Statement}

The fundamental phenomenon responsible for the chemical dispersion of oil is the reduction in the oil/water interfacial tension (IFT). The unprecedented subsea application of dispersants 
during the Deepwater Horizon oil spill and the limited time available to efficiently test such a procedure drew interest to understand the interfacial phenomena occurring between the spilled oil and the water at such conditions. The scarcity of simultaneous low temperature/high pressure oil/water IFT measurements builds an impression of skepticism surrounding the phase behavior of spilled oil at great water depths. This could be attributed to the difficulty of simulating the complex marine environment in the laboratory or obtaining representative fluid samples from five thousand feet under water. Moreover, being a thermodynamic property of the interface between two immiscible fluids, interfacial tension is most accurately measured at conditions of pressure and temperature representative of that interface. The effect of water salinity on the oil/water interfacial interactions complicates the problem as well.

Hence, this project was designed to address the uncertainty surrounding the effectiveness of subsea dispersant application. The phenomenon of chemical dispersion of spilled oil and how it is influenced by the oil/water interfacial interactions needs to be studied thoroughly to aid in the design of oil spill remedial measures.

\subsection{Objectives}

The objectives of this study are as follows:

- Establish a laboratory apparatus capable of replicating the Deepwater Horizon oil spill conditions of pressure and temperature for both density and IFT measurements.

- Measure the densities of oil and water of different salinities at the representative conditions of pressure and temperature.

- Utilize the computerized Pendant Drop method to measure the hydrocarbon/water IFT at the specific conditions, with and without the addition of dispersant. 
- Evaluate the effect of temperature, pressure, water salinity and dispersant concentration on the hydrocarbon/water IFT by conducting experiments using a range of values for each variable. 


\section{CHAPTER 2. LITERATURE REVIEW}

\subsection{Oil Spill Dispersants}

Oil spill dispersants are chemicals used to dissipate and promote the break-up of an oil slick into smaller droplets that redistribute into a water column [Clayton et al., 1993]. Dispersants change the distribution, not the amount of oil, within a marine environment. Ideally, the small oil droplets should not recombine or coalesce to reform surface slicks, while delaying the formation of persistent oil-in-water emulsions. Instead, the dispersed oil droplets will be subjected to dilution to non-problematic concentrations as they mix both horizontally and vertically in the water column. In addition, dispersants enhance the microbial degradation of the spilled oil as it is broken into smaller droplets.

Typically, oil spill dispersants are a mixture of three types of chemicals: additives, solvents, and most importantly, surface-active agents (i.e., surfactants) [NRC, 2005]. Additives are included in the mixture for a number of purposes such as improving the dissolution of the dispersant into an oil slick, increasing the biodegradability of the dispersed oil and increasing the long-term stability of the dispersion.

Solvents are primarily present to promote the dissolution of surfactants and additives into a homogenous dispersant mixture. In addition, solvents reduce the viscosity of the formulation to facilitate more uniform application and penetration of the dispersant onto and into the oil. There are three main classes of solvents used in dispersant formulations [Clayton et al., 1993]: (1) water, (2) water-miscible hydroxyl compounds (e.g.: ethylene glycol and monobutyl ether), and (3) hydrocarbons (e.g.: kerosene). Aqueous solvents (i.e. water and hydroxyl compounds) permit surfactants to be mixed with water while hydrocarbon solvents promote mixing and penetration of surfactants into oils that have higher viscosities. 
For the actual dispersion process, however, the most important components in the dispersant formulation are the surfactant molecules. Surfactants are molecules that have an affinity for two fluids that do not mix and act as an interface between the immiscible fluids. They contain both oil-compatible (i.e., lipophilic or hydrophobic) and water-compatible (i.e., hydrophilic) groups. Because of this amphipathic nature, a surfactant molecule will reside at the oil/water interface and tend to reduce the oil/water interfacial tension. Surfactants used in dispersant formulations can be classified according to the nature of their hydrophilic head group [Wells et al., 1985; Brochu et al., 1986; Fingas et al., 1990]:

- Non-ionic surfactants have hydrophilic head groups that do not carry an apparent ionic charge. They are the most commonly used type of surfactants in dispersant formulations. Examples include sorbitan esters of oleic or lauric acids (sorbitan monooleate), ethoxylated sorbitan esters of oleic or lauric acid (ethoxylated sorbitan monooleate) and polyethylene glycol esters of unsaturated fatty acids.

- Anionic surfactants have negatively charged head groups. Examples include sulfosuccinate esters (sodium dioctyl sulfosuccinate).

- Cationic surfactants have head groups that are positively charged. They are not commonly used in dispersant formulations because of their inherent toxicity to a variety of organisms. An example is the quaternary ammonium salt $\mathrm{R}\left(\mathrm{CH}_{3}\right)_{3} \mathrm{~N}^{+} \mathrm{Cl}^{-}$.

- Amphoteric (Zwitterionic) surfactants can have both positively and negatively charged hydrophiles. They are not commonly used in dispersant formulations. An example would be a molecule containing both a quaternary ammonium group and a sulfonic acid group. Modern chemical dispersants contain two or more surfactant molecules that have different solubilities in both water and oil characterized by the hydrophile-lipophile balance (HLB). The 
HLB is a coding scale that ranges from 0 to 20 for nonionic surfactants and takes into account the chemical structure of the surfactant molecule. A low HLB value (3 to 6 ) is used to characterize a predominantly lipophilic surfactant that has a tendency to dissolve preferentially in an oil phase and, consequently, favors water-in-oil emulsions (i.e. mousse). On the other hand, a high HLB value (8 to 18) means that the surfactant is more of a hydrophilic nature and favors oil-in-water emulsions (i.e. dispersed oil droplets in a water body). The blend of surfactants in commercial dispersant formulations tends to be hydrophilic with an overall HLB in the range of 9 to 11 [Clayton et al., 1993]. Figure 3 illustrates the orientation of two different surfactants with distinctive HLB values at the oil/water interface.

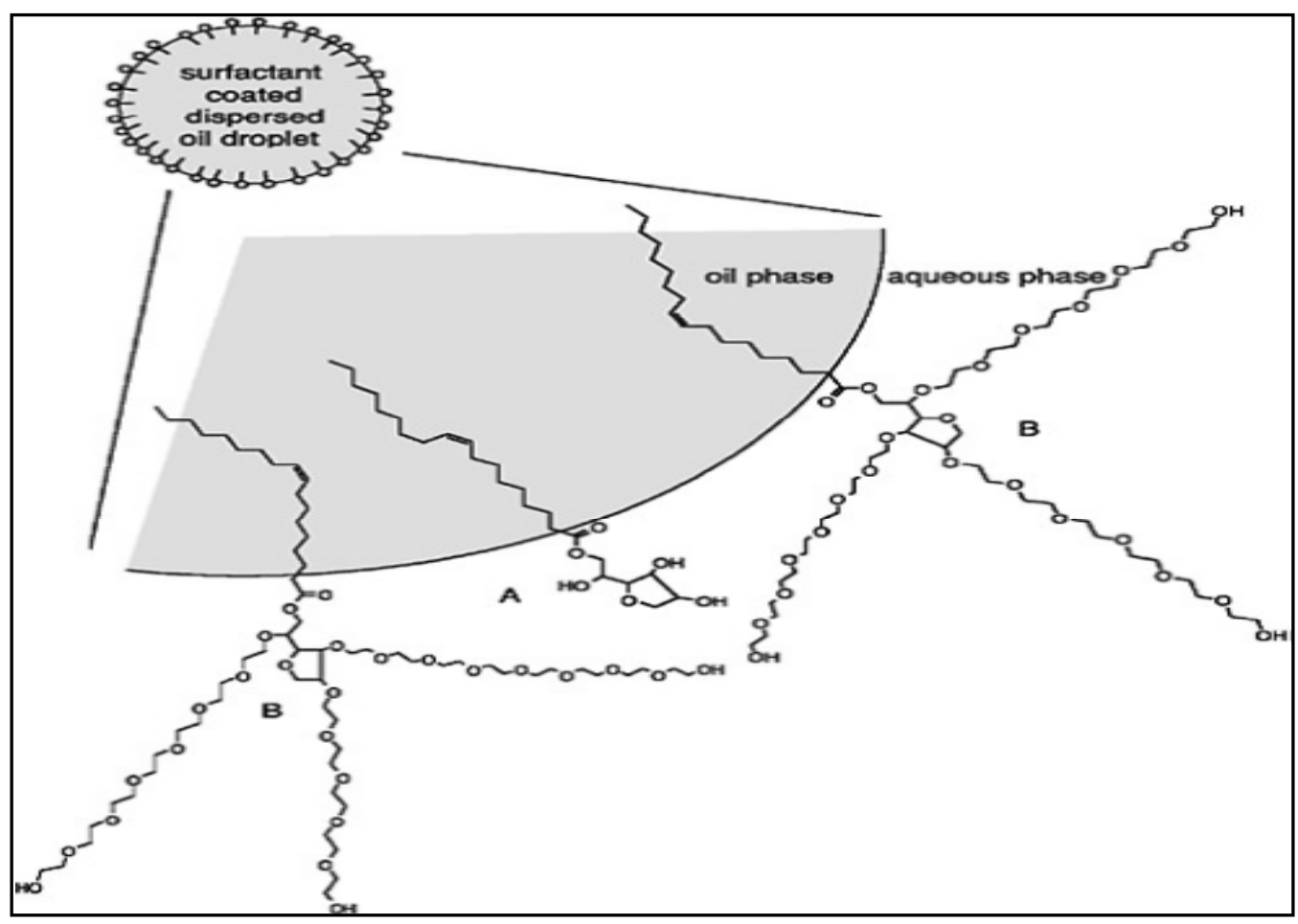

Figure 3: Orientation of surfactants at the oil/water interface in dispersed oil droplets, surfactant $\mathrm{A}$ is sorbitan monooleate $(\mathrm{HLB} \approx 4.3$ ) and surfactant $\mathrm{B}$ is ethoxylated sorbitan monooleate (HLB $\approx 15)$ [NRC, 2005]

The Corexit ${ }^{\circledR}$ products, manufactured by Nalco Holding Company, are by far the most prevalent of all commercial dispersants used in the United States. Corexit ${ }^{\circledR} 9527$ was developed 
in the 1980s; it was supplemented in the 1990s by the introduction of Corexit ${ }^{\circ} 9500$, which includes the same surfactants incorporated into a different solvent [George-Ares and Clark, $2000]$. Both products contain a mixture of nonionic (48\%) and anionic (35\%) surfactants. The major nonionic surfactants include ethoxylated sorbitan mono- and trioleates and sorbitan monooleate; while the major anionic surfactant is sodium dioctyl sulfosuccinate [Singer et al., 1991].

\subsection{Oil/Water/Dispersant Interactions}

The purpose of an oil spill dispersant application is to lower the oil/water IFT to promote entrainment of small oil droplets into the water column. Entrainment of small oil droplets into the underlying water, by either physical or chemical means, increases the oil/water interfacial area and requires some form of energy defined as the mixing energy (Equation 1):

$$
\mathrm{W}_{\mathrm{k}}=\gamma_{\mathrm{o} / \mathrm{w}} \mathrm{A}_{\mathrm{o} / \mathrm{w}}
$$

Where $\mathrm{W}_{\mathrm{k}}$ is the mixing energy, $\gamma_{\mathrm{o} / \mathrm{w}}$ is the oil/water IFT and $\mathrm{A}_{\mathrm{o} / \mathrm{w}}$ is the oil/water interfacial area. Thus, the reduction of the oil/water IFT will allow the formation of a greater interfacial area with a minimal amount of energy input to the system.

The amphipathic nature of the surfactant molecules contained in the dispersant formulation will allow a surfactant molecule to reside at the oil/water interface as illustrated in Figure 4. By the indicated orientation at the oil/water interface, hydrophobic and hydrophilic groups positioned toward the oil and water respectively, the surfactant will reduce the oil/water interfacial tension. The oil/water interface, which normally resists deformation, becomes less stable, and natural wind or wave turbulence assisted by interfacial energy gradients will tend to cause oil drops to shear from the slick [Mackay et al., 1984]. The seven requirements for a chemical dispersant to enhance the formation of oil droplets are [NRC, 1989]: 
(1) The dispersant must hit the target oil at the desired dosage.

(2) Surfactant molecules within the dispersant must have time to penetrate and mix into the oil.

(3) The surfactant molecules must reside at the oil/water interface with an orientation as indicated in Figure 4.

(4) The oil/water interfacial tension must decrease, thereby weakening the cohesive strength of the oil film.

(5) Sufficient mixing energy must be applied at the oil/water interface (by wind and/or wave action) to allow generation of smaller oil droplets.

(6) The droplets must be dispersed throughout the water column by a combination of diffusive and advective processes to minimize droplet-droplet coalescence to form larger droplets, which can resurface in the absence of continued turbulence.

(7) After entrainment, the droplets must be diluted to nontoxic concentrations and remain suspended in the water column long enough for the majority of the oil to be biodegraded.

On the water surface, three phases - gas (air), oil and water - are present and, therefore, the interfacial forces between all three phases have to be considered when studying the mechanism of chemical dispersion of oil. When the oil reaches the water surface, it either adopts the shape of droplets floating on water or spreads out in the form of a thin film. The imbalance of the fluid interfacial tensions acting along the line of contact between all three phases, expressed by the spreading coefficient, determines the nature of distribution of oil on the water surface. Through direct measurement of the water/air, oil/water and oil/air IFT, the oil spreading coefficient, $\mathrm{S}_{\mathrm{o}}$, can be calculated:

$$
S_{o}=\gamma_{w / a}-\gamma_{o / w}-\gamma_{o / a}
$$


Where $\gamma_{\mathrm{w} / \mathrm{a}}, \gamma_{\mathrm{o} / \mathrm{w}}$ and $\gamma_{\mathrm{o} / \mathrm{a}}$ are the water/air, oil/water and oil/air interfacial tensions respectively. $S_{o}$ can be positive, indicating spreading, or negative, indicating non-spreading.

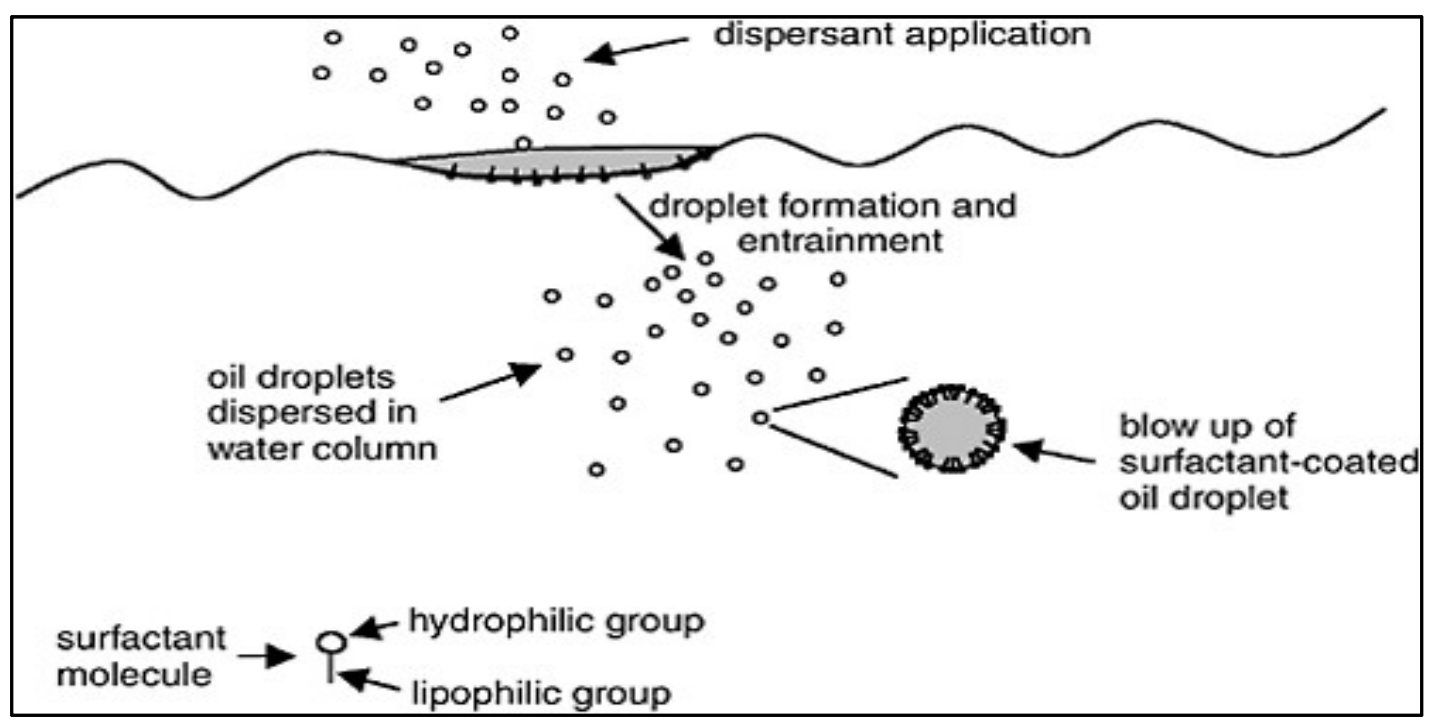

Figure 4: Mechanism of chemical dispersion: the reduction of the oil/water interfacial tension is facilitated by the accumulation of surfactant molecules at the oil/water interface [NRC, 2005]

\subsection{Effectiveness of Chemical Dispersants}

The effectiveness of a chemical dispersant can be quantified by the magnitude of the reduction in oil/water IFT [Clayton et al., 1993]. The oil/water IFT will decline progressively in proportion to the increase in the concentration of surfactants residing at the oil/water interface. The critical micelle concentration (CMC) is the concentration of dispersant at which the surfactant molecules form a uniform monolayer at the oil/water interface. Further increase in the dispersant concentration above the $\mathrm{CMC}$ would result in a less pronounced decline in the oil/water IFT, as shown in Figure 5, because the oil/water interface is already occupied by a complete monolayer of surfactant molecules. The effectiveness of a chemical dispersant can be defined by the magnitude of the decrease in oil/water IFT to the CMC (i.e. the higher the magnitude of the oil/water IFT reduction to the $\mathrm{CMC}$, the more effective the dispersant agent). 
On the other hand, the efficiency of a chemical dispersant can be defined as the concentration or amount of dispersant required to reach the $\mathrm{CMC}$ (i.e. efficiency is greater when the $\mathrm{CMC}$ is reached at a lower dispersant concentration). A favorable dispersant will have high degrees of both effectiveness and efficiency. However, effectiveness and efficiency are completely different concepts that do not necessarily follow similar trends (i.e. an effective dispersant may not be efficient and vice versa).

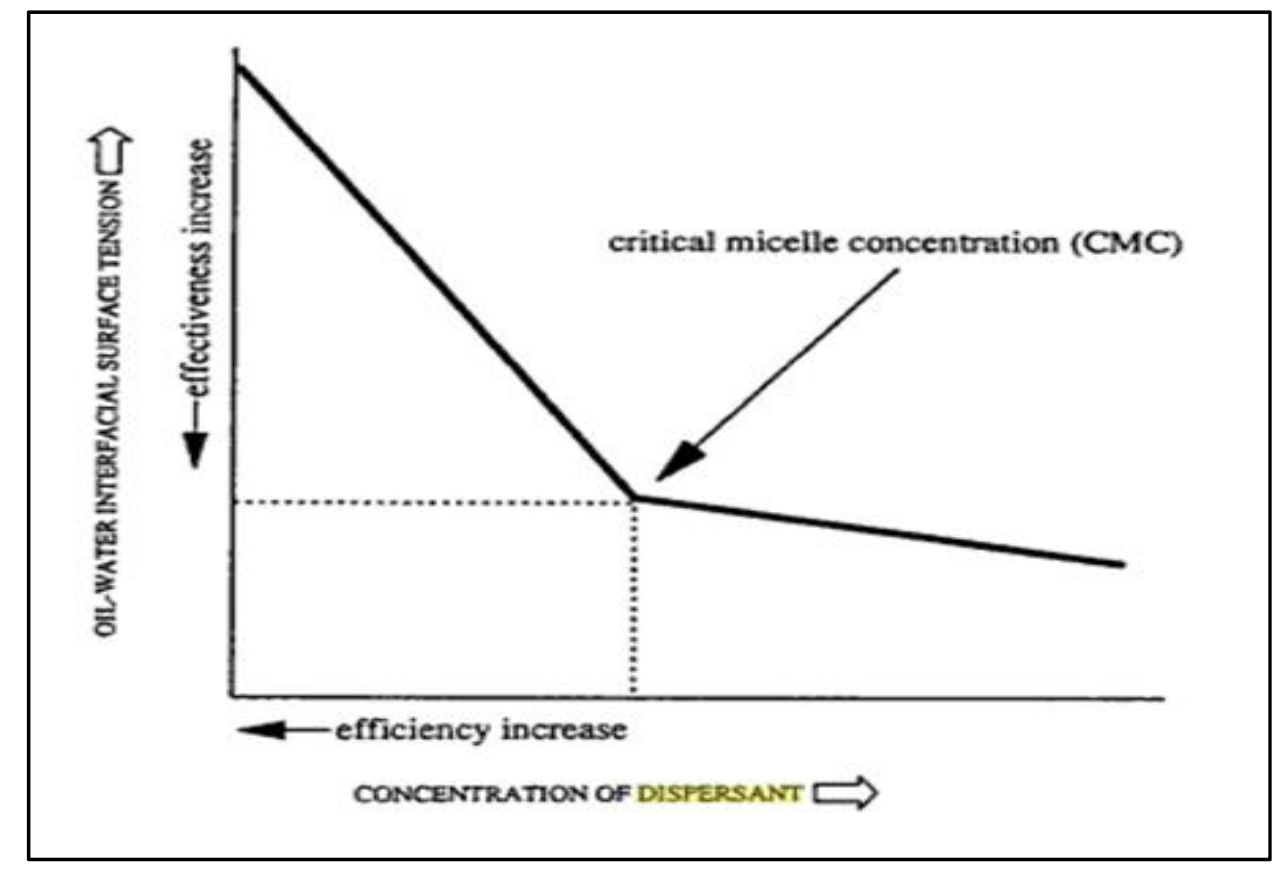

Figure 5: Relationship between the oil/water IFT and the dispersant concentration [Clayton et al., 1993]

An operational definition for dispersant effectiveness (or performance) may also be based on analytical measurement of quantities of dispersed oil in a water column beneath a slick [Clayton et al., 1993]. Testing procedures in the laboratory as well as field studies frequently utilize this operational approach to define dispersant effectiveness. It must be recognized, however, that those measurements define dispersant performance rather than its effectiveness. In addition, there are several uncontrollable factors that have pronounced influences on the quantities of oil 
that will be available for measurement in a water column beneath a slick such as natural weathering and evaporation.

The surfactant concentration at the oil/water interface is strongly influenced by the partition coefficient of that surfactant. The partition coefficient of a surfactant describes how that surfactant distributes between two immiscible phases - oil and water - at equilibrium. It is defined as a measure of the hydrophilic-lipophilic property of the surfactant and is presumed to be an emulsion-type determining factor [Harusawa et al., 1979]. When volumes of oil, water and a dispersant (or surfactant) are in equilibrium, the dispersant will partition between the oil, water and possibly a micelle phase. The partition coefficient is basically a ratio of the amount of surfactant in oil to the amount of surfactant in water. If the oil/water partition coefficient is low, the surfactant will be rapidly depleted from the relatively small oil volume into the relatively large water volume, thus reducing the interfacial tension reducing capabilities of that surfactant. Therefore, a desirable dispersant will have a high oil/water partition coefficient, from an effectiveness point of view. Direct measurement of partition coefficients is difficult because most dispersant formulations consist of surfactant mixtures which may have synergistic effects. However, Buist and Ross (1986/87) have reported that most commercial dispersants, including Corexit ${ }^{\circledR} 9527$, have an oil/water partition coefficient of 10 to 15 .

The packing, or adsorption, efficiency of a surfactant at the interface is another factor influencing the IFT reducing capabilities of that surfactant. The extent of reduction in the IFT is directly related to the amount of surfactant that can be adsorbed on a given interfacial area. The concentration of a surfactant in the interfacial area relative to its concentration in the bulk phase should, therefore, serve as an indicator of the adsorption efficiency of a given surfactant. The maximum number of surfactant molecules that could be fitted into the area depends on the area 
occupied by each molecule. That area will be determined by either the cross-sectional area of the lipophilic chain or the area required for the closest packing of the hydrophilic head groups (Figure 6), whichever is greater. If the lipophilic chain is straight and has a cross-section smaller than that of the hydrophilic head group, the surfactant molecules will favor close and efficient packing as seen in Figure 6 (a). Branching and the presence of multiple lipophilic chains within each individual surfactant molecule, as illustrated in Figure 6 (b), hinders the close packing of surfactants at the interface Consequently, the amount of surfactant molecules available for IFT reduction at the interface is significantly reduced [Myers, 1999].

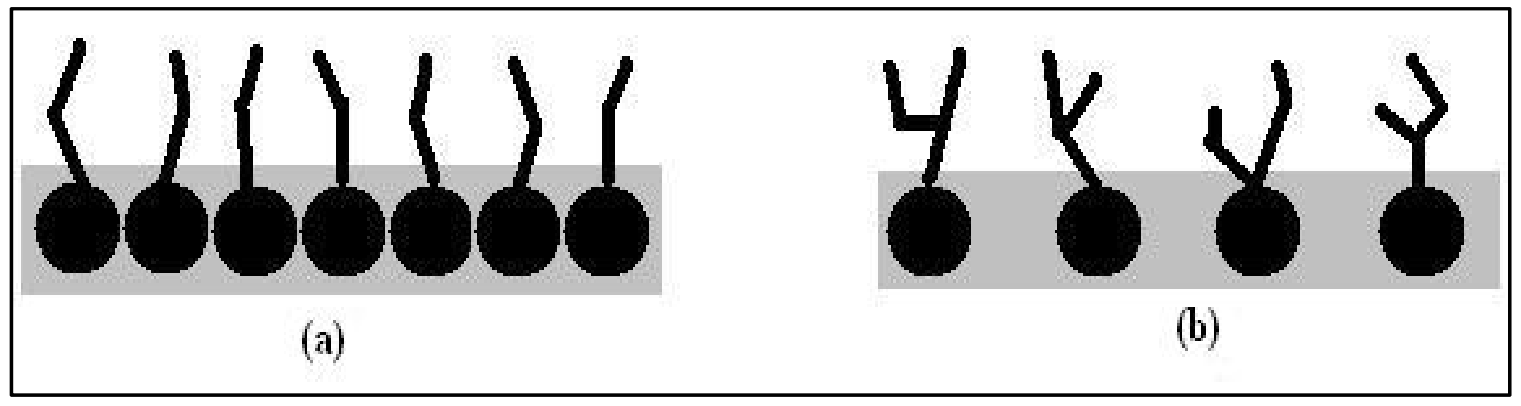

Figure 6: Illustration of surfactant packing efficiency at the interface: (a) close, efficient packing of surfactant molecules; and (b) inefficient packing

\subsection{Effectiveness Testing}

A variety of laboratory testing methods have been used in attempts to evaluate dispersant effectiveness (or performance). In general, laboratory tests can be organized into four categories [Clayton et al., 1993]: (1) tank tests with water volumes ranging from 1 to $150 \mathrm{~L}$ (e.g.: Mackay/Nadeau/Steelman (MNS) test), (2) shake/flask tests that are conducted on a relatively smaller scale (e.g.: Swirling Flask test), (3) interfacial tension tests that measure properties of the treated oil instead of dispersant performance directly, (4) flume tests using flowing water systems with the capacity for breaking/non-breaking waves to generate energy regimes (e.g.: 
Cascading Weir test). The dispersant effectiveness (or performance) is then determined by one of the following methods:

- Concentration of dispersed oil in the water column is determined by either solvent extraction and spectrophotometric determination or simple visual observations.

- Percent oil in the surface slick is estimated.

- Dispersed oil droplet sizes are determined.

- Oil/water interfacial tension measurements are determined and extrapolated to dispersant effectiveness.

- The quantities and properties of stable dispersed oil droplet are evaluated as functions of time and mixing energy in both static and dynamic systems.

Since this study is aimed at measuring the oil/water IFT, a summary of various interfacial tension tests that have been previously used to evaluate the effectiveness of chemical dispersants is provided below.

\subsubsection{The Drop-Weight Test}

The Drop-Weight test was adapted by investigators at SRI (Stanford Research Institute) and was later used by Rewick et al. (1984) to estimate dispersant effectiveness based on changes in oil/water interfacial tension. A diagram of the testing apparatus is presented in Figure 7. In a test, a premixed solution of dispersant and seawater is added to a serum vial. Oil is added to a syringe, which is then weighed. The syringe is attached to the serum vial and an oil drop is forced under pressure in the syringe to detach from the U-shaped capillary tube into the dispersant/seawater solution. The syringe must be placed at a constant position in the dispersant/seawater solution to equalize buoyancy effects, and oil drops must be allowed to grow slowly before detachment. 
Following the detachment of one or more oil drops, the syringe is weighed to determine the drop weight(s) of oil released from the syringe.

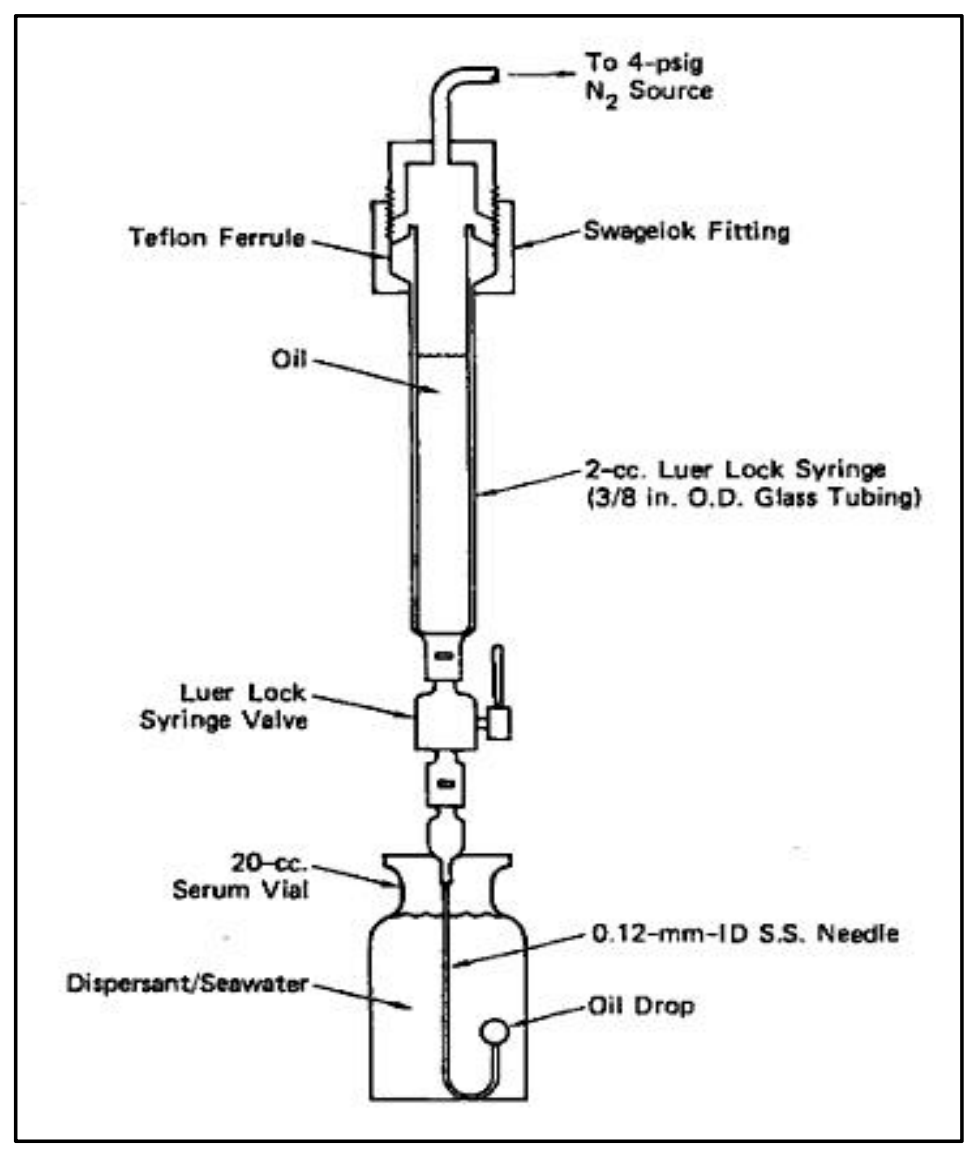

Figure 7: The SRI drop-weight apparatus [Rewick et al., 1984]

The weight of detached oil drop is plotted against the concentration of the dispersant in the seawater medium, as shown in Figure 8. The data points generate a Critical Micelle Concentration (CMC) curve, with the CMC being the intersection of two straight lines fitted by linear regression for a given chemical dispersant. The differences in the weights of the detached oil drops, $\Delta \mathrm{wt}$, up to the $\mathrm{CMC}$ are proportional to the reduction in the oil/water interfacial tension. The success of the Drop-Weight test depends upon the oil drop in the aqueous solution reaching an equilibrium surface coverage with the surfactant molecules in the dispersant formulation before detaching from the syringe needle. 
Evaluation of dispersant effectiveness is based on values of (1) the actual CMC concentration, (2) the initial slope of the CMC curve, and (3) the interfacial tension reduction which is proportional to the difference in drop weight, $\Delta$ wt. These three parameters are calculated assuming that a given chemical dispersant (1) reaches full surface coverage at the oil/water interface at the lowest concentration, (2) promotes the largest reduction in oil/water interfacial tension per unit concentration, and (3) achieves the largest reduction in interfacial tension (i.e. $\Delta \mathrm{wt}$ ).

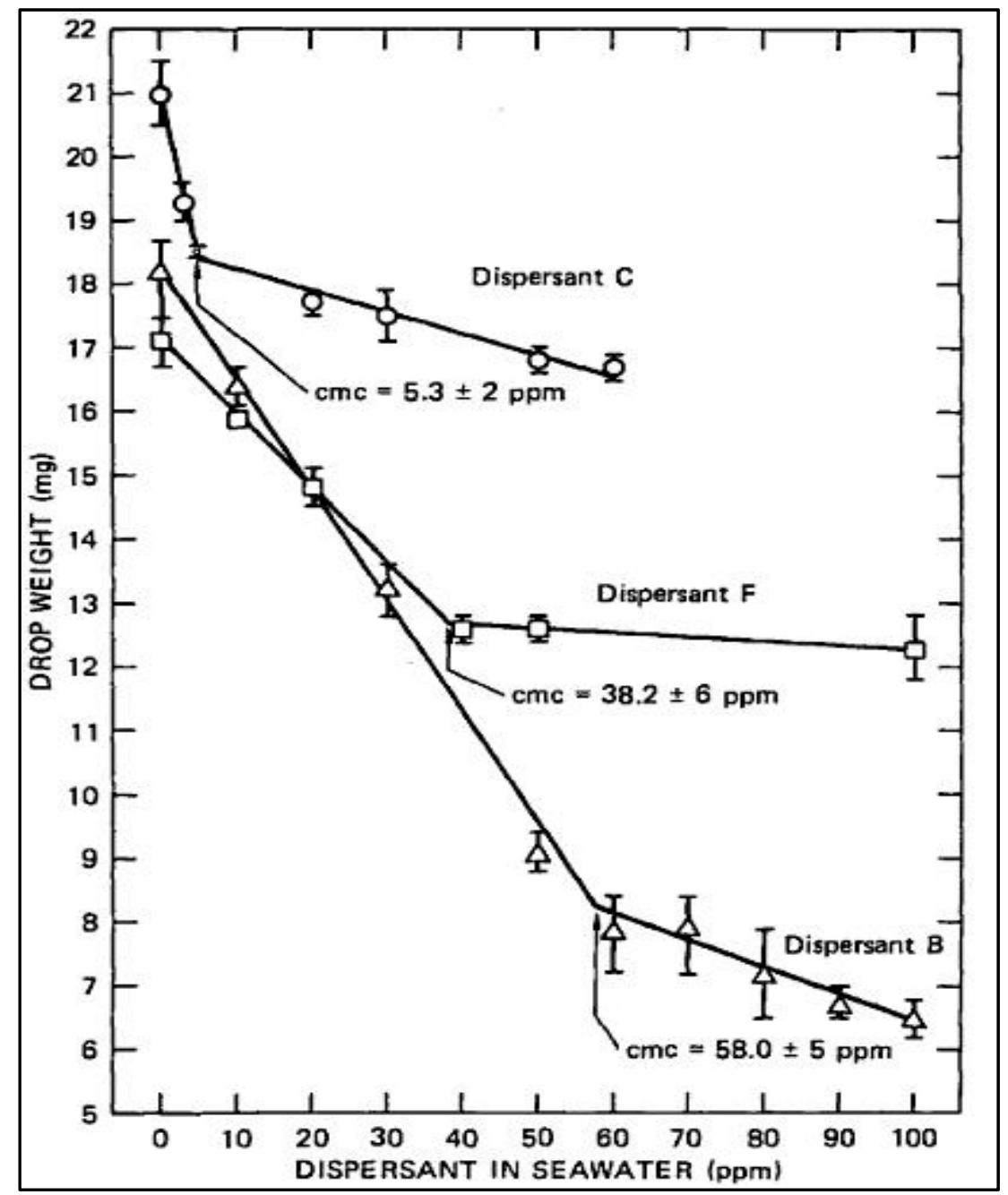

Figure 8: Typical CMC curves for light Arabian crude oil versus dispersant in seawater for three different chemical dispersants with the Drop-Weight test method, temperature $=28{ }^{\circ} \mathrm{C}$ and salinity $=38$ ppt [Rewick et al., 1984] 


\subsubsection{The Spinning Drop Technique}

This technique relies on the fact that gravitational acceleration has little effect on the shape of a less dense fluid drop suspended in a denser liquid, when the drop and the liquid are contained in a horizontal tube spun about its longitudinal axis. At low rotational velocities, $\omega$, the fluid drop will take on an ellipsoidal shape, but when $\omega$ is sufficiently large, it will become cylindrical. The shape of the oil drop is controlled by a balance between centrifugal forces, which tend to elongate the drop, and interfacial forces, which tend to oppose elongation as to reduce the interfacial area. Princen et al. (1967) has described the technique and provided the following equation to calculate interfacial tension:

$$
(1 / \gamma)^{1 / 3}(3 X / 2)\left(\Delta \rho \omega^{2} / 4\right)^{1 / 3}=\left(\Delta \rho \omega^{2} / 4\right)^{1 / 3}\left(r^{3} / \gamma\right)+1
$$

Where $\mathrm{X}$ is the semi-major drop axis (i.e. half the length), $\Delta \rho$ is the density difference between the two phases and $\mathrm{r}$ is the radius of a drop sphere of equivalent volume. A schematic of the Spinning Drop apparatus is illustrated in Figure 9.

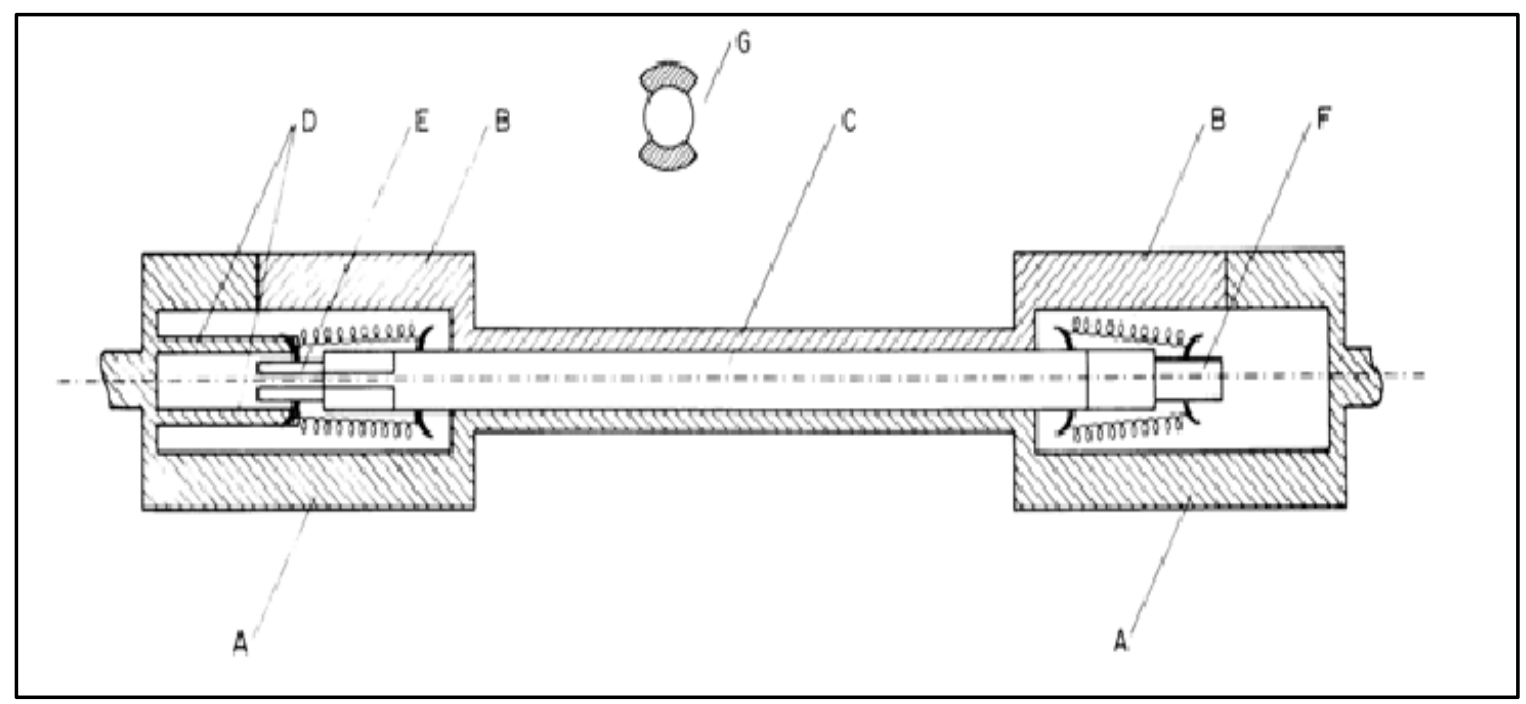

Figure 9: Spinning drop apparatus, A-fixed part of clamp assembly, B-removable part of clamp assembly, C-glass tubing, D-two pins to prevent the slip between glass tubing and clamp assembly, E, F-ground-glass stoppers; E has capillary at its center, G-cross section [Princen et al., 1967] 
Mackay and Hossain (1982) used the Spinning Drop technique to measure the oil-water interfacial tension for systems of crude oils, distilled and salt water, and chemical dispersants at different temperatures. In this technique, known volumes of oil, water and dispersant are shaken in a separatory funnel and allowed to settle for at least 6 hours. Samples of the oil and water layers were then transferred to the capillary tube of the Spinning Drop apparatus for interfacial tension measurements. The Spinning Drop length was measured by photographing the drop with scales located directly above and below the axis of rotation.

Their work was focused on inferring an effective oil-water partition coefficient by varying the dispersant dosage and the volumetric ratio of water to oil. They were also able to postulate a relationship (Equation 4) between the magnitude of the interfacial tension reduction and dispersant concentration based on their experimental results:

$$
\gamma=\gamma_{0} \mathrm{e}^{-\mathrm{Ey}}
$$

Where $\gamma$ and $\gamma_{0}$ are the experimentally measured interfacial tension value and the dispersantfree value respectively, $\mathrm{y}$ is the volumetric ratio of dispersant to oil and $\mathrm{E}$ is a dimensionless constant characteristic of the dispersant and oil. Experimental results showed that as y increases the oil/water interfacial tension falls from its dispersant-free value, $\gamma_{0}$, to $\gamma$. Interfacial tension, $\gamma$, was measured in a series of experiments in which constant volumes of dispersant and oil were contacted with varying volumes of water. The results are then plotted as $1 / \ln \left(\gamma_{0} / \gamma\right)$ versus the water volume as in Figure 10. The slope of this plot is defined as $(1 / \mathrm{KED})$ and the $\mathrm{x}$-axis intercept at zero water volume is (H/ED). K, D and $\mathrm{H}$ are used to designate the oil/water partition coefficient, the dispersant volume and oil volume respectively. The intercept was obtained by a least squares fitting procedure. Ultimately, values of $\mathrm{E}$ and $\mathrm{K}$ were obtained for different crude oil/water/dispersant systems. 


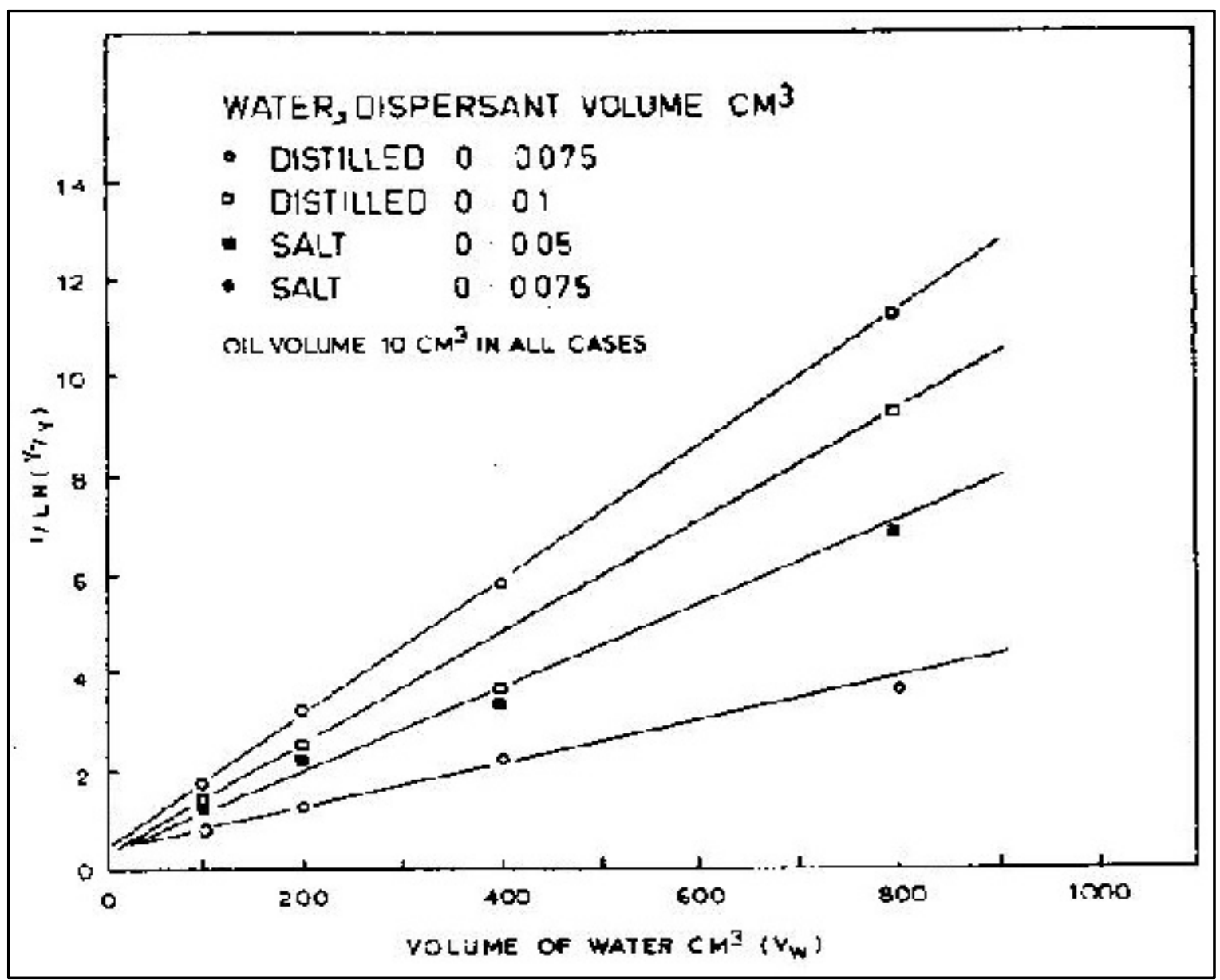

Figure 10: Plot of interfacial tension function, $1 / \ln \left(\gamma_{0} / \gamma\right)$, versus water volume for Murban crude oil and Corexit ${ }^{\circledR} 9527$ dispersant [Mackay and Hossain, 1982]

\subsection{Factors Affecting the Chemical Dispersion of Spilled Oil}

Many factors influence the chemical dispersion of spilled oil and the effectiveness of treatment. These factors include properties and composition of oil, dispersant chemical formulation, dispersant-to-oil ratio, energy input (breaking waves, subsea turbulence, mechanical mixing, etc.), water salinity and temperature and natural weathering of oil (loss of volatile hydrocarbons, photo oxidation and water-in-oil emulsion formation). Since this study is aimed at investigating the effect of temperature and water salinity on the phase behavior of oil and water under dispersant application, this section will focus on the properties and composition of oil, water salinity and temperature. 


\subsubsection{Properties and Composition of Oil}

Both crude and refined petroleum products are complex mixtures of hydrocarbon compounds. A generalized characterization of crude and refined oil can be considered in five broad categories: low molecular weight (1) aliphatics and (2) aromatics, and high molecular weight (3) asphaltenes, (4) resins, and (5) waxes. Solvency interactions between these compounds allow a complex oil to be maintained in a liquid state [Bobra, 1991]. That is, the lower molecular weight components act as solvents for the less soluble, higher molecular weight components. The solvency interactions between these components are sensitive to thermodynamic conditions. If the equilibrium state is changed (i.e. pressure or temperature change), the higher molecular weight components become less soluble in the lower molecular weight components and ultimately precipitate as solid particles. Accompanying changes in the physical properties and chemical composition can influence the way chemical dispersants interact with the oil that has undergone such changes.

It is generally accepted that oils characterized by high viscosities will exhibit lower capacities for chemical dispersion. An increase in oil viscosity can inhibit the chemical dispersion process by retarding the migration of surfactants to the oil/water interface and by increasing the energy required to shear off oil droplets from a slick [Clayton et al., 1993]. For lower viscosity oils, most of the mixing energy is consumed creating new surface areas for the oil. On the other hand, a relatively greater portion of the mixing energy will be consumed in the deformation of higher viscosity oils, therefore, reducing the energy available to create new surface area. Cormack et al. (1986/87) has reported that chemical dispersants will generally perform better for oils with viscosities less than $2,000 \mathrm{cSt}$ and essentially no dispersion will occur at viscosities greater than $10,000 \mathrm{cSt}$. 
The specific chemical composition of oil can also be an important factor in the capacity for an oil to be chemically dispersed. Canevari $(1984,1985)$ reported that the overall composition and presence of indigenous surfactants in oil can affect the chemical dispersion process in both increasing and decreasing manners. The La Rosa crude oil (viscosity $=73 \mathrm{cSt}$ ) was mixed with a pure isoparaffin oil to produce modified crude with a viscosity similar to that of the Murban crude oil (viscosity $=6 \mathrm{cSt}$ ). Dispersion tests performed in the MNS test revealed that the dispersion of the La Rosa crude was enhanced but was still significantly lower (by $36 \%$ ) than that of the Murban crude. This illustrates the fact that the characteristics of oil can be a main factor affecting the dispersion of spilled oil. In further studies, Canevari (1987) investigated the role of natural surfactants in oil in influencing the chemical dispersion process. Natural surfactant fractions were isolated from five different crude oils (Kuwait, La Rosa, North Slope, Murban and South Louisiana) and added to tetradecane in amounts equivalent to those in the parent crude oils. The dispersion of tetradecane was reduced from 46 to $13-20 \%$ following the addition of the natural surfactants from the five crude oils. Fingas et al. (1991) reported that the chemical dispersion of oil increases with increasing saturate content and declines with increasing content of aromatic, polar and asphaltene components. Bridie et al. (1980) and Bobra (1990, 1991) have indicated that wax content can be important in the formation and stabilization of water-in-oil emulsions (mousse) and that a high wax content has a negative effect on the chemical dispersion of emulsified oil.

\subsubsection{Water Salinity}

Chemical dispersants are usually formulated to provide maximum dispersion at normal seawater salinities. The migration of surfactant molecules into the water phase is deterred by high water salinities because the presence of salt in the water tends to delay the process of 
surfactant diffusion and dissolution in it [Mackay et al., 1984]. This effect is known as "salting out" of surfactants and it results in the surfactant molecules spending a relatively longer time at the oil/water interface. Additionally, the association of surfactant molecules with oil at the oil/water interface is enhanced, leading to effective lowering of the oil/water IFT and consequently improved dispersant effectiveness.

Mackay and Hossain (1982) used the Spinning Drop technique to measure the oil/water interfacial tension for systems of crude oils, distilled and salt water, and chemical dispersants. Their results indicated an increase in dispersant effectiveness with increasing water salinity. The oil/water partition coefficient was approximately 5 for distilled water as compared to 10 for salt water, reflecting a near doubling of solubility in fresh water. Therefore, the measured oil/water interfacial tension values were noticeably higher in distilled water as shown in Figure 11.

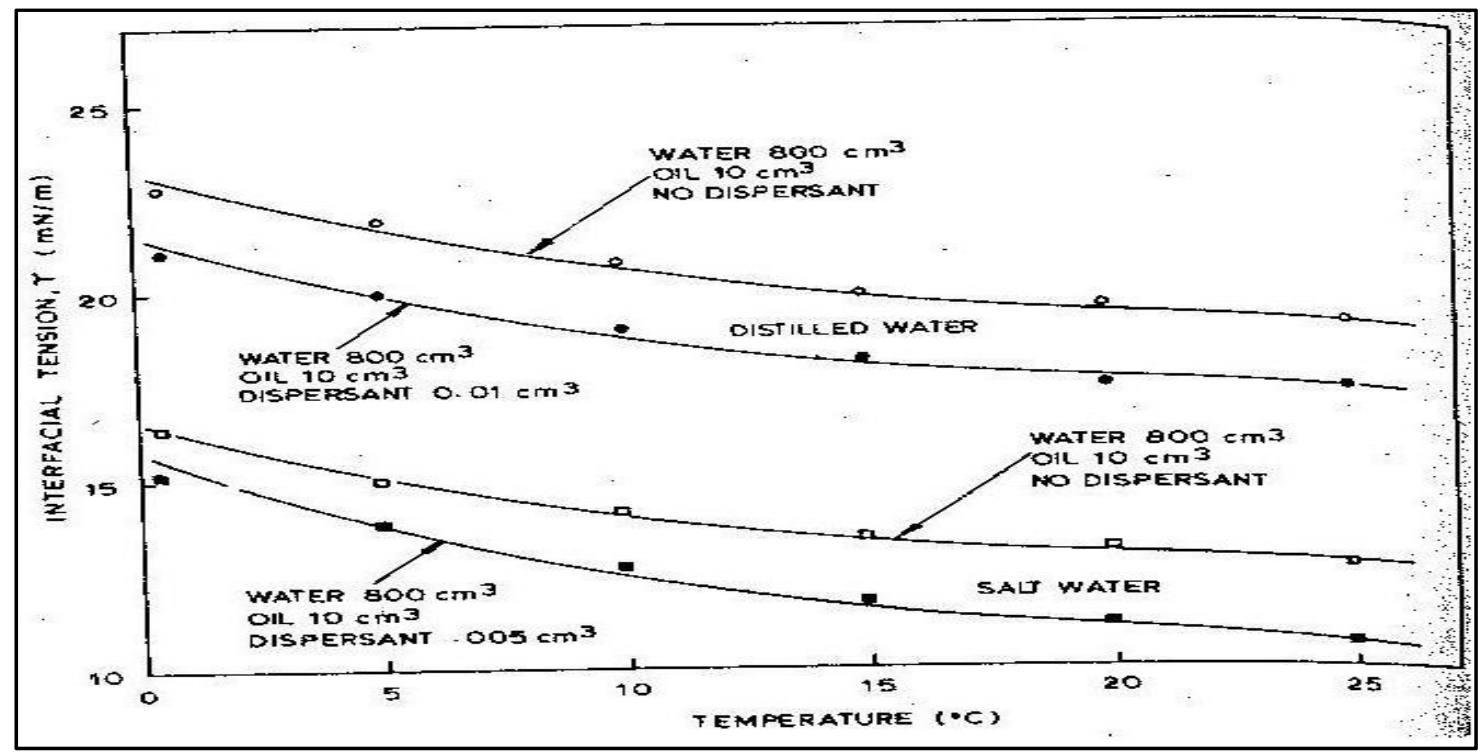

Figure 11: Effect of water salinity and temperature on the interfacial tension of Alberta crude oil-water-Corexit@ 9527 mixtures [After Mackay and Hossain, 1982]

Rewick et al. (1984) also investigated the effect of water salinity on the oil/water IFT using the Drop-Weight test method. Light Arabian crude oil was used and several values of water 
salinity were tested as shown in Figure 12. Curve (A) which exhibits the CMC values over the salinity range tested does not show any specific trend and salinity was ruled as having little or no effect on the CMC for that dispersant/oil system. Curve (B) shows the values of the initial slope of the $\mathrm{CMC}$ curve over the salinity range which is indicative of the dispersant packing efficiency at the oil/water interface. The initial slope is that of the drop weight plotted as a function of dispersant concentration. Curve (B) shows that a maximum packing density occurs at 25 ppt and, therefore, the greatest drop-weight reduction was observed near $25 \mathrm{ppt}$ in curve $(\mathrm{C})$. The data from curve (C) showed that the drop-weight reduction declined (i.e. interfacial tension increased) beyond 25ppt. This trend was attributed to the fact that the chemical dispersant test included a complex blend of surfactants and it was noted that salinity will likely alter other dispersant/oil systems differently.

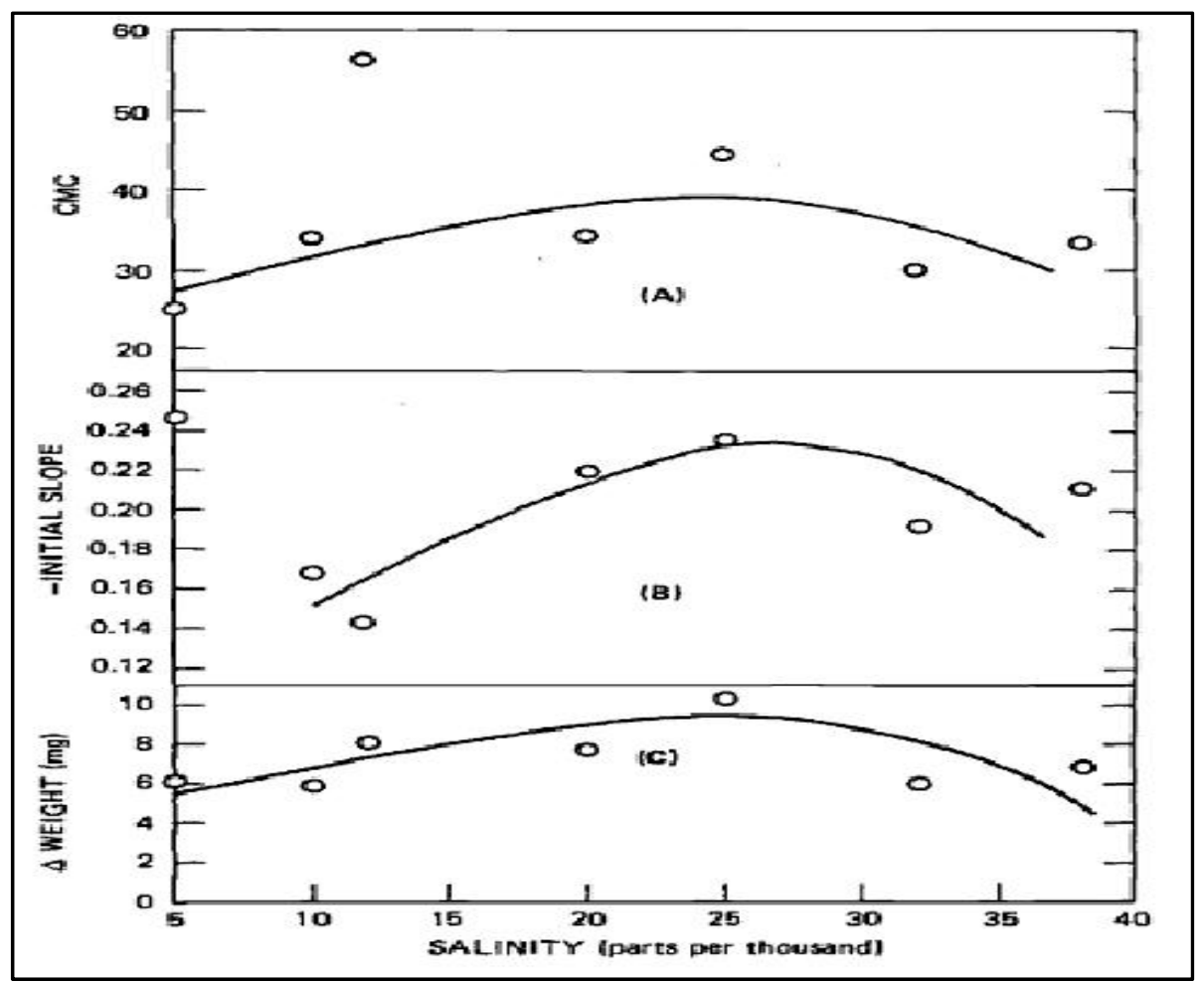

Figure 12: Effect of water salinity on the CMC (A), the initial slope of the CMC curve (B), and the drop weight reduction (C) for a light Arabian crude oil at $28{ }^{\circ} \mathrm{C}$ [Rewick et al., 1984] 
Lehtinen and Vesala (1984) evaluated the effect of salinity on dispersant performance using two different dispersant formulations (a "marine" and a "low salinity" formulation) and a light Russian crude in both fresh and weathered states. Dispersant performance was evaluated using the MNS test. Generally, dispersion increased with increasing salinity for the "marine" dispersant, whereas trends for the "low salinity" dispersant were less conclusive.

\subsubsection{Temperature}

Temperature can play an important role in the interfacial interactions related to the dispersion of oil by chemical dispersants. Temperature affects dispersant effectiveness by influencing (1) the kinetics of surfactant packing at the oil/water interface, (2) diffusion of the surfactant through the oil slick, and (3) solubilization differences between the polar and nonpolar ends of the surfactant molecule [Rewick et al., 1984]. For example, the water solubility of ethoxylated surfactants found in commercial dispersant formulations increases with decreasing temperature, which can lead to temperature-dependent losses of surfactants from the oil/water interface and a change in the overall HLB value [Clayton et al., 1993]. Furthermore, a decrease in temperature increases the oil viscosity which can have a detrimental effect on the dispersion process. This is due to the fact that the penetration and mixing of surfactants into the oil phase is less effective for more viscous oils and, therefore, most of the surfactant molecules are lost to the surrounding water.

In their study of the interfacial tensions of oil, water, chemical dispersant systems, Mackay and Hossain (1982) concluded that dispersion is more difficult at lower temperatures. Their conclusion was based on the fact that the experimentally measured oil/water interfacial values were higher at lower temperatures as shown in Figure 11 (Section 2.5.2). 
Rewick et al. (1984) also studied the effect of temperature on the effectiveness of dispersants using the three previously discussed parameters, the CMC, initial slope of drop-weight reduction versus dispersant concentration (CMC curve) and the actual drop-weight reduction. The effect of temperature is illustrated in Figure 13.

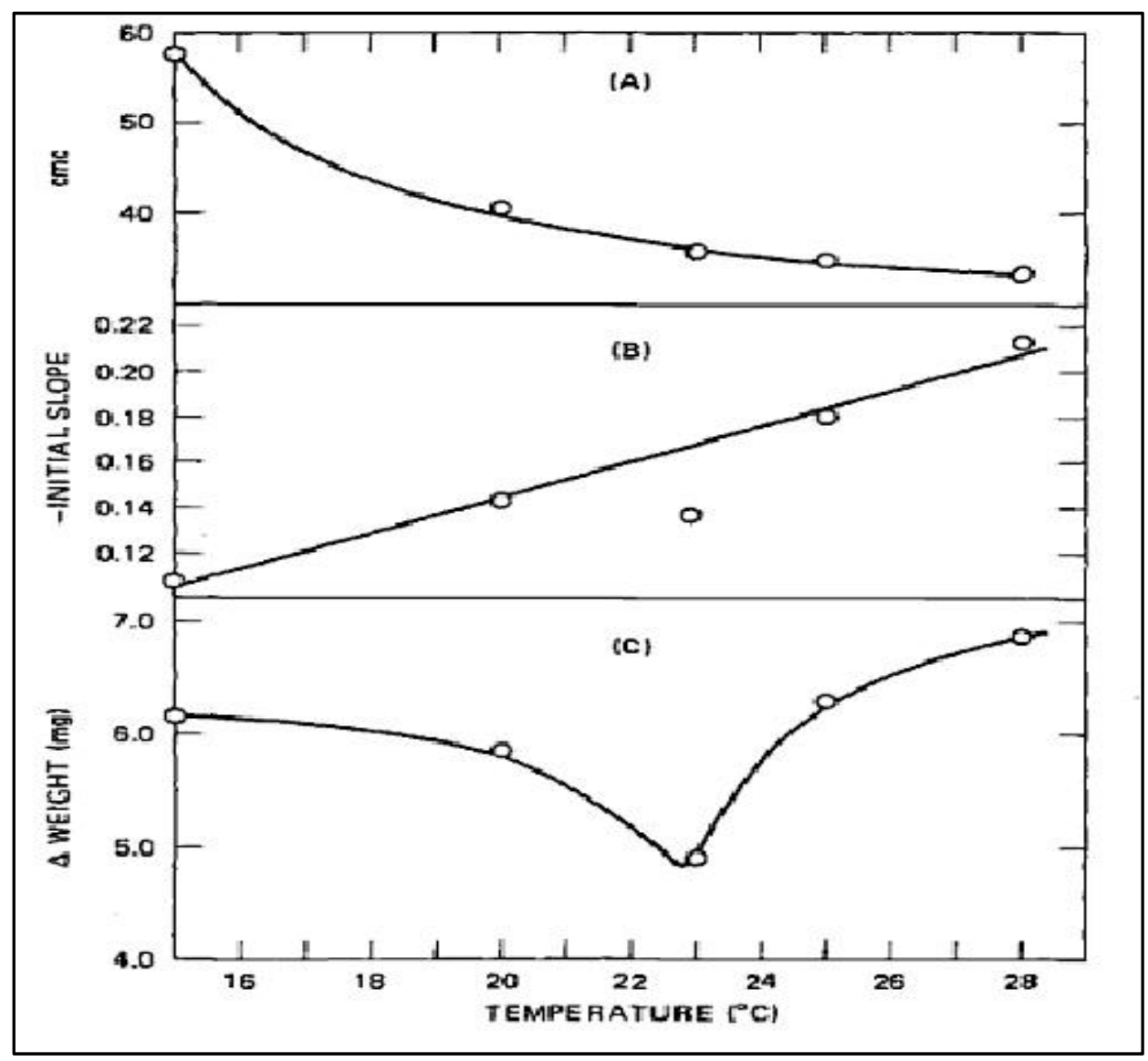

Figure 13: Effect of temperature on the CMC (A), the initial slope of the CMC curve (B), and the drop weight reduction (C) for a light Arabian crude oil [Rewick et al., 1984]

Curve (A) in Figure 13 shows that as the temperature increased, the CMC decreased to a minimum at $28^{\circ} \mathrm{C}$ implying that the dispersant will perform more efficiently at higher temperatures. It was noted that the hydration of the surfactant hydrophilic group was the dominant thermal effect causing this effect. However, it was also pointed out that curve (A) may represent a semi-parabola with a minimum near $28^{\circ} \mathrm{C}$ and, therefore, the value for the $\mathrm{CMC}$ may 
increase with further increase of temperature. Curve (B) shows that the surfactant packing efficiency increases with temperature, but may be opposed by the decrease in CMC and account for the minimum in interfacial tension reduction at $23{ }^{\circ} \mathrm{C}$ as shown in curve (C).

Lehtinen and Vesala (1984) also reported an increase in dispersion with increasing temperature using the MNS test and two different dispersant formulations (a "marine" and a "low salinity" formulation). Fingas et al. (1991b) utilized the Swirling Flask Test to evaluate the effect of temperature on the dispersion of Alberta Sweet Mixed Blend crude oil using Corexit ${ }^{\circledR}$ 9527 dispersant. Their results showed an increase in dispersion with increasing temperature as well. 


\section{CHAPTER 3. EXPERIMENTAL METHODOLOGY}

\subsection{Preliminary Experiments}

Before oil/water IFT measurements were made, two sets of experiments including the variation of temperature at constant pressure and vice versa were conducted. The interfacial tension between n-octane and de-ionized water was measured at the conditions listed in Tables 1 and 2. The temperature and pressure conditions were chosen as to match the ones at which Motomura et al. (1983), Cai et al. (1996) and Al-Shahhaf et al. (2005) measured the n-octane/deionized water IFT.

Table 1: Overview of the conditions of the first set of preliminary experiments

\begin{tabular}{|c|c|}
\hline Pressure (psi) & $\begin{array}{c}\text { Temperature } \\
\left({ }^{\circ} \mathbf{F}\right)\end{array}$ \\
\hline 1,000 & 76 \\
\hline 2,000 & 76 \\
\hline 3,000 & 76 \\
\hline
\end{tabular}

Table 2: Overview of the conditions of the second set of preliminary experiments

\begin{tabular}{|c|c|}
\hline Pressure (psi) & $\begin{array}{c}\text { Temperature } \\
\left({ }^{\circ} \mathbf{F}\right)\end{array}$ \\
\hline 14.7 & 40 \\
\hline 14.7 & 50 \\
\hline 14.7 & 60 \\
\hline 14.7 & 76 \\
\hline
\end{tabular}

\subsection{Experimental Design}

As previously mentioned, the main purpose of this work is to provide precise oil/water IFT values at conditions representative of the Deepwater Horizon oil spill. For this reason, the conditions of pressure and temperature in the Gulf of Mexico waters have to be known. Data acquired from the National Oceanographic Data Center (NODC) are represented in Figure 14, 
illustrating the change of temperature with water depth in the Gulf of Mexico. This plot was digitized using Win $\operatorname{Dig}{ }^{\circledR}$ so that the values of temperature and depth could be read accurately. The pressure due to a hydrostatic column of seawater was then calculated using an average seawater density of $1.025 \mathrm{~g} / \mathrm{cc}$. The pressure and temperature values along with the corresponding water depth are listed in Table 3. The values of pressure and temperature were then plotted as a function of water depth in Figure 15.

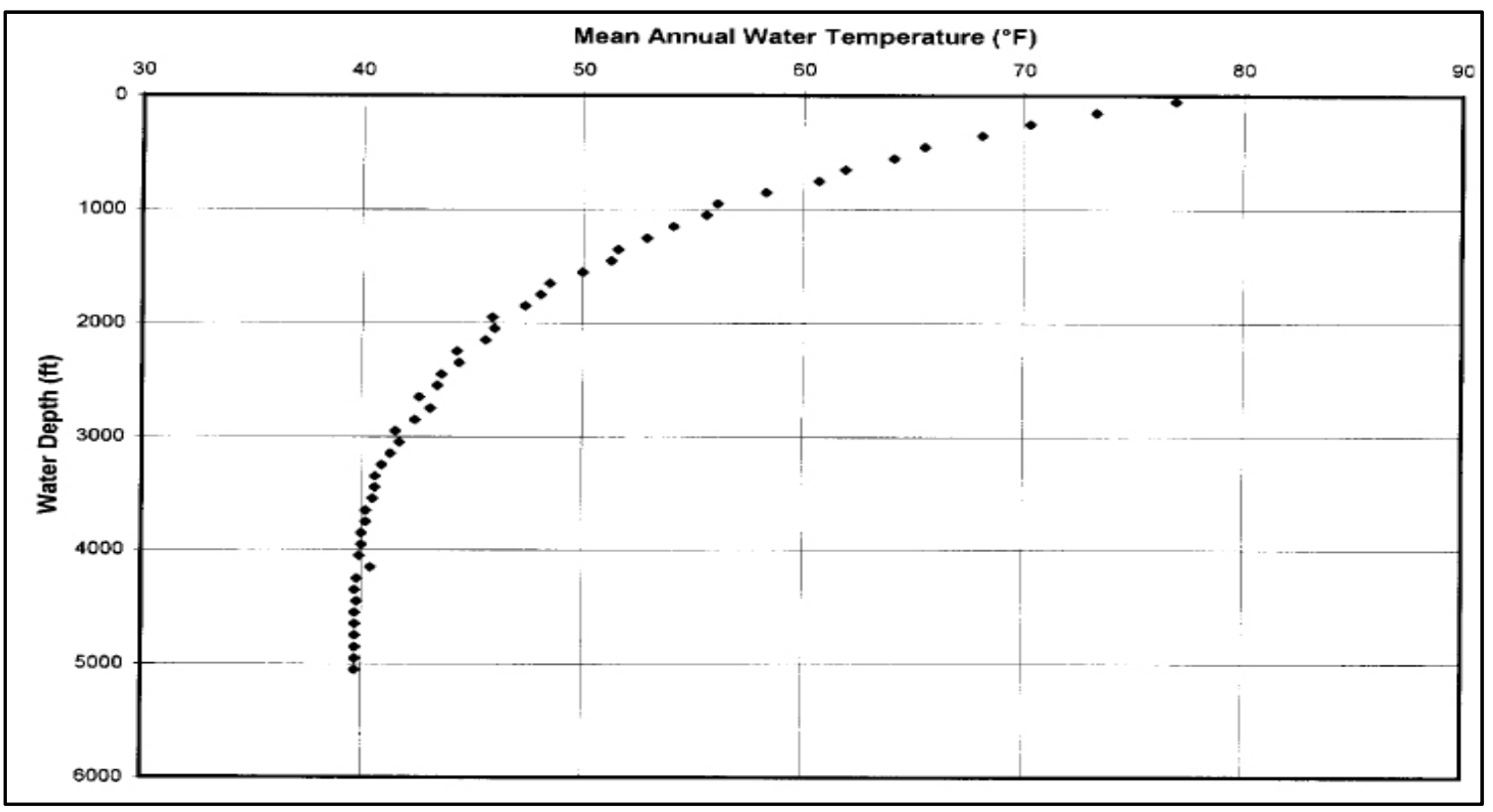

Figure 14: Mean annual water temperature of the Gulf of Mexico waters versus water depth [www.nodc.noaa.gov]

Table 3: Pressure and temperature values corresponding to various water depths

\begin{tabular}{|c|c|c|}
\hline $\begin{array}{c}\text { Water depth } \\
\text { (ft) }\end{array}$ & Pressure (psi) & $\begin{array}{c}\text { Temperature } \\
\left({ }^{\circ} \mathbf{F}\right)\end{array}$ \\
\hline 0 & 0 & 76 \\
\hline 787 & 350 & 60 \\
\hline 1,125 & 500 & 55 \\
\hline 2,250 & 1,000 & 45 \\
\hline 3,374 & 1,500 & 40 \\
\hline 5,005 & 2,225 & 40 \\
\hline
\end{tabular}




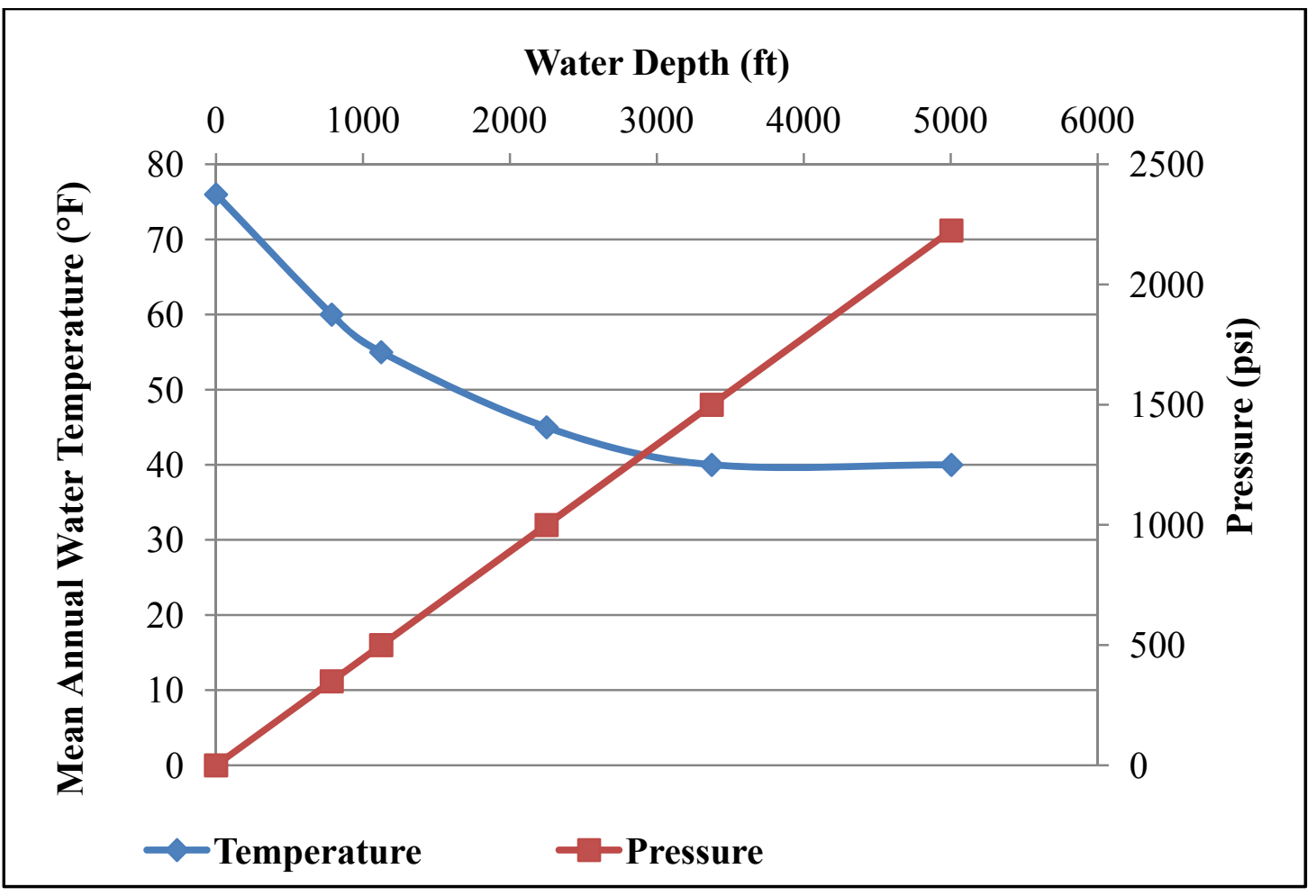

Figure 15: Representation of the conditions of pressure and temperature as a function of water depth in the Gulf of Mexico

\subsubsection{Experiment Set 1: Water Depth Variation}

Each combination of pressure and temperature as shown in Figure 14 constitutes the conditions of an individual experiment at which the hydrocarbon/water IFT was measured. A value of $2.5 \mathrm{wt} \%$ for water salinity was chosen for all individual experiments in experiment set 1 , as to represent the average salinity of the Gulf of Mexico waters [www.nodc.noaa.gov]. A dispersant concentration of 1,000 ppm was chosen for the experiments involving the addition of chemical dispersants to the water phase. It was intended to dissolve as much dispersant in the water as possible as to approach or exceed the CMC. However, addition of more than 1,000 ppm dispersant to the water resulted in a hazy solution through which a clear image of the 
hydrocarbon drop could not be captured. An overview of the conditions of experiment set 1 is provided in Table 4.

Table 4: Overview of the conditions of experiment set 1; all 12 experiments were conducted using a water salinity of $2.5 \mathrm{wt} \%$

\begin{tabular}{|c|c|c|c|}
\hline $\begin{array}{c}\text { Experiment } \\
\text { number }\end{array}$ & Pressure (psi) & $\begin{array}{c}\text { Temperature } \\
\left({ }^{\circ} \mathbf{F}\right)\end{array}$ & $\begin{array}{c}\text { Dispersant } \\
\text { concentration } \\
\text { (ppm) }\end{array}$ \\
\hline 1 & 14.7 & 76 & 0 \\
\hline 2 & 350 & 60 & 0 \\
\hline 3 & 500 & 55 & 0 \\
\hline 4 & 1,000 & 45 & 0 \\
\hline 5 & 1,500 & 40 & 0 \\
\hline 6 & 2,225 & 40 & 0 \\
\hline 7 & 14.7 & 76 & 1,000 \\
\hline 8 & 350 & 60 & 1,000 \\
\hline 9 & 500 & 55 & 1,000 \\
\hline 10 & 1,000 & 45 & 1,000 \\
\hline 11 & 1,500 & 40 & 1,000 \\
\hline 12 & 2,225 & 40 & 1,000 \\
\hline
\end{tabular}

\subsubsection{Experiment Set 2: Temperature Variation}

Experiment set 2 evaluated the effect of temperature on the hydrocarbon/water IFT. This was accomplished by holding all other variables constant and only changing the temperature. Again, a $2.5 \mathrm{wt} \%$ salt water was used and $1,000 \mathrm{ppm}$ of Corexit ${ }^{\circledR} 9500$ was dissolved in the water for the experiments involving the addition of dispersant to the system. A pressure of 2,225 psi was chosen to represent seafloor conditions as it relates to the subsea dispersant application. Table 5 lists the individual experiments that make up experiment set 2. 
Table 5: Overview of the conditions of experiment set 2; all 6 experiments were conducted at $2,225 \mathrm{psi}$ and using a water salinity of $2.5 \mathrm{wt} \%$

\begin{tabular}{|c|c|c|}
\hline $\begin{array}{c}\text { Experiment } \\
\text { number }\end{array}$ & $\begin{array}{c}\text { Temperature } \\
\left({ }^{\circ} \mathbf{F}\right)\end{array}$ & $\begin{array}{c}\text { Dispersant } \\
\text { concentration } \\
(\mathbf{p p m})\end{array}$ \\
\hline 1 & 76 & 0 \\
\hline 2 & 65 & 0 \\
\hline 3 & 55 & 0 \\
\hline 4 & 40 & 0 \\
\hline 5 & 76 & 1,000 \\
\hline 6 & 65 & 1,000 \\
\hline 7 & 55 & 1,000 \\
\hline 8 & 40 & 1,000 \\
\hline
\end{tabular}

\subsubsection{Experiment Set 3: Pressure Variation}

In experiment set 3 , the effect of pressure on the oil/water IFT was evaluated. The same water salinity $(2.5 \mathrm{wt} \%)$ and dispersant-in-water concentrations $(0 \& 1,000 \mathrm{ppm})$ used in experiment set 2 were also used in set 3 . Due to the fact that low temperature hydrocarbon/water IFT measurements are scarce, a constant temperature of $40^{\circ} \mathrm{F}$ was chosen for experiment set 3 . Table 6 details the conditions for experiment set 3 .

Table 6: Overview of the conditions of experiment set 3; all 6 experiments were conducted at 40 ${ }^{\circ} \mathrm{F}$ and using a water salinity of $2.5 \mathrm{wt} \%$

\begin{tabular}{|c|c|c|}
\hline $\begin{array}{c}\text { Experiment } \\
\text { number }\end{array}$ & Pressure (psi) & $\begin{array}{c}\text { Dispersant } \\
\text { concentration } \\
\text { (ppm) }\end{array}$ \\
\hline 1 & 0 & 0 \\
\hline 2 & 500 & 0 \\
\hline 3 & 1,500 & 0 \\
\hline 4 & 2,225 & 0 \\
\hline
\end{tabular}

Table 6 continued 


\begin{tabular}{|c|c|c|}
\hline 5 & 0 & 1,000 \\
\hline 6 & 500 & 1,000 \\
\hline 7 & 1,500 & 1,000 \\
\hline 8 & 2,225 & 1,000 \\
\hline
\end{tabular}

Table 6 continued

\subsubsection{Experiment Set 4: Water Salinity Variation}

In this experiment set 4 , the effect of water salinity was evaluated. All experiments in this set were conducted at seafloor conditions of pressure and temperature $\left(2,225 \mathrm{psi}\right.$ and $\left.40{ }^{\circ} \mathrm{F}\right)$, while 0 and 1,000 ppm dispersant-in-water concentrations were used again. Table 7 lists the experiments making up set 4 .

Table 7: Overview of the conditions of experiment set 4; all 8 experiments were conducted at $2,225 \mathrm{psi}$ and $40^{\circ} \mathrm{F}$

\begin{tabular}{|c|c|c|}
\hline $\begin{array}{c}\text { Experiment } \\
\text { number }\end{array}$ & $\begin{array}{c}\text { Water Salinity } \\
\text { (wt\%) }\end{array}$ & $\begin{array}{c}\text { Dispersant } \\
\text { concentration } \\
\text { (ppm) }\end{array}$ \\
\hline 1 & 0 & 0 \\
\hline 2 & 1.3 & 0 \\
\hline 3 & 2.5 & 0 \\
\hline 4 & 3.7 & 0 \\
\hline 5 & 0 & 1,000 \\
\hline 6 & 1.3 & 1,000 \\
\hline 7 & 2.5 & 1,000 \\
\hline 8 & 3.7 & 1,000 \\
\hline
\end{tabular}

\subsubsection{Experiment Set 5: Dispersant-in-Oil Concentration Variation}

In experiment set 5, the dispersant was dissolved in the crude oil at different concentrations for two purposes. First, 1,000 ppm was dissolved in the crude oil to examine how effective the dispersant would be in reducing the oil/water IFT as compared to when it was dissolved in the 
water phase. Second, the influence of the dispersant concentration was evaluated by increasing the amount dissolved in the crude oil in specific proportions. All experiments in set 5 were conducted with a $2.5 \mathrm{wt} \%$ salt water and at seafloor conditions of pressure $(2,225 \mathrm{psi})$ and temperature $\left(40^{\circ} \mathrm{F}\right)$. Table 8 provides an overview of the conditions of experiment set 5 .

Table 8: Overview of the condition of experiment set 5; all experiments were conducted at 2,225 psi and $40^{\circ} \mathrm{F}$, and using a water salinity of $2.5 \mathrm{wt} \%$

\begin{tabular}{|c|c|}
\hline $\begin{array}{c}\text { Experiment } \\
\text { number }\end{array}$ & $\begin{array}{c}\text { Dispersant } \\
\text { concentration } \\
\text { (ppm) }\end{array}$ \\
\hline 1 & 1,000 \\
\hline 2 & 2,500 \\
\hline 3 & 5,000 \\
\hline 4 & 10,000 \\
\hline
\end{tabular}

\subsection{Experimental Apparatus}

\subsubsection{The Low Temperature/High Pressure Optical Cell Apparatus}

An optical cell capable of withstanding extreme pressures and temperatures was designed, fabricated and utilized to enable IFT measurements at deepwater conditions. Made of titanium and hastelloy, the optical cell has a design rating of 20,000 psi at $400{ }^{\circ} \mathrm{F}$. The cell has four moveable arms. The top arm and one of the side arms are used to hold solid surfaces (e.g.: crystals) when conducting contact angle measurements and are therefore not utilized in this work. The other side arm is used to hold a calibration ball. The bottom arm has a needle tip used to inject the oil in the form of pendant drops for IFT measurements. The set-up includes other accessories such as an air chiller used to attain the desired temperatures, an image capturing system and floating piston transfer vessels. The air chiller is connected to an ambient air supply at its inlet, and pumps air at user-defined temperatures from its outlet. The image-capturing 
system consists of a video recorder, a monitor, a light source and a high-quality digital camera connected to a computer with an installed image analysis software. The floating piston transfer vessels were used to hold and transport experimental fluids. A digital water pump and a highpressure hand pump were used to generate the required pressures. All wetted parts of the optical cell and its accessories such as valves, tubing, fittings, and floating piston transfer vessels are made of highly corrosion resistant hastelloy metal (HC-276). An image of the low temperature/high pressure optical cell is shown in Figure 16 and a simplified sketch of the experimental set-up is shown in Figure 17.

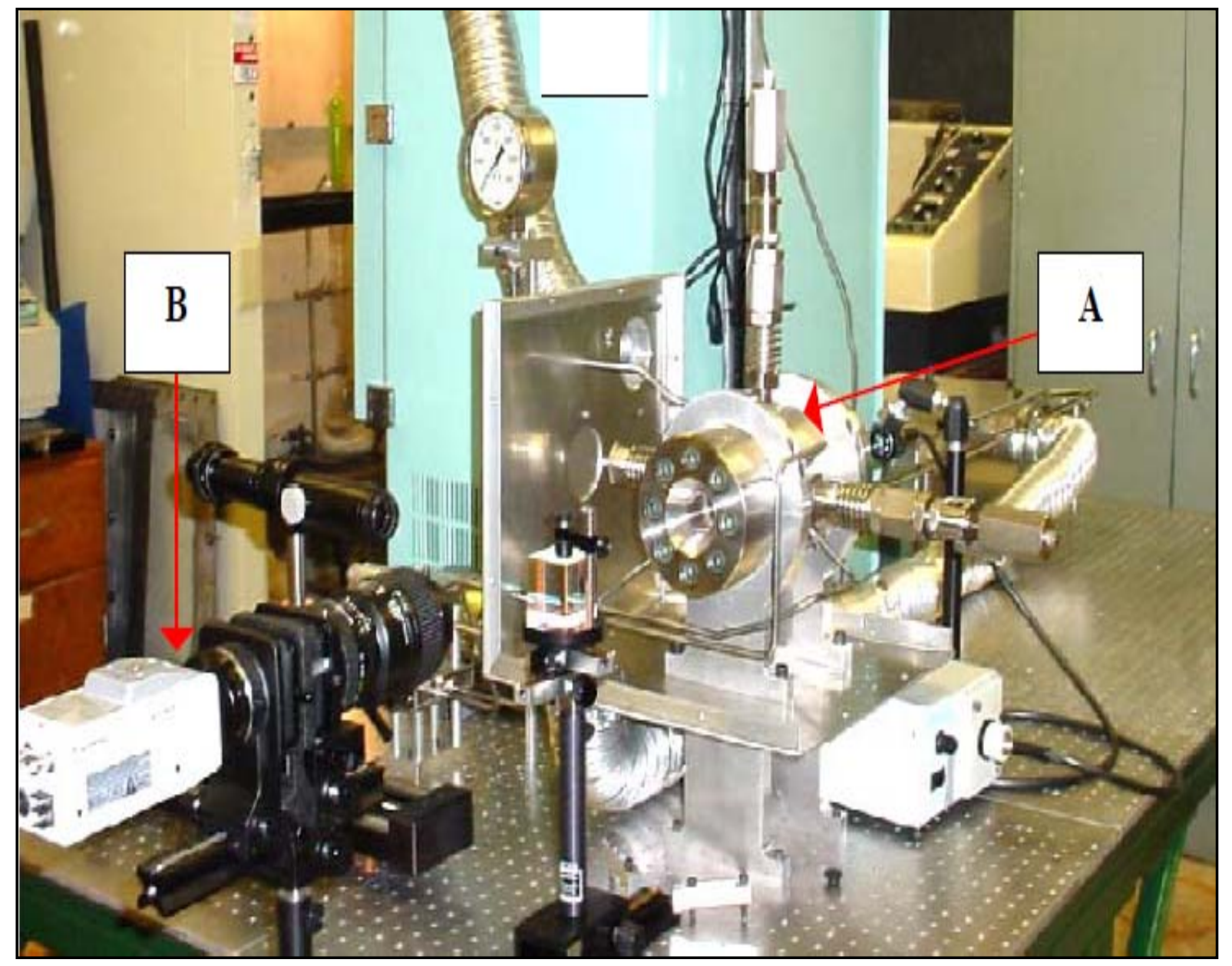

Figure 16: A picture of the low temperature/high pressure optical cell apparatus, A-Optical cell, B-Digital camera 


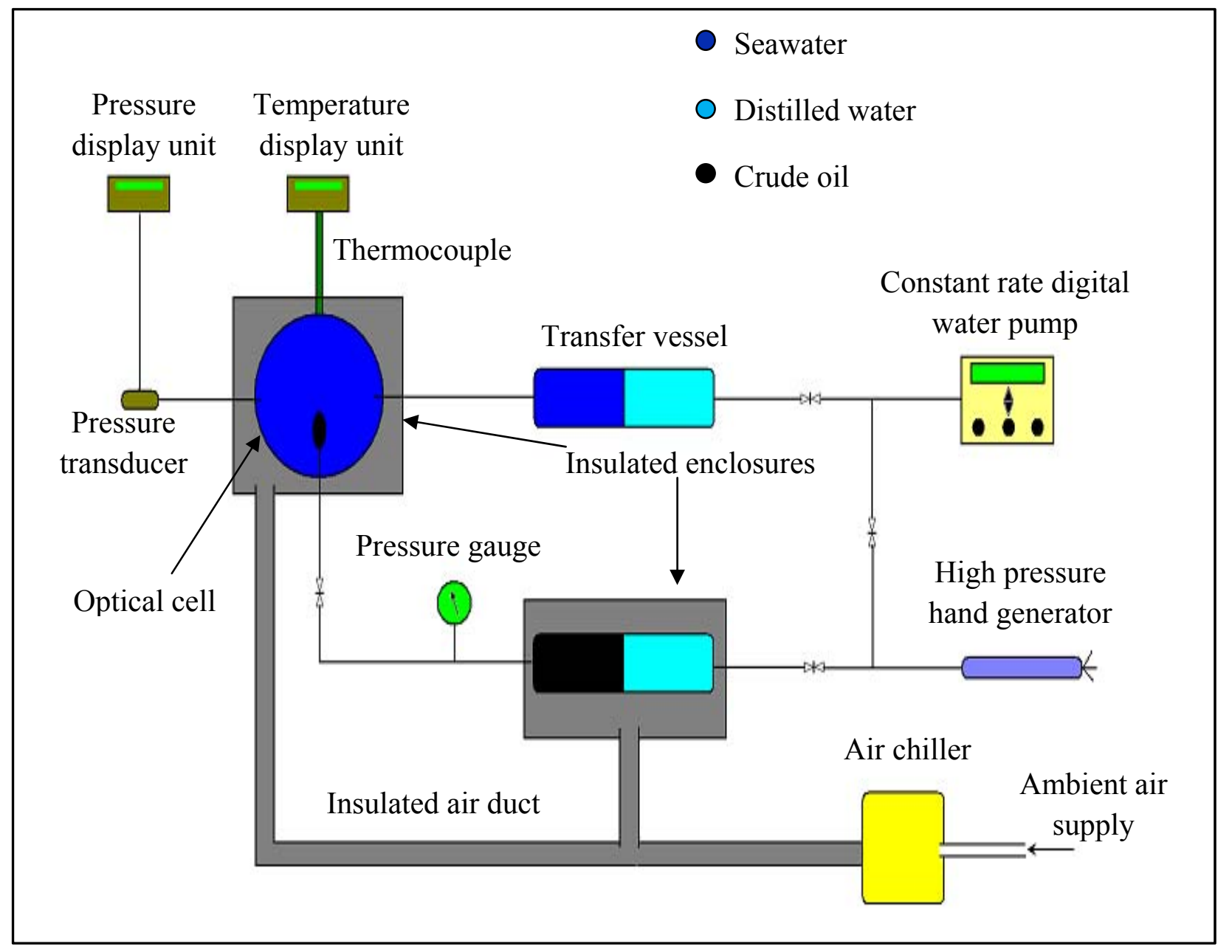

Figure 17: A schematic of the low temperature/high pressure experimental set-up

\subsubsection{The Ambient Optical Cell Apparatus}

IFT measurements at ambient conditions of pressure and temperature were made using the ambient optical cell apparatus. The ambient optical cell also has the capability of measuring contact angles as it is equipped with two crystal holders. A capillary tube, made of hastelloy, is used to inject oil from the bottom of the cell. The cell's interior is coated with Teflon to avoid contamination by the fluids used. The image capturing and analysis procedure is similar to that of the low temperature/high pressure optical cell. An image of the ambient optical cell apparatus is provided in Figure 18 and a simplified sketch of the experimental set-up is provided in Figure 19. 


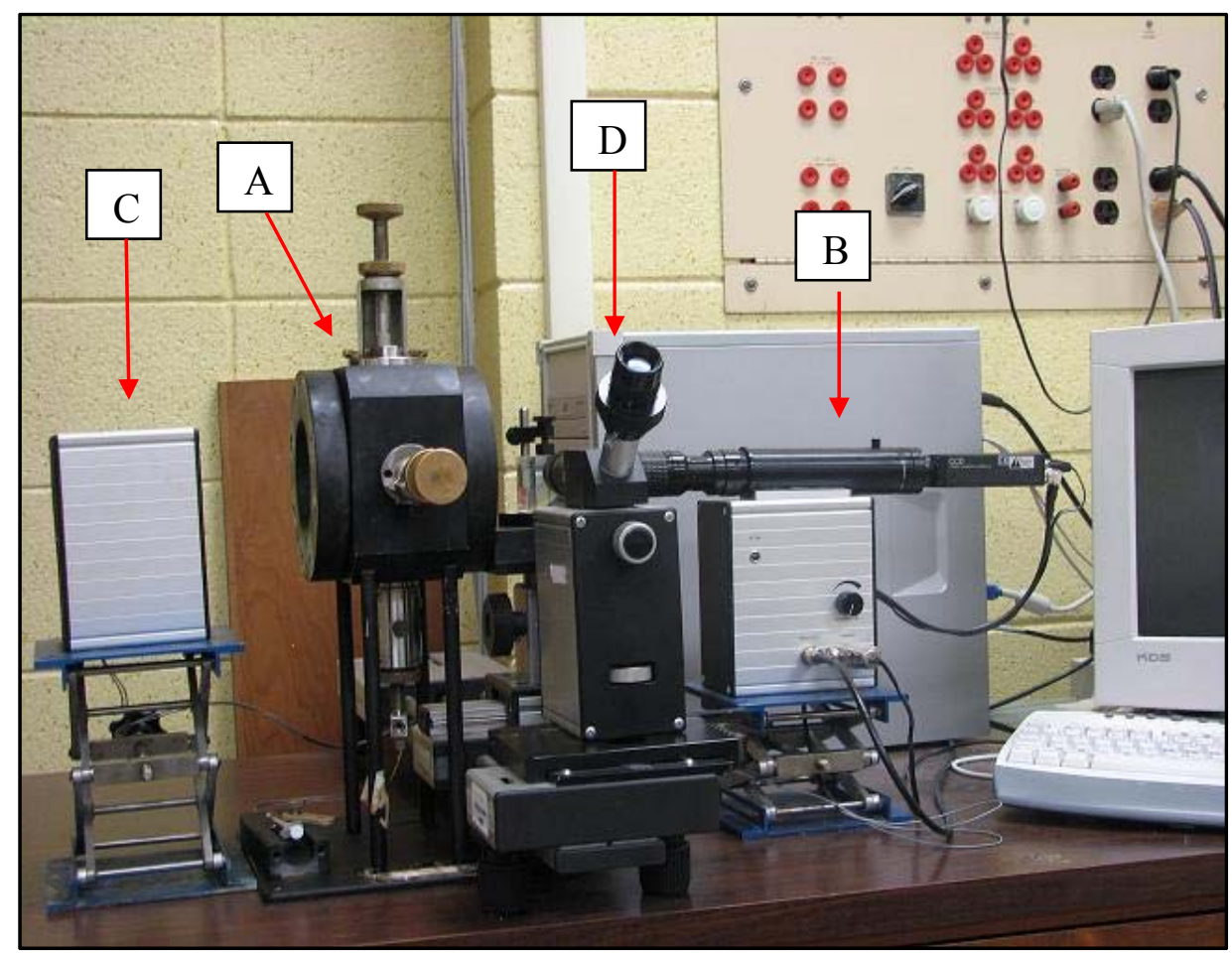

Figure 18: A picture of the ambient optical cell apparatus, A-Optical cell, B-Digital Camera, CLight source, D-Goniometer

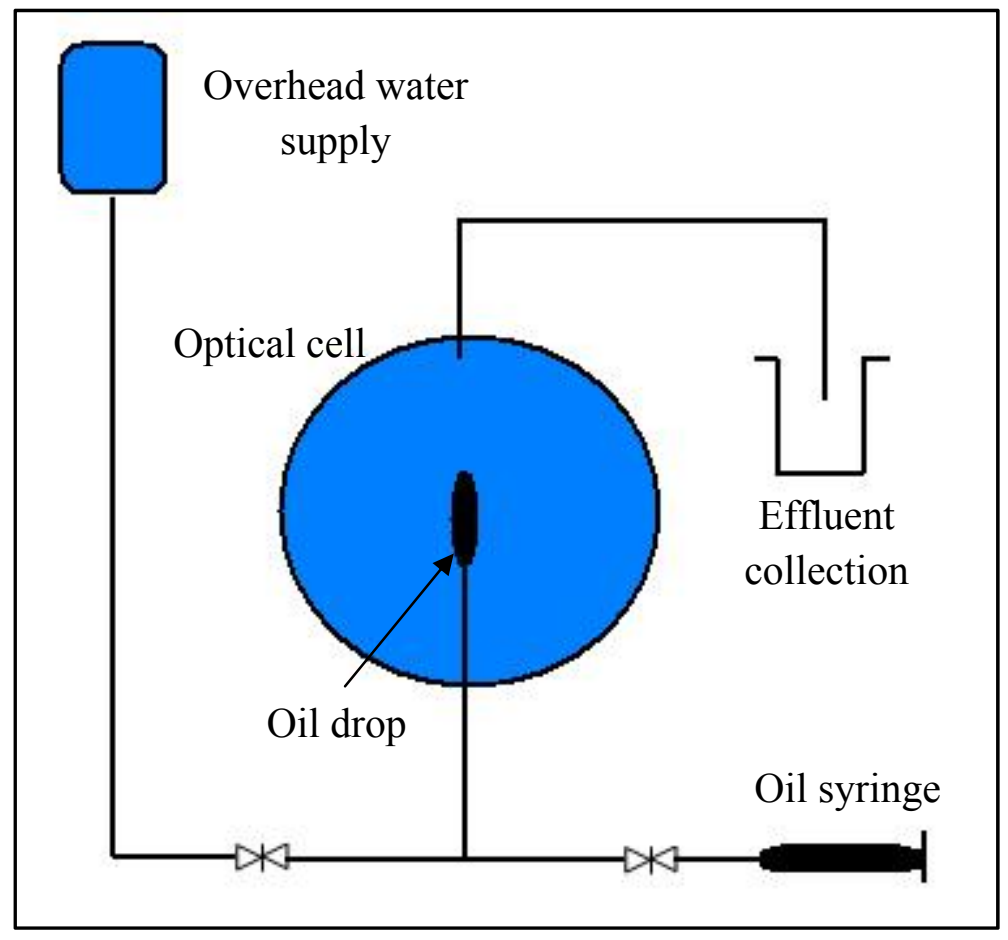

Figure 19: A simplified sketch of the ambient optical cell apparatus 


\subsubsection{Preparation and Cleaning of the Optical Cell Apparatus}

The same cleaning procedure was followed for both the ambient and low temperature/high pressure optical cell apparatus. The cell, along with all wetted parts, was flushed with large amounts of Toluene to dissolve any traces of hydrocarbons left after a previous experiment. Acetone was then used to remove Toluene. Air from a compressed cylinder was then used to vaporize the Acetone. The cell was then flushed with large amounts of de-ionized water and then dried with high-pressure nitrogen.

\subsubsection{Density and Salinity Meters}

Density measurements were made using a high quality density meter manufactured by Anton Paar. The DMA HP is a density measuring cell designed to measure the densities of fluids at pressures ranging from 0 to $10,000 \mathrm{psi}$ and temperatures ranging from $14^{\circ} \mathrm{F}$ to $392{ }^{\circ} \mathrm{F}$. The DMA HP is connected to an evaluation unit (DMA 4500) to display the measured density values as shown in Figure 20.

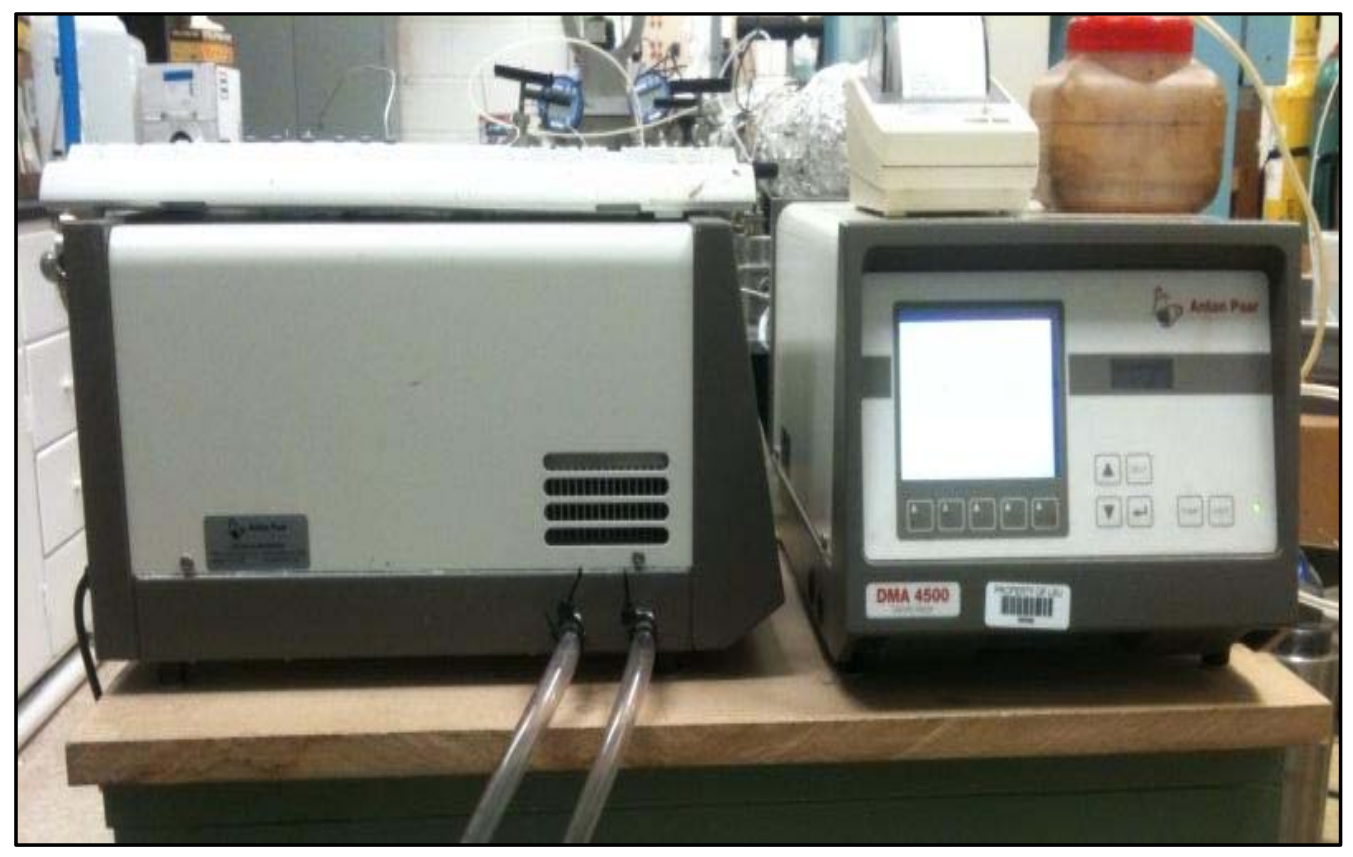

Figure 20: A picture of the DMA HP density meter connected to the DMA 4500 evaluation unit 
The DMA HP works on the principle of measuring the period of a harmonic oscillation of a built-in U-tube in which the fluid sample is contained. The cell electronically excites the U-tube, which acts as a tuning fork, at constant amplitude and a frequency meter measures the time corresponding to a fixed number of periods [DMA HP User's manual, 2005].

Salinity measurements were made using the $\mathrm{HACH}{ }^{\circledR}$ Sension ${ }^{\mathrm{TM}} 5$ conductivity meter. The applicable range is 0 to $42,000 \mathrm{ppm}$ and -2 to $35^{\circ} \mathrm{C}$ The $\mathrm{HACH}{ }^{\circledR}$ Sension ${ }^{\mathrm{TM}} 5$ conductivity meter calculates the salinity based on the Extended Practical Salinity Scale of 1978, as referenced in the $17^{\text {th }}$ edition of Standard Methods, 25200B. Salinity is a relative scale based on a Potassium Chloride, $\mathrm{KCl}$, solution. A salinity value of $35,000 \mathrm{ppm}$ is equivalent to a $\mathrm{KCl}$ solution containing $32.4356 \mathrm{~g} \mathrm{KCl}$ in $1 \mathrm{~kg}$ of solution at $15^{\circ} \mathrm{C}$. An image of the $\mathrm{HACH}{ }^{\circledR}$ Sension ${ }^{\mathrm{TM}} 5$ conductivity meter is shown in Figure 21.

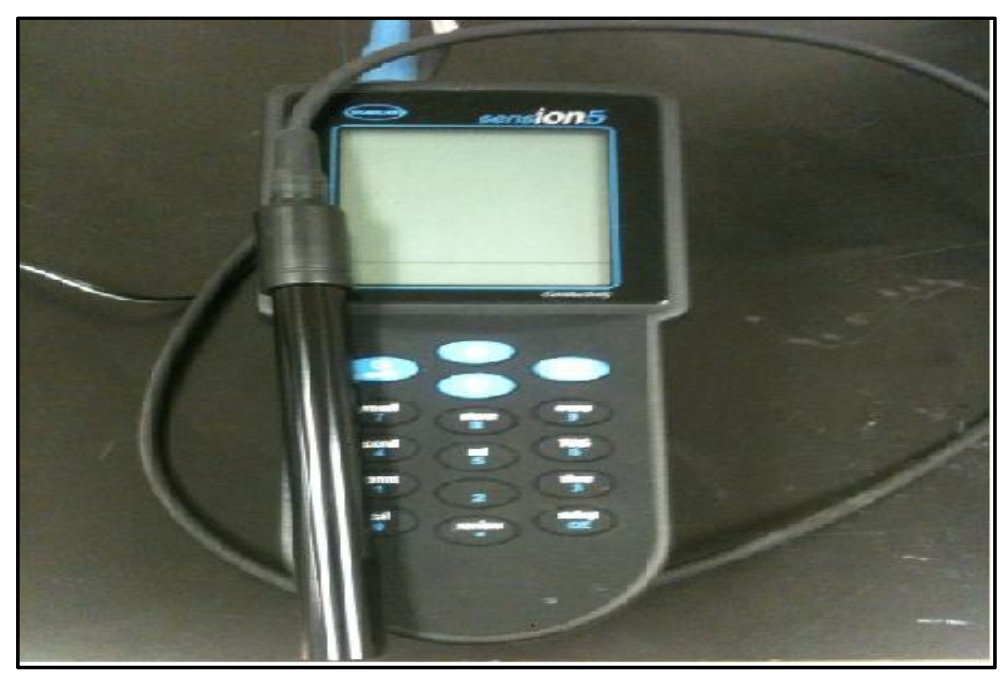

Figure 21: The $\mathrm{HACH}{ }^{\circledR}$ Sension ${ }^{\mathrm{TM}} 5$ conductivity meter

\subsection{Experimental Fluids}

\subsubsection{Aqueous Phase}

Synthetic sea water (SSW) and de-ionized water (DIW), both purchased from Cole Parmer, were mixed in specific proportions resulting in the various salinities. The composition of SSW is 
provided in Table 9. The dispersant used in this study was Corexit ${ }^{\circledR} 9500$ (EC9500A), and was provided by Nalco Holding Company. The dispersant will be pre-mixed with either the aqueous or oleic phase at the desired concentration for the IFT measurements. Table 10 provides the proportion of each of DIW and SSW in the prepared aqueous fluids and the resulting salinity as measured in the lab by the $\mathrm{HACH}{ }^{\circledR}$ Sension ${ }^{\mathrm{TM}} 5$ conductivity meter.

Table 9: Composition of the synthetic seawater (SSW)

\begin{tabular}{|c|c|}
\hline Ion & $\begin{array}{c}\text { Concentration } \\
\text { in SSW } \\
(\mathbf{m g} / \mathbf{k g})\end{array}$ \\
\hline Bicarbonate & 125.4 \\
\hline Boron & 3.9 \\
\hline Bromide & 53.2 \\
\hline Calcium & 542.8 \\
\hline Carbonate & 1.7 \\
\hline Chloride & 19300.8 \\
\hline Magnesium & 1637.2 \\
\hline Potassium & 376.4 \\
\hline Silicon & 0.1 \\
\hline Sodium & 11781.3 \\
\hline Strontium & 10.7 \\
\hline Sulfate & 2622.0 \\
\hline
\end{tabular}


Table 10: Salinities of the prepared aqueous fluids

\begin{tabular}{|c|c|}
\hline $\begin{array}{c}\text { DIW : SSW } \\
\text { ratio }\end{array}$ & Salinity (wt\%) \\
\hline $1: 0$ & 0 \\
\hline $2: 1$ & 1.3 \\
\hline $1: 2$ & 2.5 \\
\hline $0: 1$ & 3.7 \\
\hline
\end{tabular}

\subsubsection{Oleic Phase}

Originating from the Macondo prospect, in which the Deepwater Horizon rig was drilling, Mississippi Canyon Block 252 (MC252) crude oil was provided by sponsoring company. The sample was collected directly from the source on June 19, 2010, as 'dead' oil (without its dissolved light ends) and maintained at $45^{\circ} \mathrm{F}$ until analysis. A chemical composition analysis, provided with the sample, has indicated that the crude oil is 'fresh' or uncontaminated and has not undergone any weathering or evaporation processes. Table 11 provides some typical physical properties of the MC252 crude oil sample. Reagent grade (99.8\% purity) n-octane was also used as the oleic phase for comparison.

Table 11: Physical properties of MC252 crude oil

\begin{tabular}{|c|c|}
\hline Property & Value \\
\hline API gravity @ $60^{\circ} \mathrm{F}\left({ }^{\circ} \mathrm{API}\right)$ & 36.2 \\
\hline Kinematic viscosity @ $104^{\circ} \mathrm{F}(\mathrm{cSt})$ & 5.067 \\
\hline Sulfur content $(\mathrm{wt} \%)$ & 0.261 \\
\hline
\end{tabular}

Table 11 continued 


\begin{tabular}{|c|c|}
\hline Water content $(\mathrm{mg} / \mathrm{Kg})$ & 1680 \\
\hline Total light ends $(\mathrm{wt} \%)$ & 27.19 \\
\hline Nitrogen content $(\mathrm{mg} / \mathrm{Kg})$ & 690 \\
\hline True vapor pressure (psi) & 3.3 \\
\hline Corrected flashpoint $\left({ }^{\circ} \mathrm{F}\right)$ & 104 \\
\hline pH-water extract & 6.4 \\
\hline
\end{tabular}

Table 11 continued

\subsection{Experimental Procedure}

\subsubsection{The Pendant Drop Method}

Consider an oil drop hanging from the tip of a capillary tube in a medium filled with equilibrated water as shown in Figure 22. At static conditions, the shape and size of the oil drop are controlled by the gravity and surface forces. The equilibrium shape of the hanging pendant drop is a balance between the forces acting on the drop, namely gravity pulling the drop upwards by elongation, and surface tension preventing the growth of surface area and pulling the drop into a spherical shape. The relationship between the oil/water interfacial tension and the drop dimensions can be described as follows [Danesh, 1998]:

$$
\gamma=\frac{\mathrm{g} \Delta \rho \mathrm{d}_{\mathrm{e}}^{2}}{\mathrm{~S}}
$$

Where $\mathrm{g}$ is the acceleration due to gravity, $\Delta \rho$ is the density difference between the two phases, $d_{e}$ is the equatorial diameter or the maximum horizontal diameter and $\mathrm{S}$ is the drop shape factor and is a function of both $d_{e}$ and $d_{s}$. The latter being the diameter of the drop measured at a specific height above the bottom of the drop. Nierderhauser and Bartell (1947) have determined 
and reported values of S, by relating the pressure difference across the interface to the interface curvature.

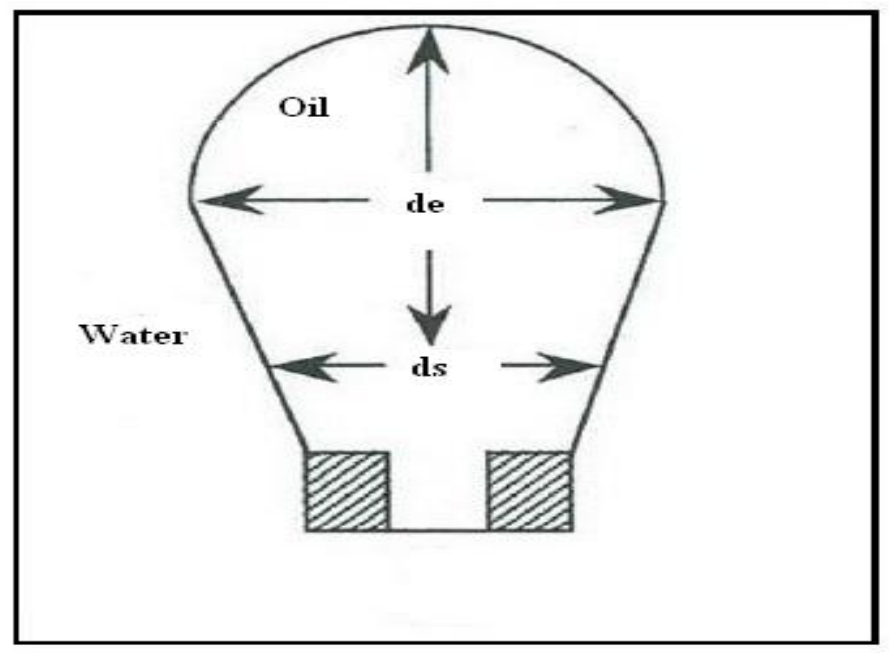

Figure 22: Illustration of the shape of a pendant drop

In the laboratory, the low temperature/high pressure optical cell was first filled with the aqueous phase and pressurized to the desired pressure. A few drops of crude oil or n-octane were introduced into the optical cell through a capillary tube and left to float to the top of the cell. The optical cell and the transfer vessel containing the oleic phase were then cooled to the desired temperature. Typically, it took about 10-12 hours for the temperature to be lowered from ambient conditions $\left(76^{\circ} \mathrm{F}\right)$ to the lowest desired temperature $\left(40^{\circ} \mathrm{F}\right)$. An aging period of 24 hours, at which the desired pressure and temperature were constantly maintained, was allowed to attain equilibrium. The same aging period was also applied to the ambient condition experiments after both phases were introduced into the ambient cell.

After equilibrium was reached, a drop of crude oil or n-octane was introduced through the capillary tube into the optical cell, as illustrated in Figure 23, at a very slow rate ( $\sim 2$ minutes). When the oil drop is just about to detach from the tip of the capillary tube, due to buoyancy forces exceeding the IFT, images of the drop were captured using a digital camera. 


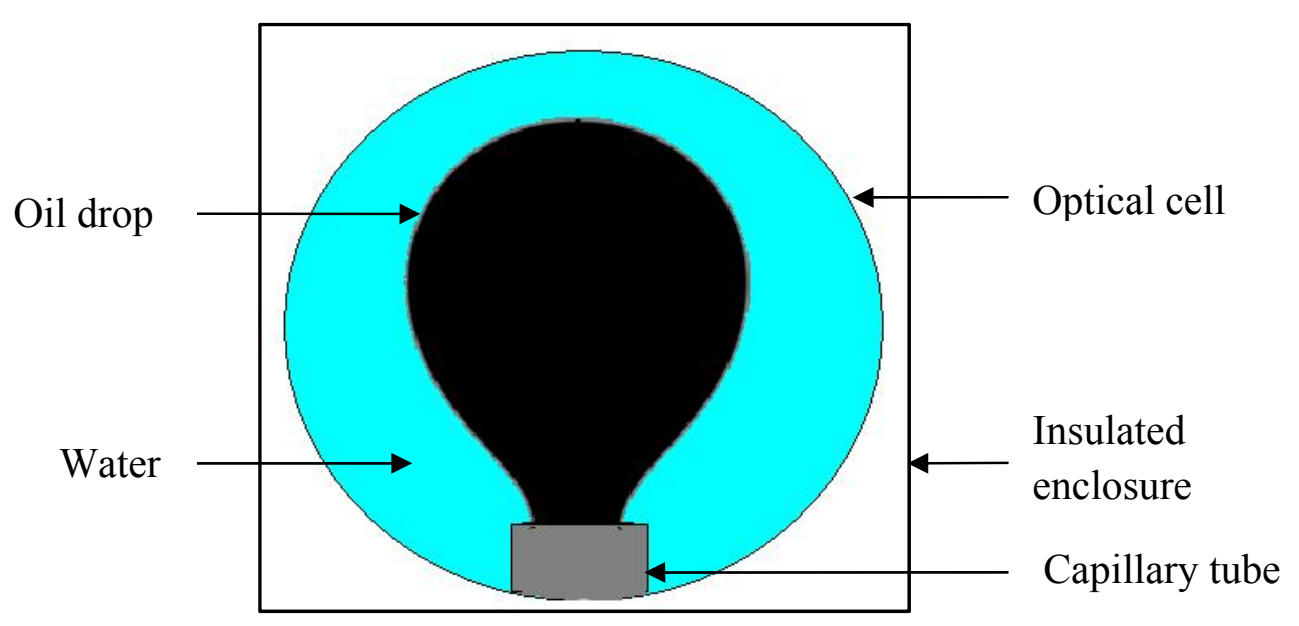

Figure 23: Implementation of the Pendant Drop method in the laboratory

The images were then transmitted to a computer for image analysis using a commercial software named Drop Shape Analysis (DSA), provided by Kruss USA, which utilizes the Axisymmetric Drop Shape Analysis (ASDA) technique. This procedure was followed until the standard deviation between 10 consecutive drops, all introduced at approximately the same rate, was less than $0.25 \mathrm{mN} / \mathrm{m}$. The average IFT among theses 10 drops was then used as the reported value.

\subsubsection{The Axisymmetric Drop Shape Analysis (ASDA) Technique}

In hydro-mechanical equilibrium the gravitational force which depends on the height of the drop corresponds to the Laplace pressure, resulting from the curvature of the drop contour at that point [Sequeira, 2006]. The tendency of an interface between two immiscible phases to create the smallest surface area, gives rise to a pressure difference between the two fluids on either side of a curved interface. This pressure difference is known as capillary pressure and is related to the interfacial tension as defined by the Young-Laplace equation of capillarity [Rotenberg et al., 1983]:

$$
\Delta \mathrm{P}=\gamma\left(\frac{1}{\mathrm{R}_{1}}+\frac{1}{\mathrm{R}_{2}}\right)
$$


Where $\Delta \mathrm{P}$ is the capillary pressure, $\gamma$ is the interfacial tension and $\mathrm{R}_{1}$ and $\mathrm{R}_{2}$ are the principal radii of curvature.

The shape of the pendant drop has to be analyzed and the fluid densities have to be known in order to determine the interfacial tension. Several researchers [Rotenberg et al., 1983; Rio and Neumann, 1996] traced the developments and limitations of various methods used to analyze the shapes of pendant drops for liquid-liquid interfacial tension measurements. They presented a procedure for obtaining the values of surface and interfacial tension from the shape of the axisymmetric fluid interfaces. This method is known as the Axisymmetric Drop Shape Analysis (ADSA) technique.

If the drop is assumed to be axisymmetric about its vertical axis, as shown in Figure 24, then $\Delta \mathrm{P}$ at any given point on the interface curve can be written with reference to the apex point where $\mathrm{R}_{1}=\mathrm{R}_{2}=\mathrm{R}_{0}$ [Rotenberg et al., 1983]:

$$
\Delta \mathrm{P}=\frac{2 \gamma}{\mathrm{R}_{0}}+\Delta \rho g z=\gamma\left(\frac{1}{\mathrm{R}_{1}}+\frac{\sin \Phi}{\mathrm{X}}\right)
$$

Where $R_{0}$ is the radius of curvature at the origin of the $\mathrm{x}-\mathrm{z}$ coordinate (apex point), $\Delta \rho$ is the difference in the densities of the two phases, $g$ is the gravitational acceleration, $\mathrm{z}$ is the vertical height measured from the datum plane and $\Phi$ is the turning angle measured between the tangent to the interface at the point $(\mathrm{x}, \mathrm{z})$ and the datum plane. $\mathrm{R}_{1}$ is defined as inverse of the rate of change of the turning angle, $\Phi$, with respect to the arc-length parameter, s, and turns in the plane of paper:

$$
\frac{1}{\mathrm{R}_{1}}=\frac{\mathrm{d} \Phi}{\mathrm{ds}}
$$

And $\mathrm{R}_{2}$ rotates in a plane perpendicular to the plane of paper and about the axis of symmetry:

$$
\mathrm{R}_{2}=\frac{\mathrm{x}}{\sin \Phi}
$$




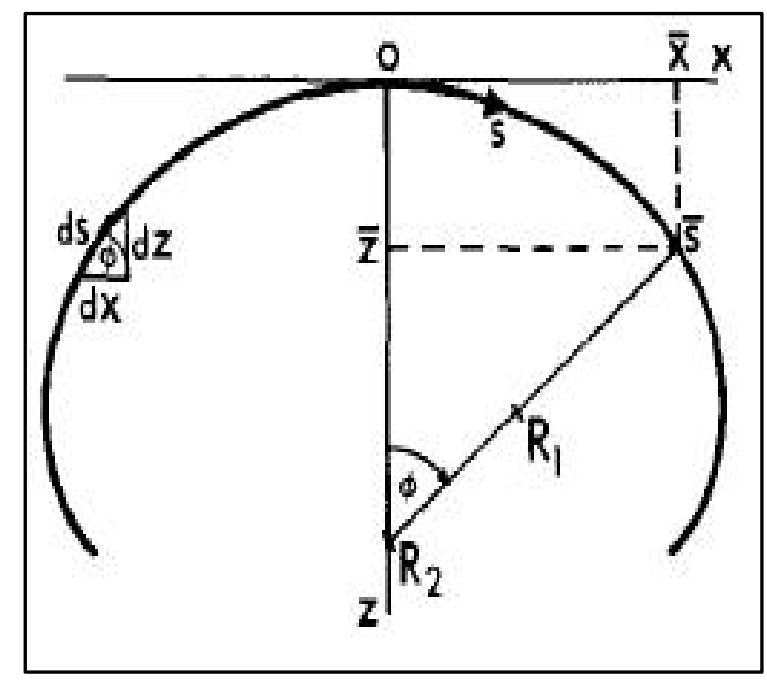

Figure 24: Geometrical consideration of the ASDA technique [Rotenberg et al., 1983]

Expanding on the geometrical consideration shown in Figure 24 yields the following differential identities:

$$
\begin{aligned}
& \frac{\mathrm{dx}}{\mathrm{ds}}=\cos \Phi \\
& \frac{\mathrm{dz}}{\mathrm{ds}}=\sin \Phi .
\end{aligned}
$$

Combining Equation (8) with (7) and rearranging gives:

$$
\frac{\mathrm{d} \Phi}{\mathrm{ds}}=\frac{2}{\mathrm{R}_{0}}+\frac{\Delta \rho \mathrm{gz}}{\gamma}-\frac{\sin \Phi}{\mathrm{x}}
$$

The complete shape of the interface curve can then be defined by the simultaneous integration of Equations (10), (11) and (12), all functions of the arc-length, s, with the following boundary conditions:

$$
\mathrm{x}(0)=\mathrm{z}(0)=\Phi(0)
$$

The method then constructs an objective function which expresses the error between a physically observed and a theoretical Laplacian curve that represents a solution of the Laplacian capillarity: 


$$
\mathrm{E}=1 / 2 \sum_{\mathrm{n}=1}^{\mathrm{N}}\left[\mathrm{d}\left(\mathrm{u}_{\mathrm{n}}, \mathrm{v}\right)\right]^{2}
$$

Where $\mathrm{u}_{\mathrm{n}}=1,2,3 \ldots . \mathrm{N}$, are a set of experimental points on a physically observed (measured) curve, $v$ is a theoretically calculated curve and $d\left(u_{n}, v\right)$ is the normal distance between $u_{n}$ and the curve $\mathrm{v}$ as shown in Figure 25. This objective function (Equation 14) is then minimized using the method of incremental loading in conjunction with the Newton-Raphson method.

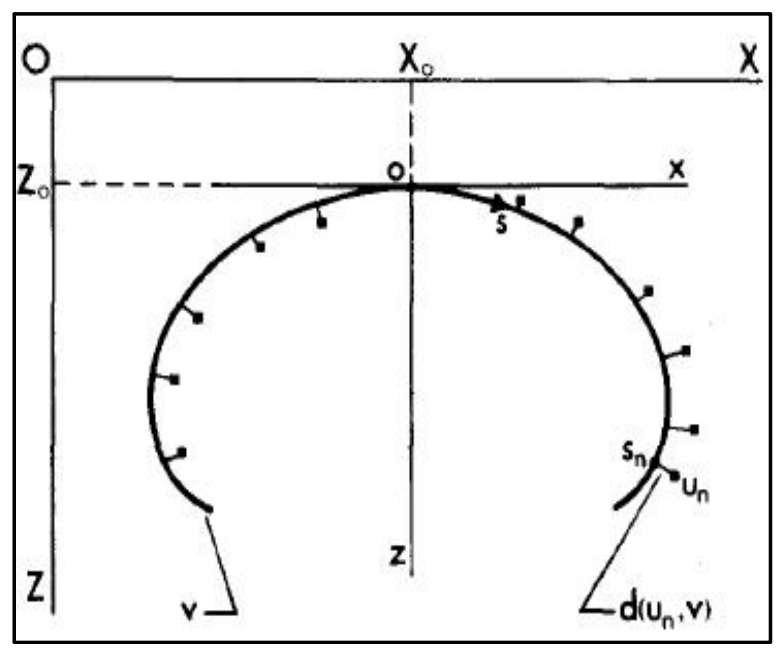

Figure 25: Illustration of a measured (observed) curve and a calculated interface curve [Rotenberg et al., 1983]

\subsubsection{Previous Use of the Pendant Drop Method}

Motomura et al. (1983) measured the IFT between water and four members of a homologous series of alkane (hexane, octane, decane, and dodecane) at atmospheric pressure and temperatures ranging from 32 to $95^{\circ} \mathrm{F}$. Measurements were also made at a constant temperature $\left(76^{\circ} \mathrm{F}\right)$ and as a function of pressure (14.7 to $\left.21,700 \mathrm{psi}\right)$. It was reported that the interfacial tension decreased with increasing temperatures and decreasing pressures.

Cai et al. (1996) reported experimental data on the IFT of 10 normal alkane/water + brine and hydrocarbon mixtures/water + brine systems in a study where the effects of temperature, 
pressure, and salt content were assessed. The behavior of the IFT was sensitive to temperature and salt concentration but weakly dependent on pressure.

Al-Shahhaf et al. (2005) measured the n-octane/de-ionized water IFT at various pressure and temperature conditions pertaining to reservoir conditions. The influence of water salinity and surfactant concentration on the IFT was also studied. The measured IFT values were found to be linearly dependent on pressure, temperature and salt concentration. There was an almost 20 -fold reduction in the IFT values following the addition of surfactants.

Rao (2001) has reported interfacial tension values of n-octane/water system measured using the computerized Pendant Drop method which utilizes the ASDA technique to analyze drop profiles. The measurements were made at pressures up to $10,000 \mathrm{psi}$ and $338^{\circ} \mathrm{F}$. An increase in the interfacial tension with increasing pressure was observed while an opposite trend was observed with temperature. The reproducibility and precision of the ASDA technique was also indicated by the low standard deviations associated with the reported IFT measurements. Rao (2001) also pointed out some of the advantages of analyzing pendant drop profiles using the ASDA technique which include: (1) the drop shape can be measured from any convenient reference frame; (2) no particular starting values are needed for the interfacial tension, radius of curvature at the apex, and the coordinates of the origin; (3) the procedure eliminates the need of a predetermined table of shape factors; and (3) the analytically determined integrands reduce the loss of accuracy in the calculation of the objective function and its first and second derivatives.

Xu et al. (2008) evaluated the effects of pressure, temperature and fluids' composition on the oil/water interfacial tension using the same method used by Rao (2001). His study focused on the influence of surfactants on the oil/water interfacial interactions at elevated pressures and temperatures. It was observed that the oil/water interfacial tension was greatly affected by both 
the oil and water compositions, and that asphaltene played an important role in influencing the interfacial interactions. 


\section{CHAPTER 4. RESULTS AND DISCUSSION}

\subsection{Density Meter Calibration}

Before actual density measurements were made, the DMA HP density meter had to be calibrated using two standard fluids, with precisely known densities, at every specific temperature and pressure. Decane and de-ionized water (DIW) were used as the standard fluids, and their density values were obtained from the National Institute of Standards and Technology (NIST) website. The calibration of the density meter was carried out at all the conditions of pressure and temperature at which the hydrocarbon/water IFT was measured.

Since the densities of the fluids are the main user-defined inputs to the software and affect the IFT calculation procedure appreciably, careful precision was taken during the calibration procedure. For validation purposes, the measured density of de-ionized water (DIW) was compared to values reported by the NIST following the calibration process. Figures 26 and 27 show the difference in measured water density values from NIST values as a function of temperature and pressure respectively. The blue crosses in the figures represent the measured water density values while the hollow red circles represent the values acquired from the NIST website.

Good agreement between measured density values and ones reported by the NIST can be seen in Figure 26, when the temperature was varied at a constant pressure of 2,225 psi. The greatest deviation, about $0.015 \%$ from the NIST value, was observed at $65^{\circ} \mathrm{F}$. The variation of

pressure, at a constant temperature of $40{ }^{\circ} \mathrm{F}$, also showed good agreement between measured and reported values, as shown in Figure 27, except for the measurement at atmospheric pressure. A deviation of $0.172 \%$ from the NIST value was recorded at $14.7 \mathrm{psi}$ and could possibly be attributed to the presence of air bubbles in the tubing connected to the density meter. 


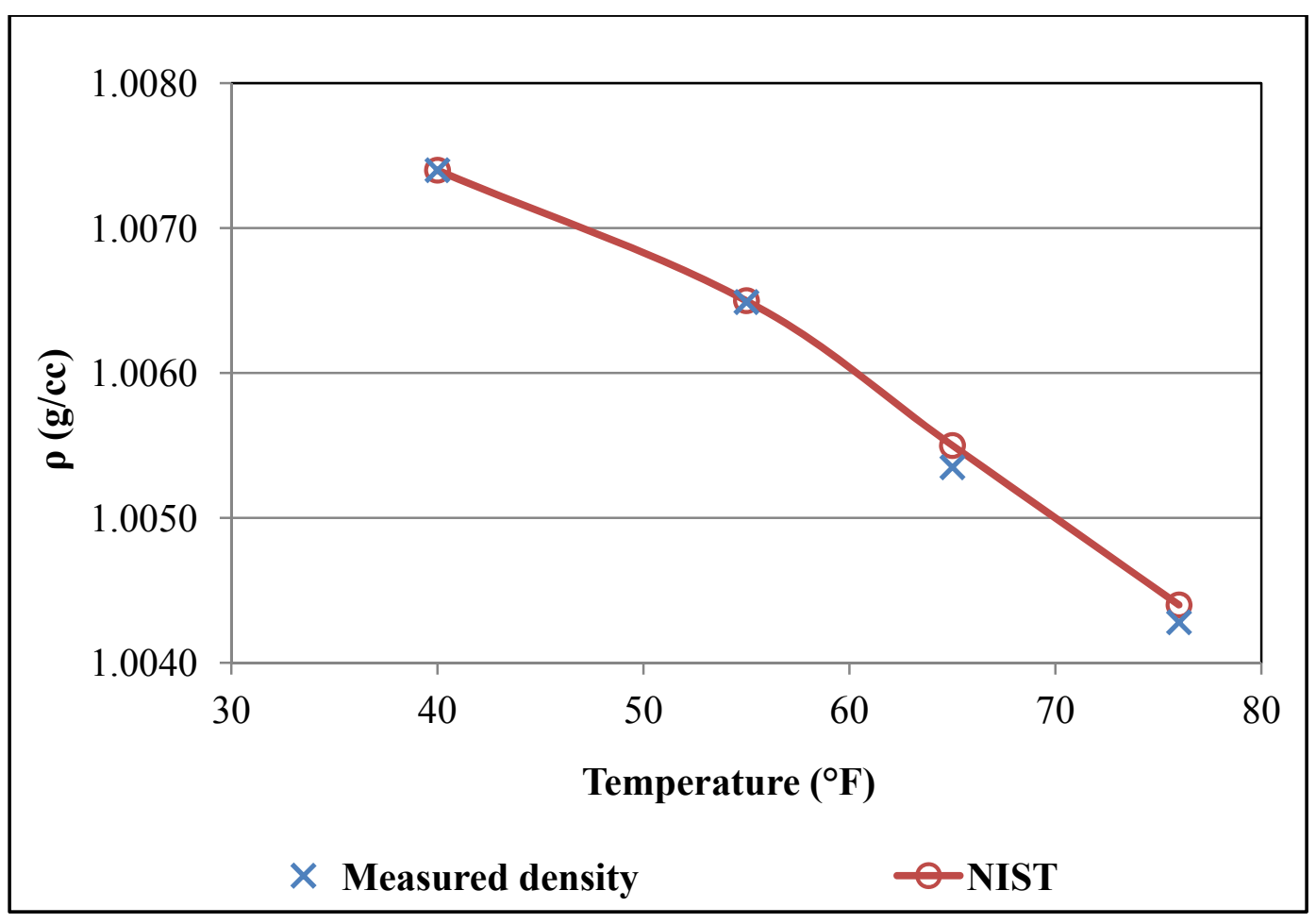

Figure 26: Measured water density compared to NIST values at 2,225 psi and as a function of temperature

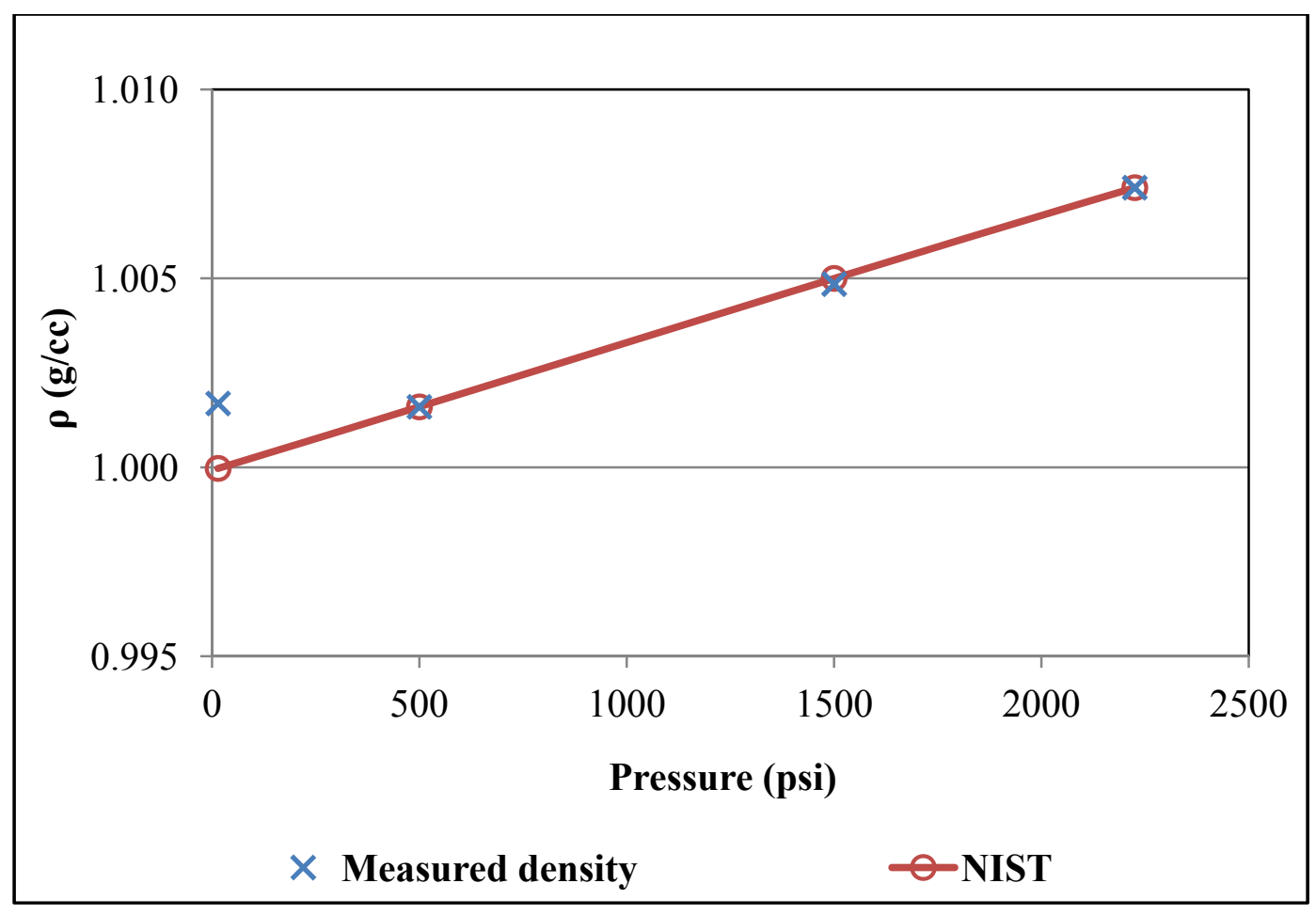

Figure 27: Measured water density compared to NIST values at $40^{\circ} \mathrm{F}$ and as a function of pressure 


\subsection{Preliminary Experiments}

The results of the first set of preliminary experiments which included the measurement of the $\mathrm{n}$-octane/de-ionized water IFT at various pressures and a constant temperature of $76^{\circ} \mathrm{F}$ are illustrated in Figure 28 and listed in Table 12. The measured average IFT was compared to values reported by both Cai et al. (1996) and Al-Shahhaf et al. (2005). Vertical error bars representing the standard deviation of the measured average IFT among 10 consecutive pendant drops are included in Figure 28.

The values of the measured n-octane/water IFT were lower than the values reported by both Cai et al. (1996) and Al-Shahhaf et al. (2005) as noted in Table 12. However, the trend observed was similar as the measured IFT was observed to increase with increasing pressure as seen in Figure 28.

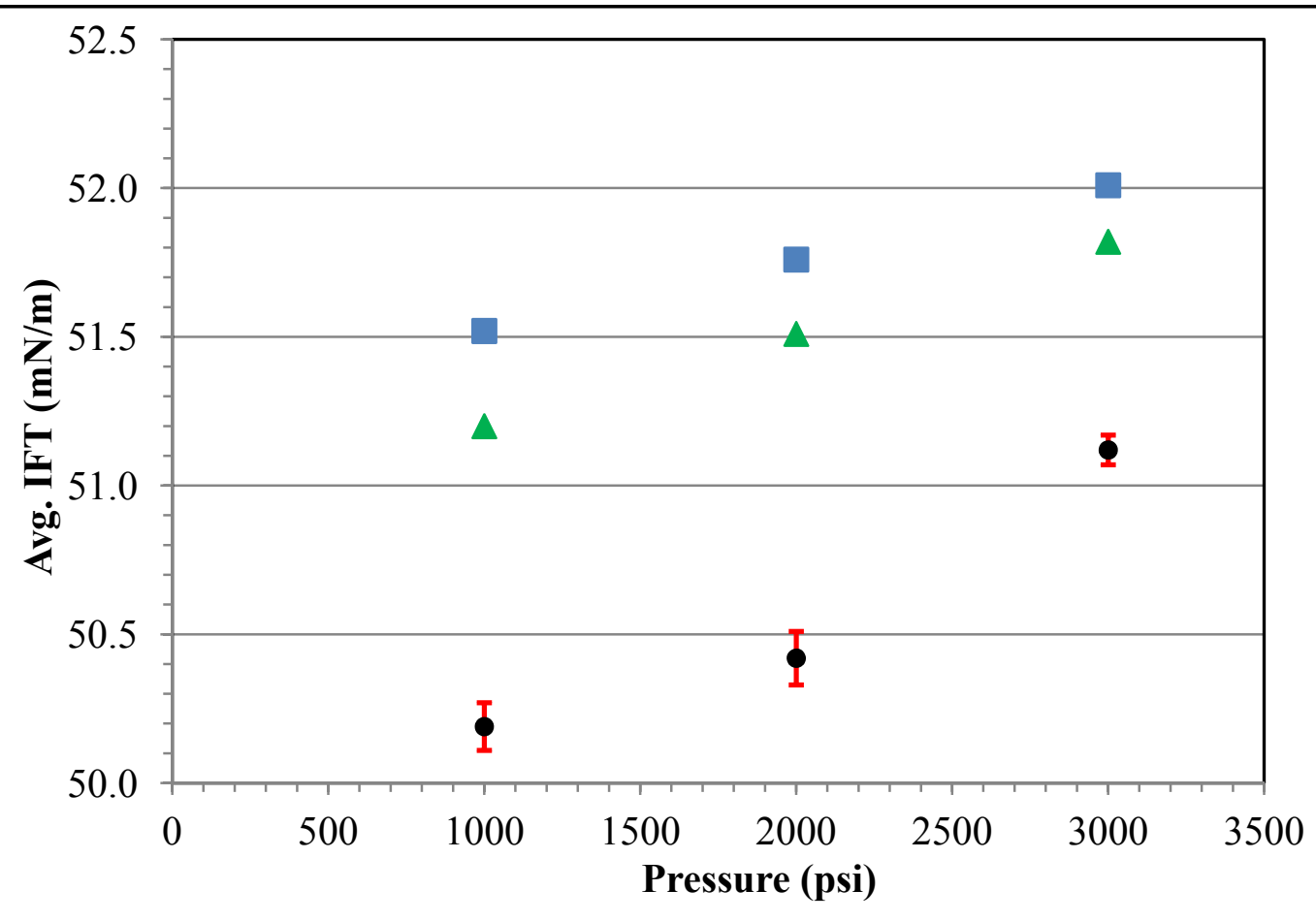

Al-Shahhaf et al. (2005) $\triangle$ Cai et al. (1996) $\bullet$ Measured IFT \pm 1 std. dev.

Figure 28: Measured n-octane/de-ionized water IFT at $76^{\circ} \mathrm{F}$ and various pressures 
Table 12: Comparison of the measured n-octane/de-ionized water IFT with values reported by Cai et al. (1996) and Al-Shahhaf et al. (2005) at $76^{\circ} \mathrm{F}$ and various pressures

\begin{tabular}{|c|c|c|c|c|c|c|}
\hline $\begin{array}{c}\text { Pressure } \\
(\mathbf{p s i})\end{array}$ & $\begin{array}{c}\text { Measured } \\
\text { Average } \\
\text { IFT } \\
(\mathbf{m N} / \mathbf{m})\end{array}$ & $\begin{array}{c}\text { Standard } \\
\text { deviation } \\
(\mathbf{m N} / \mathbf{m})\end{array}$ & $\begin{array}{c}\text { Cai et } \\
\text { al. } \\
\mathbf{( 1 9 9 6 ) ,} \\
\mathbf{( m N / m )}\end{array}$ & $\begin{array}{c}\text { Percent } \\
\text { difference } \\
\text { from Cai et } \\
\text { al. (1996) }\end{array}$ & $\begin{array}{c}\text { Al-Shahhaf } \\
\text { et al. } \\
\mathbf{( 2 0 0 5 ) ,} \\
(\mathbf{m N} / \mathbf{m})\end{array}$ & $\begin{array}{c}\text { Percent } \\
\text { difference } \\
\text { from Al- } \\
\text { Shahhaf et al. } \\
\mathbf{( 2 0 0 5 )}\end{array}$ \\
\hline 1,000 & 50.19 & 0.08 & 51.20 & $-1.97 \%$ & 51.52 & $-2.58 \%$ \\
\hline 2,000 & 50.42 & 0.09 & 51.51 & $-2.12 \%$ & 51.76 & $-2.12 \%$ \\
\hline 3,000 & 51.12 & 0.05 & 51.82 & $-1.35 \%$ & 52.01 & $-1.35 \%$ \\
\hline
\end{tabular}

Some of the factors that could have attributed to the differences between the values reported in this study and those reported by both Cai et al. (1996) and Al-Shahhaf et al. (2005) include: (1) Cai et al. (1996) used n-octane of analytical grade (99.0\% purity) which has a lower purity than that of the reagent grade $(99.8 \%$ purity) used in this study. Being very sensitive to the purity of fluids, the IFT was likely to be different in this study. (2) Al-Shahhaf et al. (2005) calculated the IFT using Equation $5\left(\gamma=\frac{{\mathrm{g} \Delta \rho \mathrm{e}_{\mathrm{e}}^{2}}^{2}}{\mathrm{~S}}\right)$ which only uses 4 points on the drop profile as compared to the ASDA technique used in this study which fits the entire drop profile to the Young-Laplace equation of capillarity (Equation 6). The reproducibility of the experimental procedure carried out in the laboratory during this study is supported by the low standard deviations of the average IFT values reported in Table 12.

The results of the second set of preliminary experiments in which the n-octane/de-ionized water IFT was measured at atmospheric pressure (14.7 psi) and various temperatures is illustrated in Figure 29 and listed in Table 13. Vertical error bars representing the standard deviation of the measured average IFT are also included in Figure 29. The results were also compared to IFT values reported by Motomura et al. (1983).

The IFT values measured in this study followed a completely different trend than the ones reported by Motomura et al. (1983) as the temperature was varied at atmospheric pressure. It can 
be noted from Figure 29, that the measured IFT decreased to a minimum at $50{ }^{\circ} \mathrm{F}$ and then continued to increase as the temperature increased. On the other hand the values reported by Motomura et al. (1983) were observed to continuously decrease as the temperature was increased.

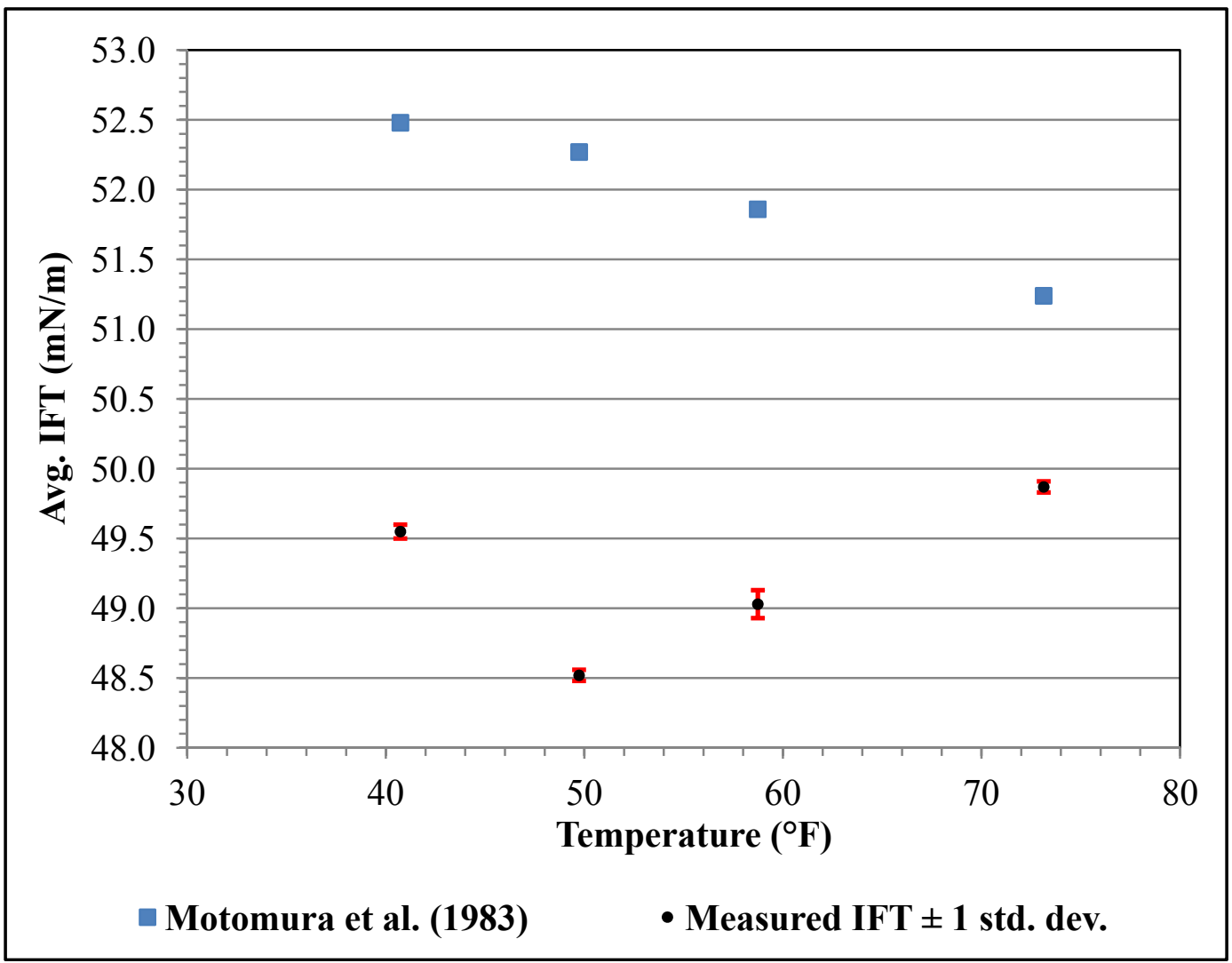

Figure 29: Measured n-octane/de-ionized water IFT at atmospheric pressure and various temperatures

Table 13: Comparison of the measured n-octane/water IFT with values reported by Motomura et al. (1983) at atmospheric pressure and various temperatures

\begin{tabular}{|c|c|c|c|c|}
\hline $\begin{array}{c}\text { Temperature } \\
\left({ }^{\circ} \mathbf{F}\right)\end{array}$ & $\begin{array}{c}\text { Measured } \\
\text { Average } \\
\text { IFT } \\
(\mathbf{m N} / \mathbf{m})\end{array}$ & $\begin{array}{c}\text { Standard } \\
\text { deviation } \\
\mathbf{( m N / m )}\end{array}$ & $\begin{array}{c}\text { Motomura } \\
\text { et al. } \\
\mathbf{( 1 9 8 3 )} \\
(\mathbf{m N} / \mathbf{m})\end{array}$ & $\begin{array}{c}\text { Percent difference } \\
\text { from Motomura et } \\
\text { al. (1983) }\end{array}$ \\
\hline 41 & 49.55 & 0.05 & 52.48 & $-5.58 \%$ \\
\hline 50 & 48.52 & 0.04 & 52.27 & $-7.17 \%$ \\
\hline 59 & 49.03 & 0.10 & 51.86 & $-5.46 \%$ \\
\hline 73 & 49.87 & 0.04 & 51.24 & $-2.67 \%$ \\
\hline
\end{tabular}


The difference between values reported in this study and ones reported by Motomura et al. (1983) are significantly large as indicated in Table 13. The fact that the water used in this study was de-ionized while the water used by Motomura et al. (1983) was only distilled could have attributed to such large discrepancies. Moreover, Motomura et al. (1983) analyzed the shape of the pendant drops using a completely different method than the ASDA technique used in this study. They used Equation 5 to calculate the n-octane/water IFT from the pendant drop dimensions using only four points on the drop profile and predetermined shape factors.

Since the behavior of the measured n-octane/water IFT in this study was unexpected as the temperature was varied, it was decided to increase the number of trials or pendant drops to further confirm the observed behavior. The average IFT was calculated from 25 consecutive drops and, as indicated in Table 13, the standard deviation was still relatively low as it ranged from 0.04 to $0.1 \mathrm{mN} / \mathrm{m}$.

\subsection{Water Depth Variation}

The results of experiment set 1 , in which both the pressure and temperature were varied according to the corresponding water depth are discussed in this section.

\subsection{1 n-Octane/Water/Dispersant System}

The density of n-octane was obtained from the NIST website while the density of the 2.5 wt $\%$ salt water was measured in the laboratory using the DMA HP density meter. Figure 30 shows the densities of n-octane and $2.5 \mathrm{wt} \%$ salt water plotted on the left vertical axis, while the density difference between the two phases, $\Delta \rho$, is plotted on the right vertical axis.

It can be noted from Figure 30 that the density of both fluids increased with increasing water depth. However, the density of n-octane was more responsive to the changes in pressure and temperature associated with varying water depth. The density of n-octane experienced a $3.75 \%$ 
increase as compared to the density of $2.5 \mathrm{wt} \%$ salt water which experienced a $1 \%$ increase, when the pressure and temperature conditions were changed from water surface to seafloor conditions. This in turn caused the density difference, $\Delta \rho$, between the two fluids to continuously decrease as the water depth increased.

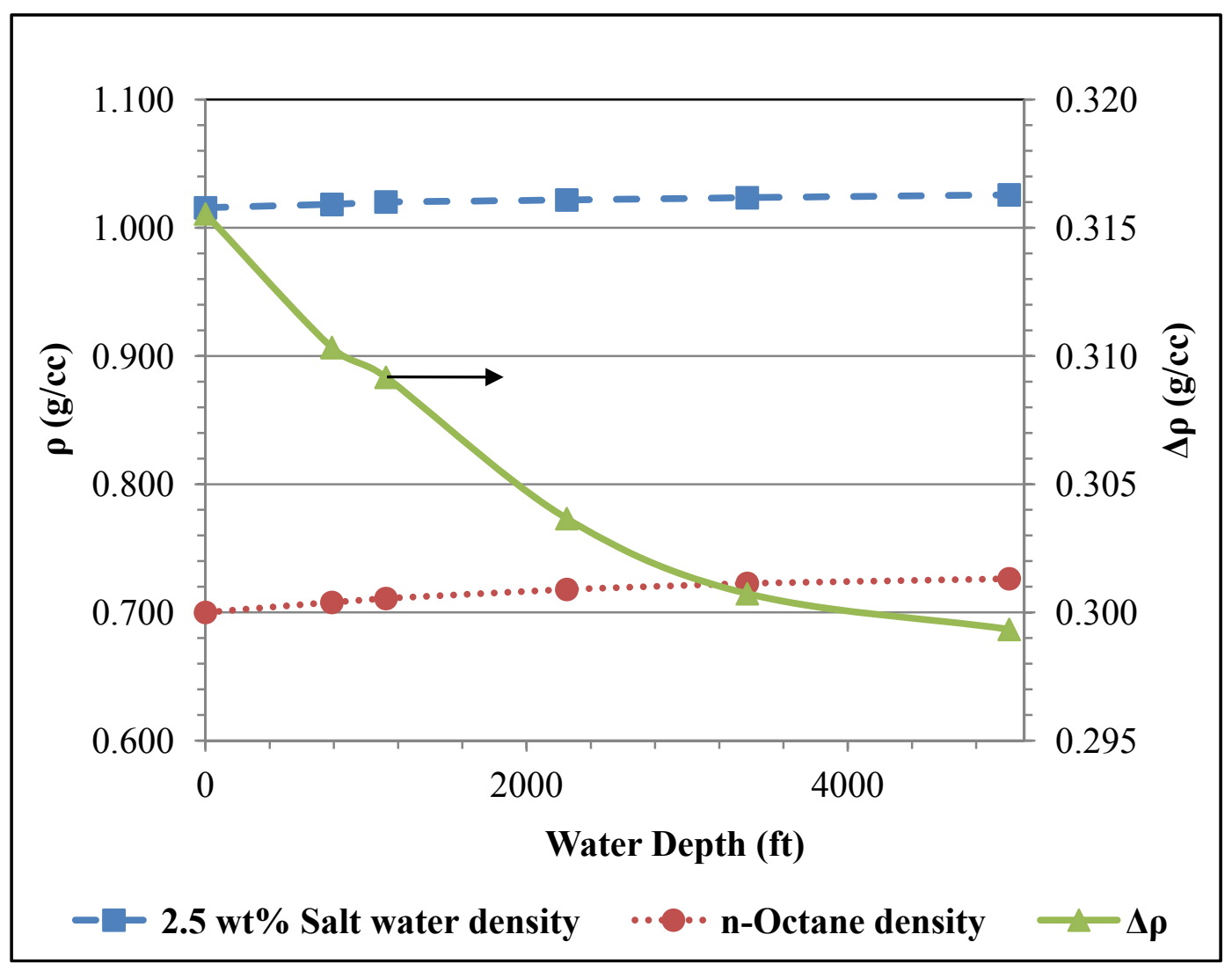

Figure 30: $\mathrm{n}-\mathrm{Octane}$ and $2.5 \mathrm{wt} \%$ salt water densities at pressure and temperature conditions corresponding to various water depths

The average IFT between n-octane and $2.5 \mathrm{wt} \%$ salt water is plotted in Figure 31 for both the dispersant-free and dispersant-in-solution cases.

As can be seen from Figure 31, the dispersant-free IFT data did not show any specific trend, instead the average IFT fluctuated between 47 and $53 \mathrm{mN} / \mathrm{m}$. With 1,000 ppm dispersant in solution, the average n-octane/water IFT slightly decreased to a minimum of $5 \mathrm{mN} / \mathrm{m}$ at $750 \mathrm{ft}$ of water depth, and then continued to increase slightly with increasing water depth. 


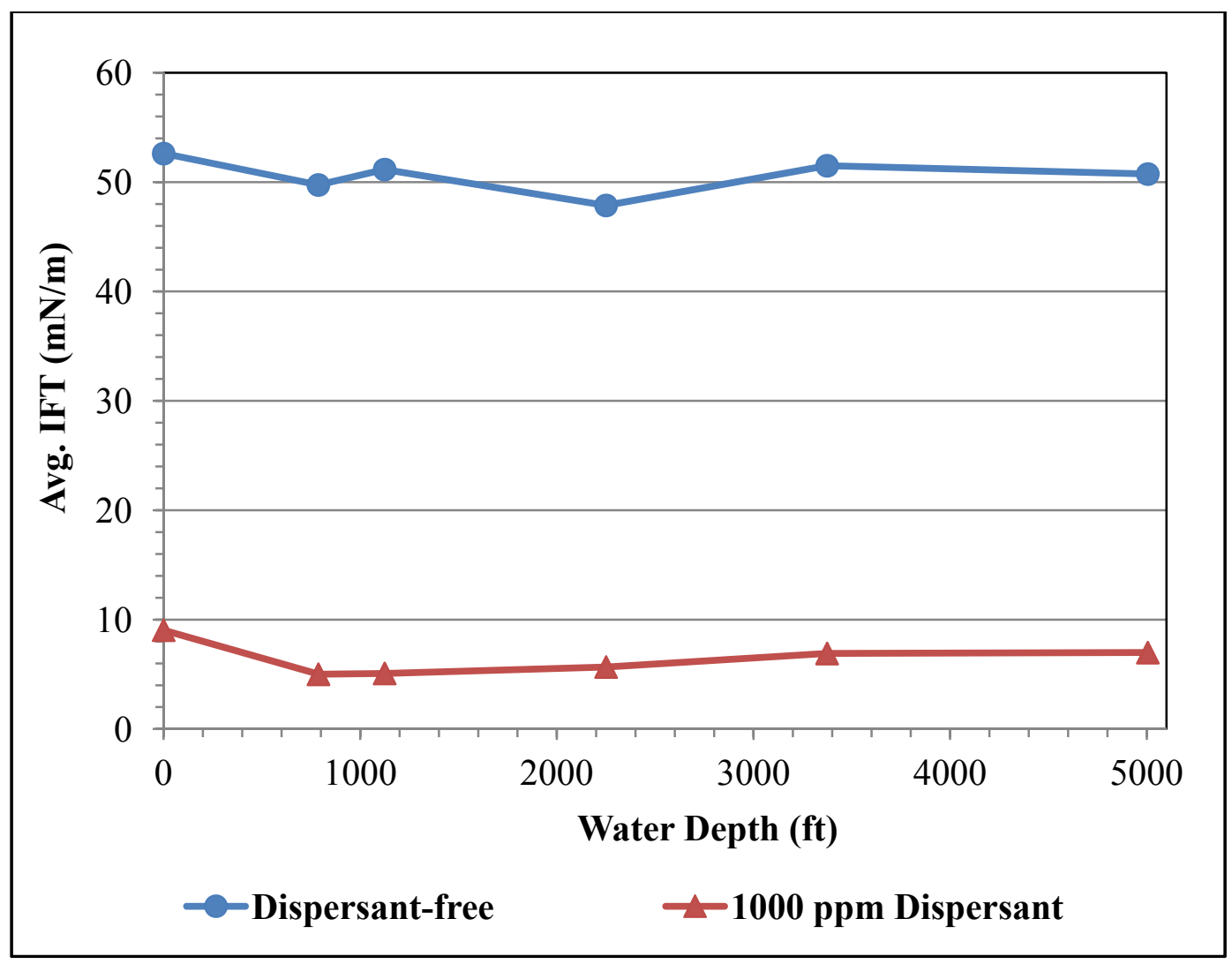

Figure 31: Average IFT between n-octane and $2.5 \mathrm{wt} \%$ salt water at pressure and temperature conditions corresponding to various water depths

\subsubsection{Crude Oil/Water/Dispersant System}

The measured densities of crude oil and $2.5 \mathrm{wt} \%$ salt water are plotted in Figure 32 on the left vertical axis while the density difference between the two, $\Delta \rho$, is plotted on the right vertical axis.

Figure 32 shows that the addition of the dispersant to the $2.5 \mathrm{wt} \%$ salt water had a negligible effect on its density, as it can be seen that the data points are virtually overlapping each other. The water phase density, with and without the addition of the dispersant, was less sensitive to changes in pressure and temperature than the MC252 crude oil. Both the oil and water densities increased as the water depth increased. However, the oil density increased by $2.5 \%$ as compared to the $2.5 \mathrm{wt} \%$ salt water density which increased by only $1 \%$ over the entire water depth range. 
Consequently, the density difference, $\Delta \rho$ between the crude oil and salt water continuously decreased with increasing water depth.

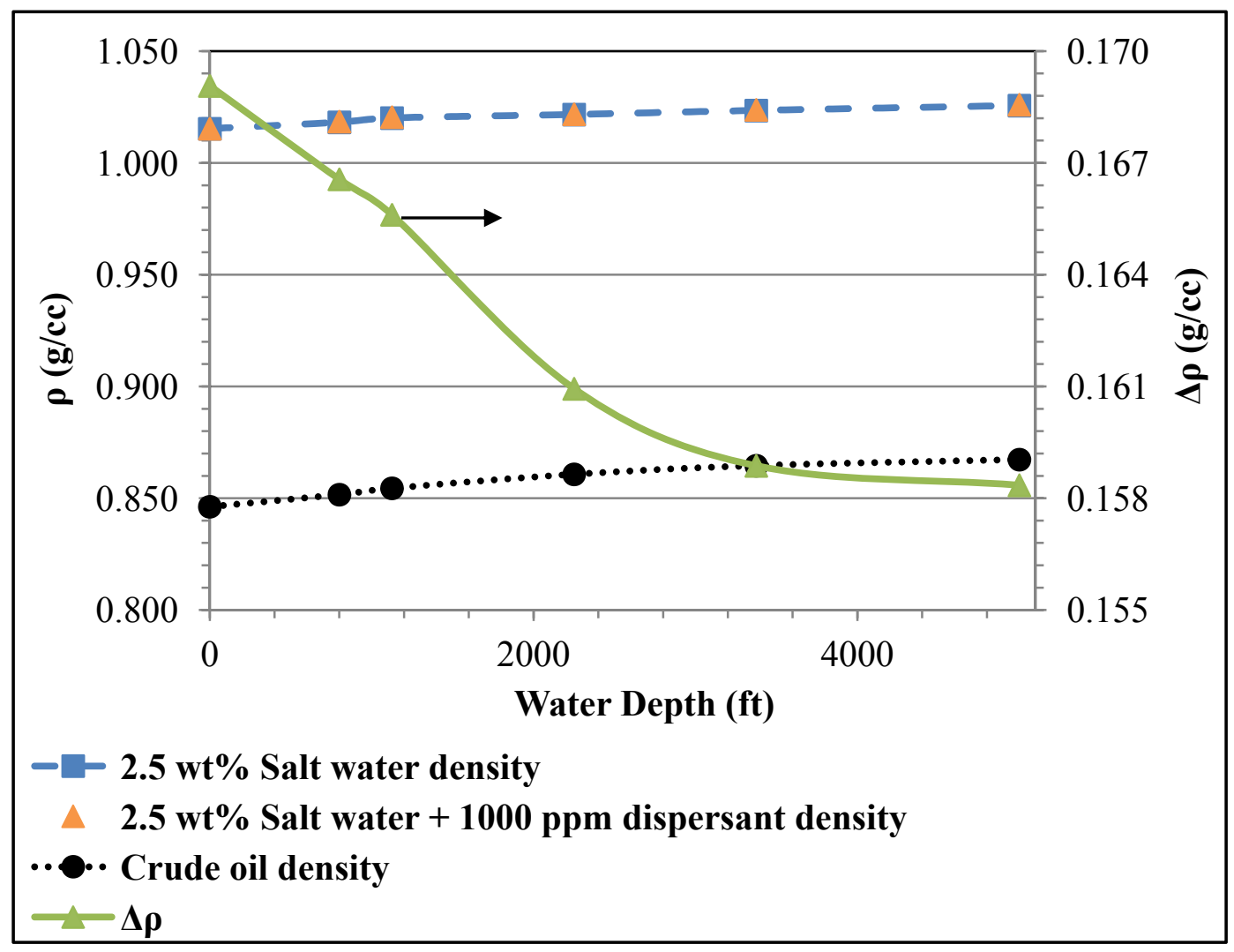

Figure 32: Crude oil and $2.5 \mathrm{wt} \%$ salt water densities at pressure and temperature conditions corresponding to various water depths

The average IFT between crude oil and $2.5 \mathrm{wt} \%$ salt water is plotted in Figure 33 for both the dispersant-free and dispersant-in-solution cases.

It can be noted from Figure 33 that the greatest change in the average IFT for the dispersantfree case was a $13 \%$ reduction that took place when the conditions were changed from the water surface to the subsequent water depth $(750 \mathrm{ft})$ conditions. Thereafter, the average IFT did not show any observable trend and continued to fluctuate between 22 and $23 \mathrm{mN} / \mathrm{m}$. With 1,000 ppm dispersant in solution with the $2.5 \mathrm{wt} \%$ salt water, the average crude oil/water IFT was much 
lower than that with the dispersant-free salt water but did not considerably change until 3,000 ft, after which it slightly increased.

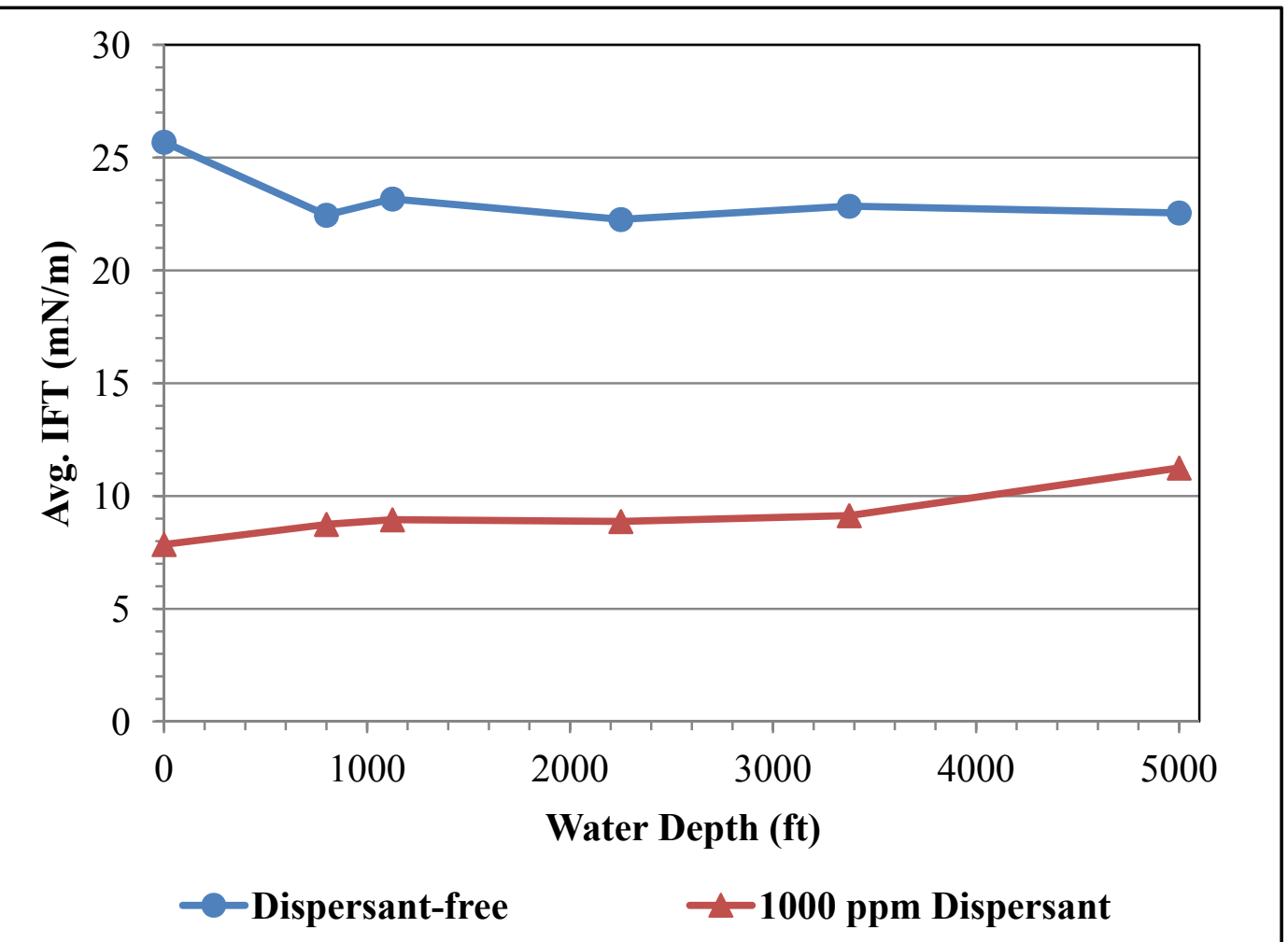

Figure 33: Average IFT between crude oil and $2.5 \mathrm{wt} \%$ salt water at pressure and temperature conditions corresponding to various water depths

\subsubsection{Comparison of n-Octane and Crude Oil Systems}

The dispersant-induced reduction in the IFT is plotted in Figure 34 as a percentage of the dispersant-free IFT for both the crude oil/water and n-octane/water systems at the same conditions.

It is very evident from Figure 34 that the chemical dispersion process was much more effective in the n-octane/water system than in the crude oil/water system based on the magnitude of the IFT reduction, $\Delta \gamma$, at the same conditions. The n-octane/water system experienced reductions in the IFT ranging from 83 to $90 \%$ decrease from the dispersant-free value. The 
magnitude of the IFT reduction increased once the pressure and temperature corresponding to water surface conditions were changed, and then slightly decreased as the water depth increased for the n-octane/water system. A 50 to $70 \%$ reduction in the IFT from its dispersant-free value was observed in the crude oil/water system at the same conditions, with an observable decrease in the magnitude of reduction at seafloor conditions.

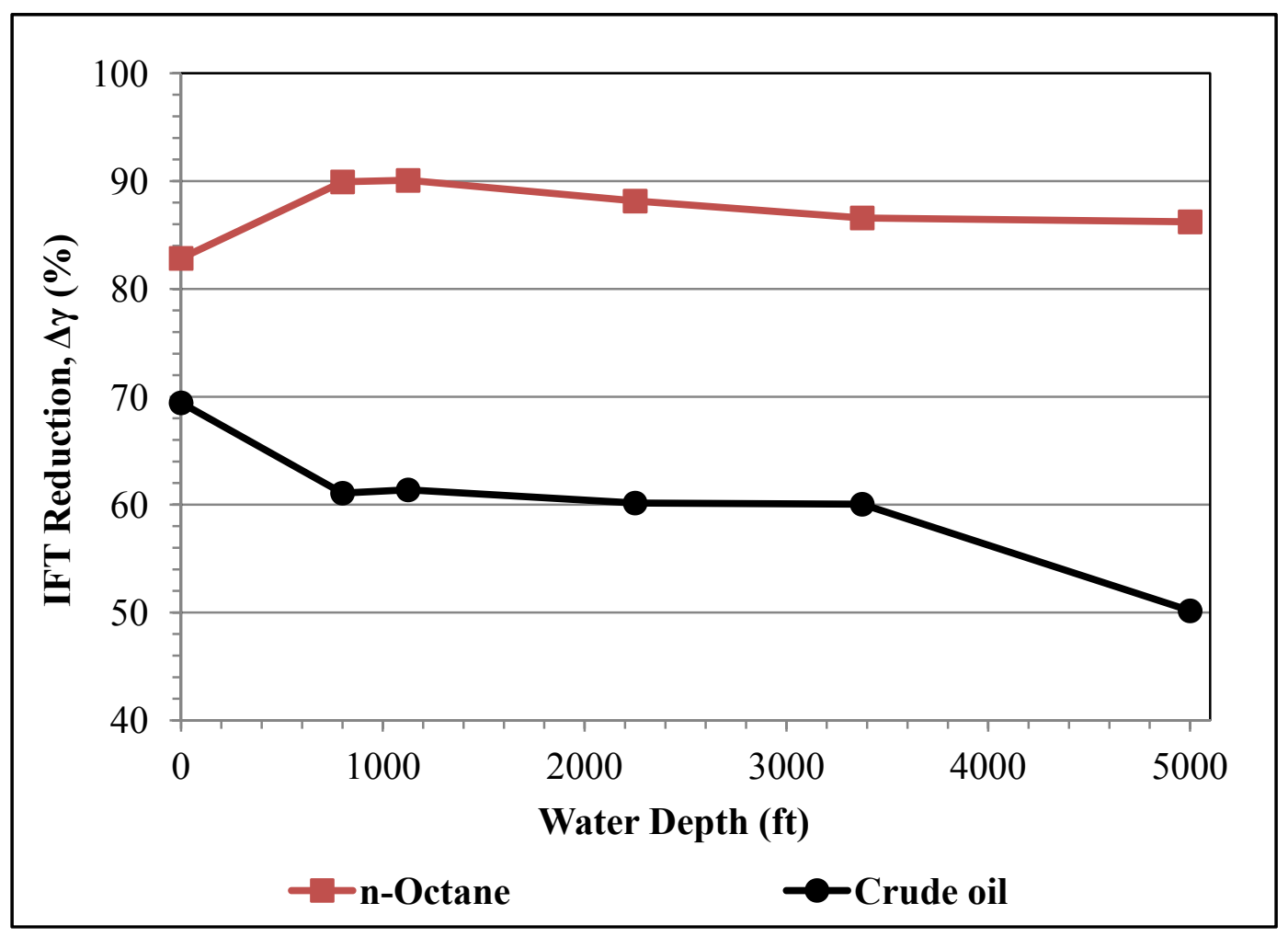

Figure 34: Dispersant-induced reduction in the hydrocarbon/water IFT as a percentage of the dispersant-free IFT at pressure and temperature conditions corresponding to various water depths

\subsection{Temperature Variation}

Since both pressure and temperature were varied according to water depth in experiment set 1, it was necessary to study the influence of each variable on the IFT independently. The results of experiment set 2 in which the temperature was varied at a constant pressure are discussed in this section. All experiments in set 2 were conducted at a pressure corresponding to seafloor conditions (2,225 psi) and using the $2.5 \mathrm{wt} \%$ salt water as the aqueous phase. 


\subsection{1 n-Octane/Water/Dispersant System}

The measured density of the $2.5 \mathrm{wt} \%$ salt water is plotted along with the density of n-octane, which was obtained from the NIST website, on the left vertical axis of Figure 35. The density difference, $\Delta \rho$, between the phases is plotted on the right vertical axis.

It can be seen from Figure 35 that the densities of both phases decreased with increasing temperature. The n-octane density decreased by $2 \%$ when the temperature was increased from seafloor $\left(40^{\circ} \mathrm{F}\right)$ to water surface conditions $\left(73^{\circ} \mathrm{F}\right)$ while the $2.5 \mathrm{wt} \%$ salt water density decreased by only $0.3 \%$ over the same range. This difference in magnitude in the density change resulted in an increase in the density difference, $\Delta \rho$, between the two fluids as the temperature was increased at 2,225 psi.

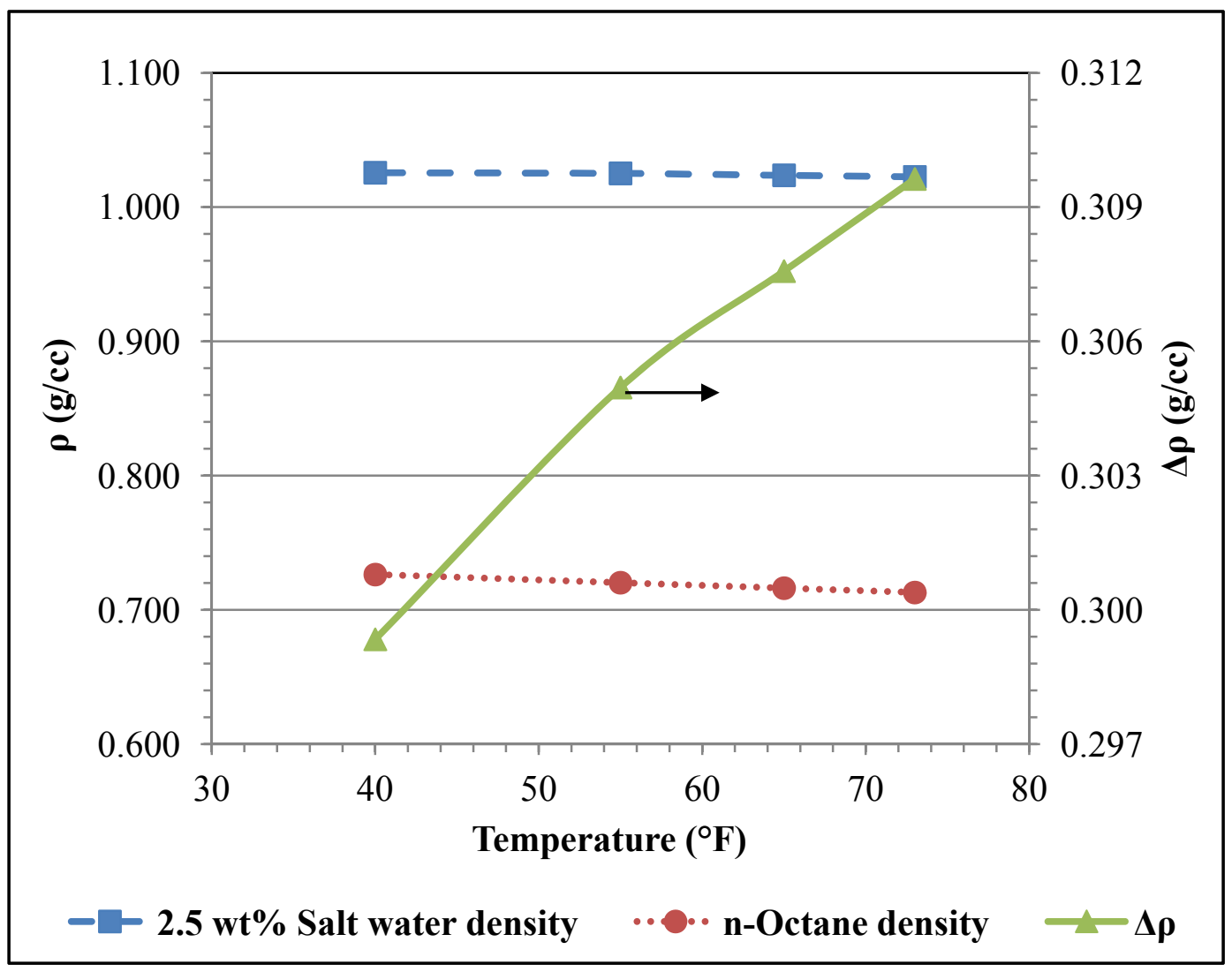

Figure 35: n-Octane and $2.5 \mathrm{wt} \%$ salt water densities at 2,225 psi and as a function of temperature 
The average IFT between n-octane and $2.5 \mathrm{wt} \%$ salt water at 2,225 psi is plotted in Figure 36 as a function of temperature for both the dispersant-free and dispersant-in-solution cases.

For the dispersant-free case, the n-octane/water IFT decreased to a minimum of $47.64 \mathrm{mN} / \mathrm{m}$ at $55^{\circ} \mathrm{F}$, after which it slightly increased with increasing temperature as seen in Figure 36. With $1,000 \mathrm{ppm}$ of dispersant in solution with the $2.5 \mathrm{wt} \%$ salt water, the average n-octane/water IFT was observed to decrease with increasing temperature reaching a minimum of $5.18 \mathrm{mN} / \mathrm{m}$ at 73 ${ }^{\circ} \mathrm{F}$.

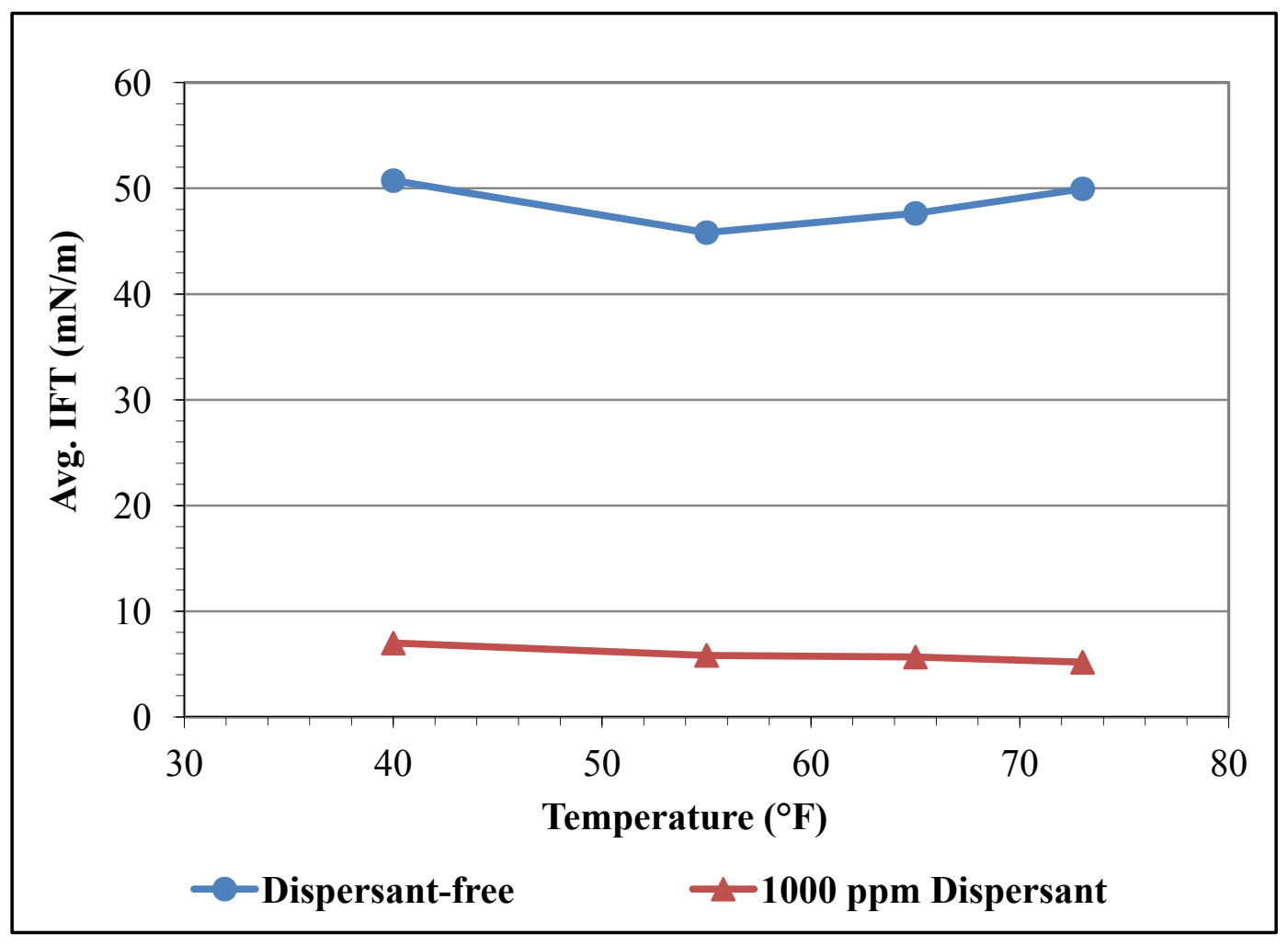

Figure 36: Average IFT between $n$-octane and $2.5 \mathrm{wt} \%$ salt water at 2,225 psi and as a function of temperature

\subsubsection{Crude Oil/Water/Dispersant System}

Crude oil and $2.5 \mathrm{wt} \%$ salt water densities were measured at 2,225 psi and at various temperatures and are plotted on the left vertical axis of Figure 37 while the density difference between the two, $\Delta \rho$, is plotted on the right vertical axis. 
As expected, an increase in temperature caused both fluids' densities to decrease, with the crude oil density being more responsive to changes in temperature as seen in Figure 37 . An increase in temperature from 40 to $73{ }^{\circ} \mathrm{F}$ caused the salt water density to decrease by only $0.3 \%$. On the other hand, the crude oil density experienced a $1.5 \%$ decrease at the same conditions. As a result, the difference in density, $\Delta \rho$ between the two phases steadily increased with increasing temperature.

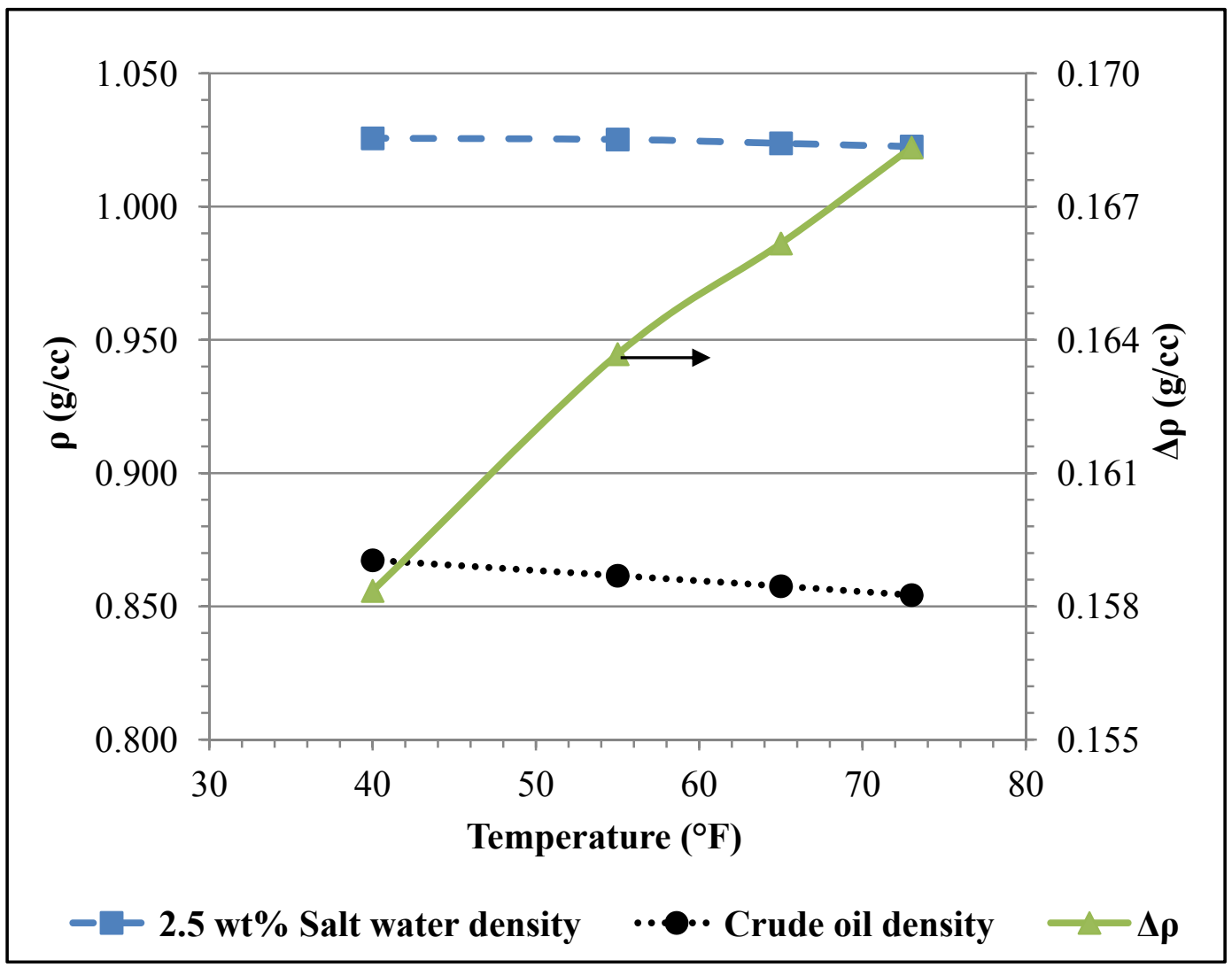

Figure 37: Crude oil and $2.5 \mathrm{wt} \%$ salt water densities at 2,225 psi and as a function of temperature

The average IFT between crude oil and $2.5 \mathrm{wt} \%$ salt water at 2,225 psi is plotted in Figure 38 as a function of temperature for both the dispersant-free and dispersant-in-solution cases.

For the dispersant-free case, the average IFT unexpectedly increased with increasing temperature reaching a maximum of $24.52 \mathrm{mN} / \mathrm{m}$ at $73^{\circ} \mathrm{F}$ as seen in Figure 38 . With 1,000 ppm 
dispersant in solution with the $2.5 \mathrm{wt} \%$ salt water, the average IFT decreased to a minimum of $8.94 \mathrm{mN} / \mathrm{m}$ at $65^{\circ} \mathrm{F}$, and then increased slightly upon further increase of the temperature.

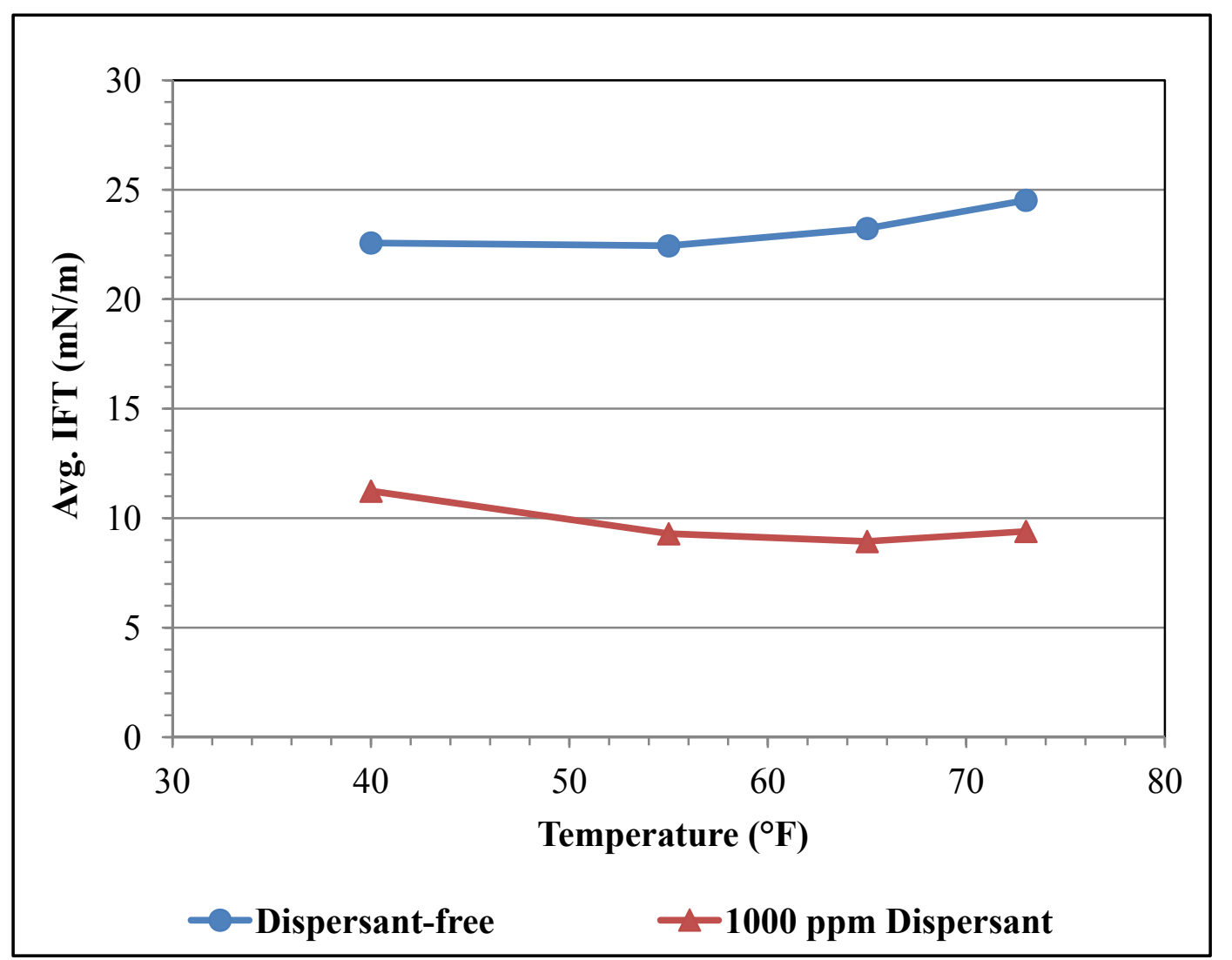

Figure 38: Average IFT between crude oil and $2.5 \mathrm{wt} \%$ salt water at 2,225 psi and as a function of temperature

\subsubsection{Comparison of n-Octane and Crude Oil Systems}

The dispersant-induced reduction in the IFT is plotted in Figure 39 as a percentage of the dispersant-free IFT for both the crude oil/water and n-octane/water systems at 2,225 psi and as a function of temperature.

It can be noted from Figure 39 that an increase in temperature had the same effect on both systems, causing the magnitude in IFT reduction, $\Delta \gamma$, to increase and validating the fact that chemical dispersion is less effective at lower temperatures. A clear distinction can be made between the magnitudes of IFT reduction in the crude oil/water and n-octane/water systems with 
the latter experiencing much greater magnitudes. However, the crude oil/water system was more sensitive to changes in temperatures, specifically when approaching seafloor conditions of $40{ }^{\circ} \mathrm{F}$ as the magnitude in IFT reduction dropped to $50 \%$ as compared to $62 \%$ at $73{ }^{\circ} \mathrm{F}$.

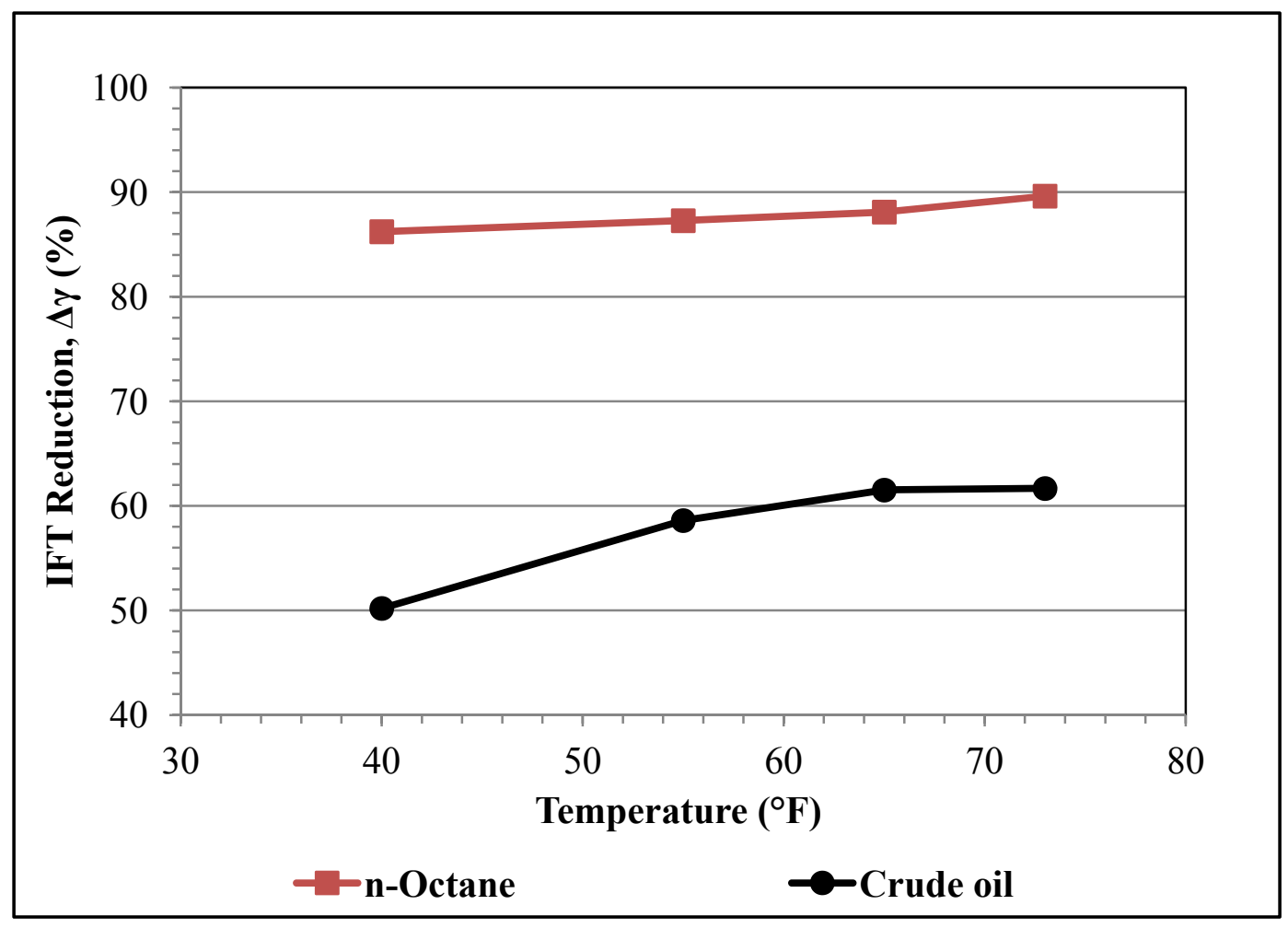

Figure 39: Dispersant-induced reduction in the hydrocarbon/water IFT as a percentage of the dispersant-free IFT at 2,225 psi and as a function of temperature

\subsection{Pressure Variation}

The results of experiment set 3 in which the pressure was varied at a constant temperature of $40{ }^{\circ} \mathrm{F}$ are discussed in this section. All experiments were conducted with the $2.5 \mathrm{wt} \%$ salt water as the aqueous phase.

\subsection{1 n-Octane/Water/Dispersant System}

The measured density of the $2.5 \mathrm{wt} \%$ salt water and the n-octane density acquired from the NIST website are plotted on the left vertical axis of Figure 40 . The density difference, $\Delta \rho$, between the two fluids is plotted on the right vertical axis. 


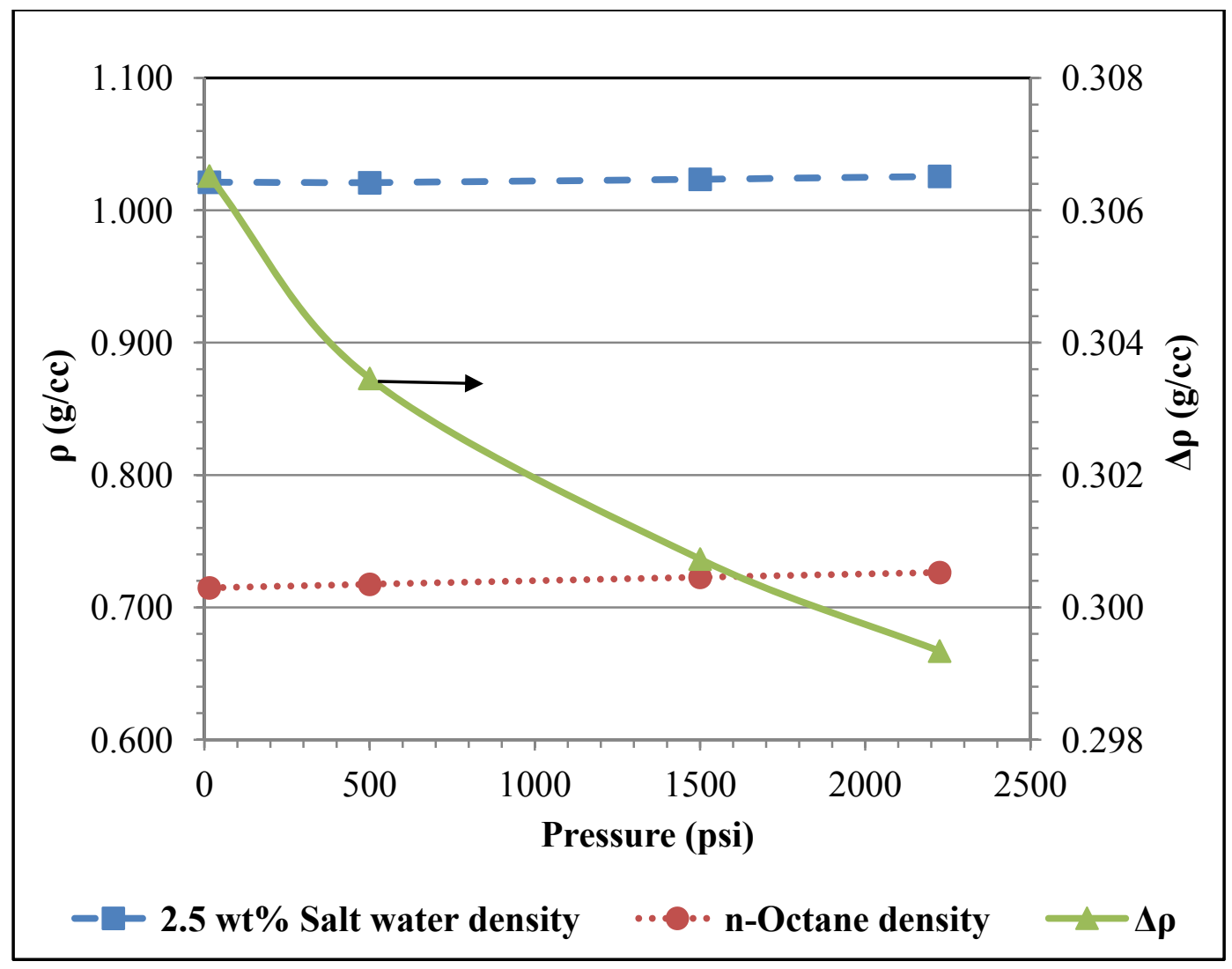

Figure 40: n-Octane and $2.5 \mathrm{wt} \%$ salt water densities at $40^{\circ} \mathrm{F}$ and as a function of pressure

It can be observed from Figure 40 that an increase in pressure at a constant temperature of 40 'F caused both fluids' densities to increase. The n-octane density was much more sensitive to changes in pressure than the $2.5 \mathrm{wt} \%$ salt water density as it experienced a $1.6 \%$ increase, over the entire pressure range, which was four times greater than the magnitude of increase in the salt water density. This in turn resulted in a substantial decrease in the density difference, $\Delta \rho$, between the two fluids with increasing pressure.

The average IFT between n-octane and the $2.5 \mathrm{wt} \%$ salt water at $40{ }^{\circ} \mathrm{F}$ is plotted in Figure 41 as a function of pressure for both the dispersant-free and dispersant-in-solution cases.

It can be noted from Figure 41, that the average IFT increased with increasing pressure for the dispersant-free case reaching a maximum of $51.5 \mathrm{mN} / \mathrm{m}$ at $1,500 \mathrm{psi}$. Thereafter, the average IFT slightly decreased upon further increase of pressure. With 1,000 ppm of dispersant in 
solution with the salt water, the average IFT was observed to behave insensitively to changes in pressure as it appears to remain fairly constant at around $7 \mathrm{mN} / \mathrm{m}$.

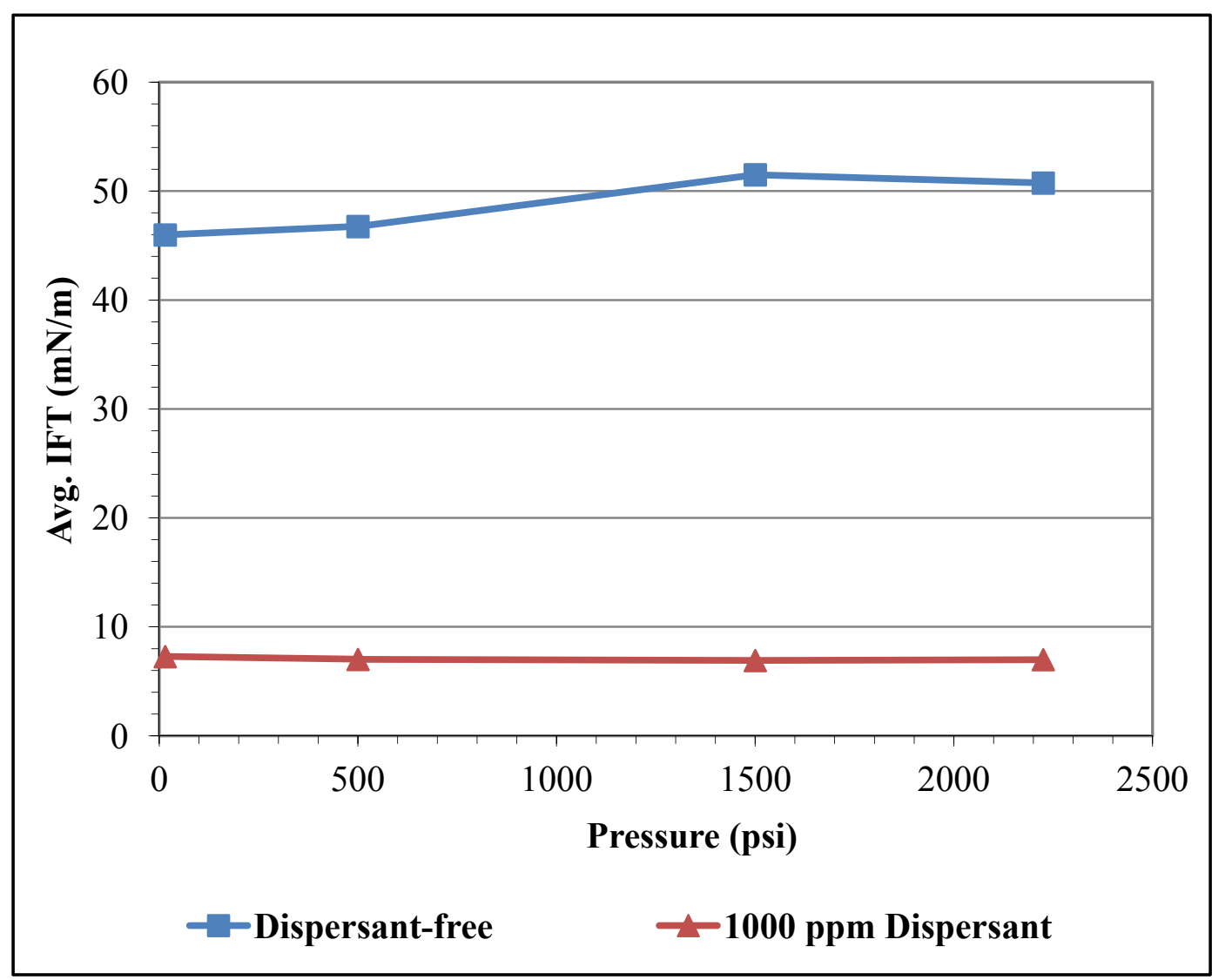

Figure 41: Average IFT between n-octane and $2.5 \mathrm{wt} \%$ salt water at $40^{\circ} \mathrm{F}$ and as a function of pressure

\subsubsection{Crude Oil/Water/Dispersant System}

Crude oil and $2.5 \mathrm{wt} \%$ salt water densities were measured at a constant temperature of $40{ }^{\circ} \mathrm{F}$ and at various pressures. The individual fluid densities are plotted on the left vertical axis of Figure 42 while the density difference, $\Delta \rho$, between the crude oil and $2.5 \mathrm{wt} \%$ salt water is plotted on the right vertical axis.

As seen on Figure 42, an increase in pressure caused both fluids' densities to increase. The crude oil density was more sensitive to the variation in pressure as it increased by $1 \%$ while the 
salt water density increased by only $0.4 \%$ over the entire pressure range. This difference in magnitude of density change between the two phases was also observed when temperature was varied at a constant pressure (Figure 37). The density difference, $\Delta \rho$, between the two phases was observed to decrease with increasing pressure as a result of the crude oil density being more responsive to the increase in pressure.

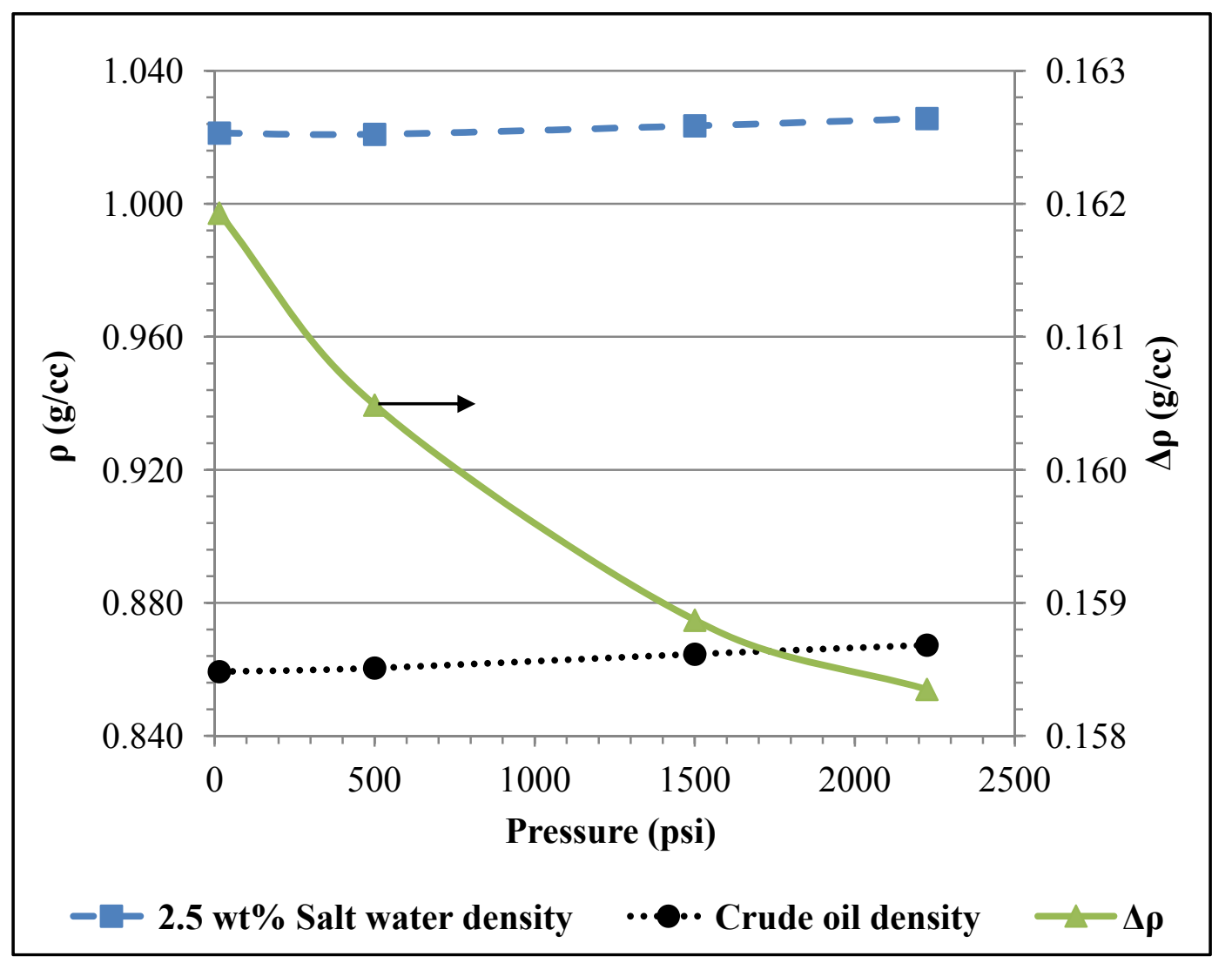

Figure 42: Crude oil and $2.5 \mathrm{wt} \%$ salt water densities at $40^{\circ} \mathrm{F}$ and as a function of pressure

The average crude oil/water IFT was measured at $40^{\circ} \mathrm{F}$ and at varying pressures for both the dispersant-free and dispersant-in-solution cases and is plotted in Figure 43.

The behavior of the dispersant-free system, as seen in Figure 43, indicates a fairly constant average IFT $(22.5 \mathrm{mN} / \mathrm{m})$ between the crude oil and the $2.5 \mathrm{wt} \%$ salt water as the pressure was varied at a constant temperature. The dissolution of $1,000 \mathrm{ppm}$ of the chemical dispersant in the 
salt water resulted in a much lower average IFT at all pressures. However, the behavior changed with the dispersant-in-solution case as the average IFT was observed to increase with increasing pressure, most apparently at seafloor conditions $\left(2,225 \mathrm{psi}\right.$ and $\left.40{ }^{\circ} \mathrm{F}\right)$ where it reached a maximum of $11.25 \mathrm{mN} / \mathrm{m}$, a $31.5 \%$ increase from the value at atmospheric pressure.

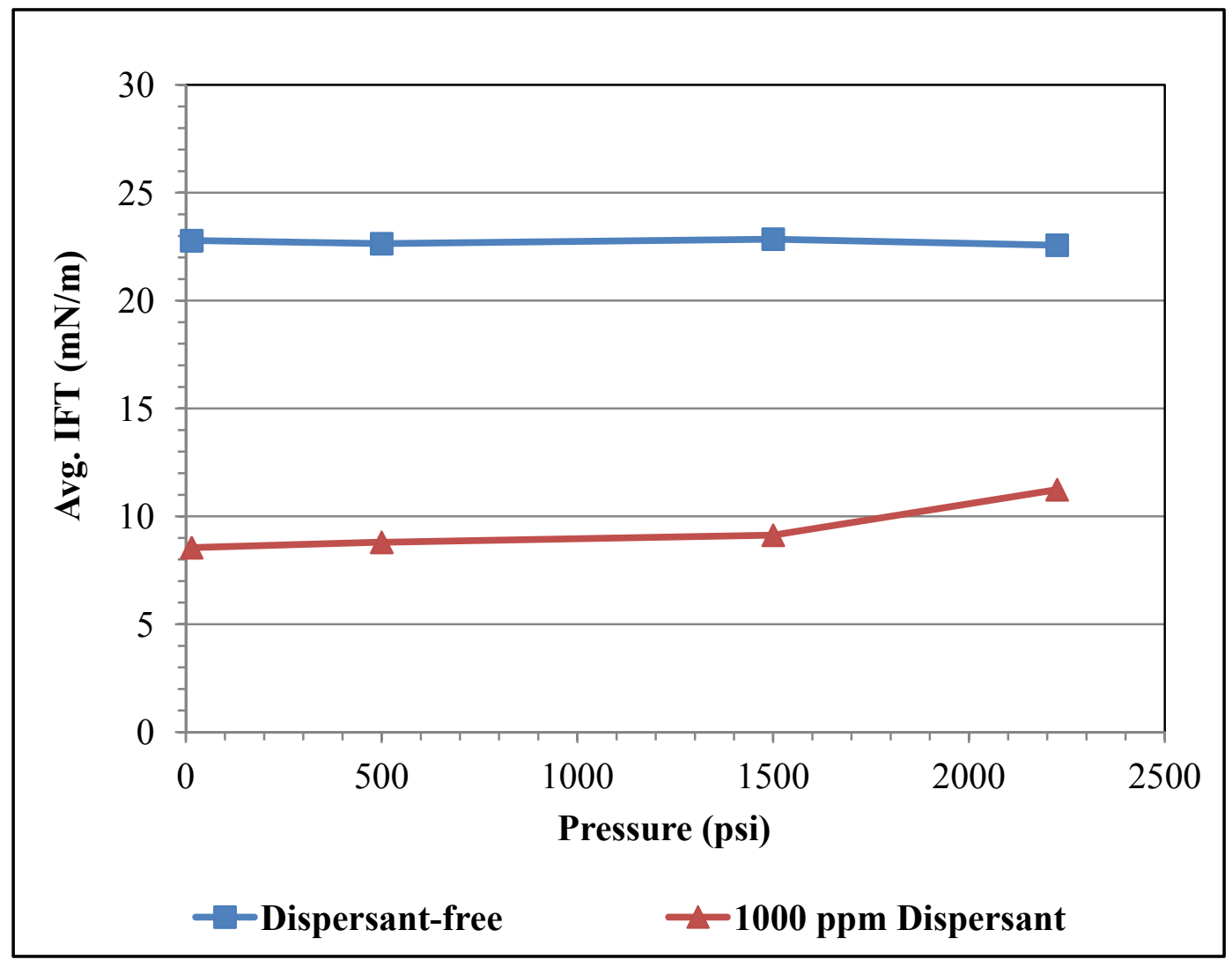

Figure 43: Average IFT between crude oil and $2.5 \mathrm{wt} \%$ salt water at $40{ }^{\circ} \mathrm{F}$ and as a function of pressure

\subsubsection{Comparison of n-Octane and Crude Oil Systems}

The dispersant-induced reduction in the IFT is plotted in Figure 44 as a percentage of the dispersant-free IFT for both the crude oil/water and n-octane/water systems at $40{ }^{\circ} \mathrm{F}$ and as a function of pressure.

Comparing the magnitudes of IFT reduction, $\Delta \gamma$, in both systems, it is very evident from Figure 44 that the chemical dispersion process was much more effective in the n-octane/water 
system than in the crude oil/water system. It can also be noted that an increase in pressure caused the magnitude of IFT reduction to increase in the n-octane/water system as opposed to the crude oil/water system in which the magnitude decreased with increasing pressure. A drastic decrease in the magnitude of IFT reduction, namely from 63 to $50 \%$, can be observed at seafloor conditions $\left(2,225 \mathrm{psi}\right.$ and $\left.40^{\circ} \mathrm{F}\right)$ for the crude oil/water system as compared to the magnitude at atmospheric pressure.

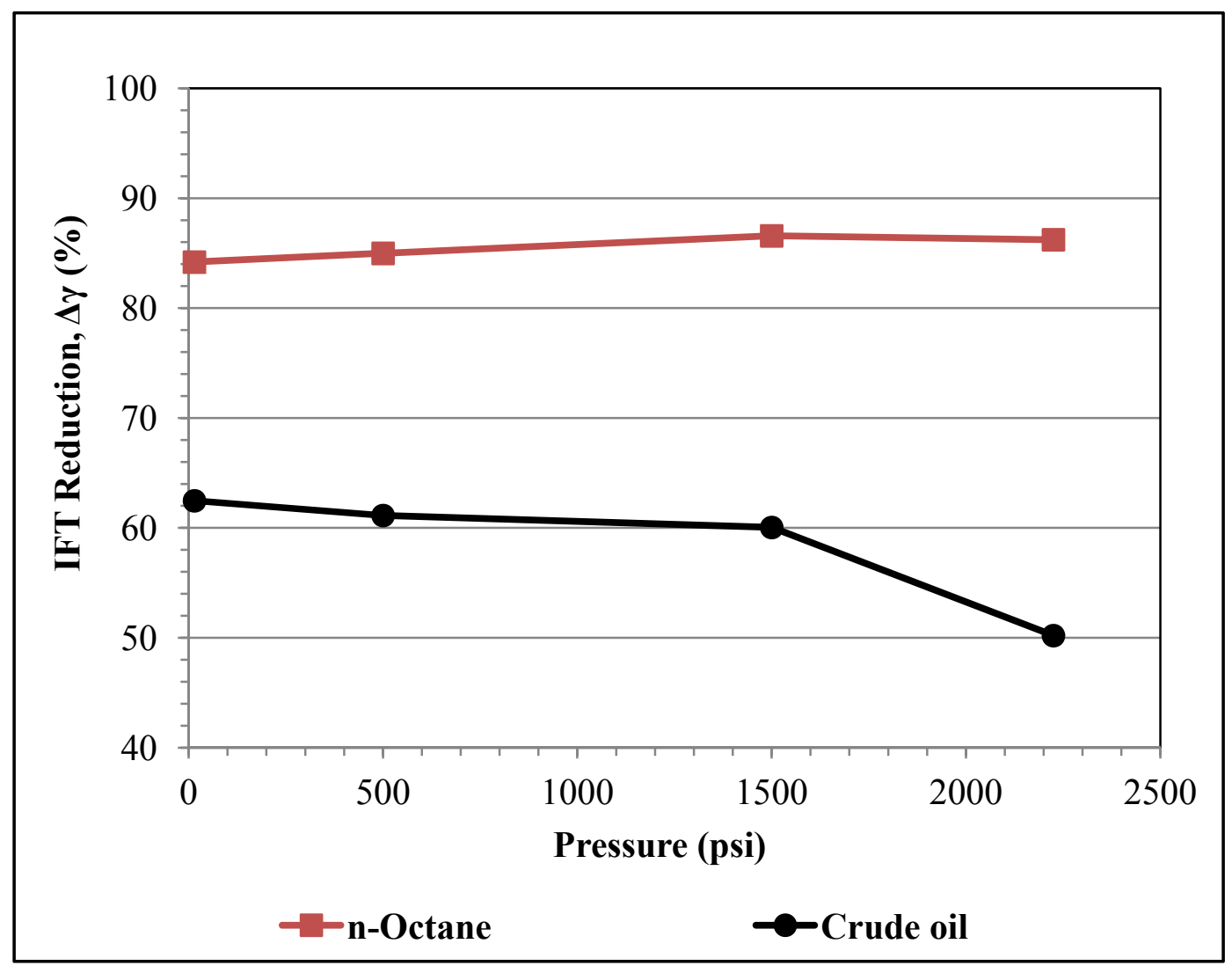

Figure 44: Dispersant-induced reduction in the hydrocarbon/water IFT as a percentage of the dispersant-free IFT at $40^{\circ} \mathrm{F}$ and as a function of pressure

\subsection{Water Salinity Variation}

The results of experiment set 4 in which only the water salinity was varied are discussed in this section. All experiments were conducted at seafloor conditions of pressure $(2,225 \mathrm{psi})$ and temperature $\left(40^{\circ} \mathrm{F}\right)$. 


\subsection{1 n-Octane/Water/Dispersant System}

The density of n-octane at 2,225 psi and $40^{\circ} \mathrm{F}$ was $0.726332 \mathrm{~g} / \mathrm{cc}$ as acquired from the NIST website. The densities of water samples of various salinities were measured at the same pressure and temperature and are plotted on the left vertical axis of Figure 45. The density difference between n-octane and the various water samples, $\Delta \rho$, is plotted on the right vertical axis.

The density of water increased as the proportion of the synthetic sea water (SSW) in the sample, or water salinity, increased. Consequently, the density difference, $\Delta \rho$, between n-octane and water increased with increasing water salinity as can be observed in Figure 45.

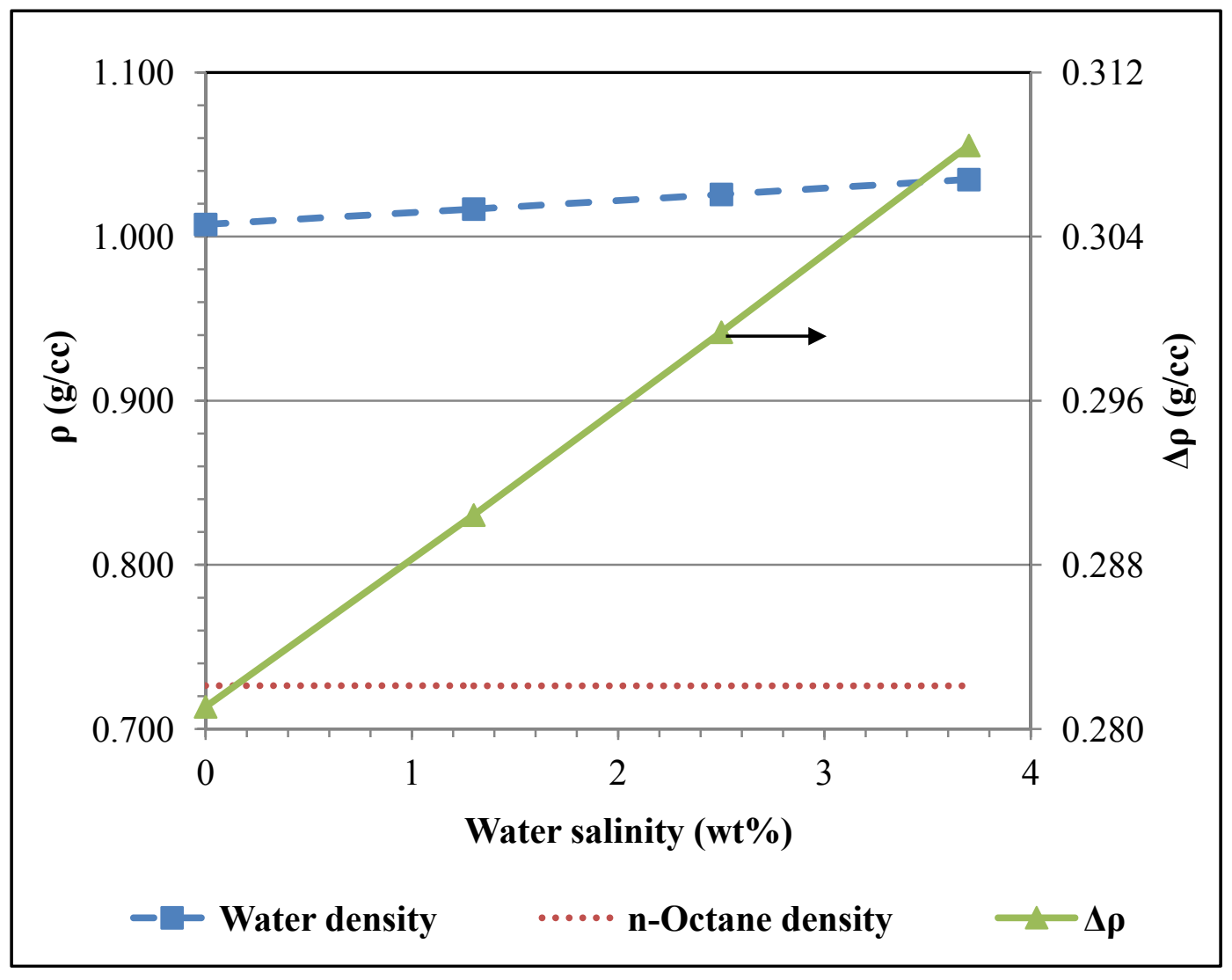

Figure 45: n-Octane and water densities at 2,225 psi and $40^{\circ} \mathrm{F}$

The average IFT between n-octane and the various water samples was measured at 2,225 psi and $40^{\circ} \mathrm{F}$ and is shown in Figure 46 for both the dispersant-free and dispersant-in-solution cases. 
For the dispersant-free case, the average IFT can be observed from Figure 46 to slightly increase with increasing water salinity reaching a maximum of $52 \mathrm{mN} / \mathrm{m}$ at a $3.7 \mathrm{wt} \%$ salinity. The behavior with the dispersant-in-solution case was more complex as the average IFT decreased to a minimum at $1.3 \mathrm{wt} \%$ water salinity followed by a slight increase at $2.5 \mathrm{wt} \%$ salinity. The average IFT then decreased slightly upon addition of more salt to the water sample.

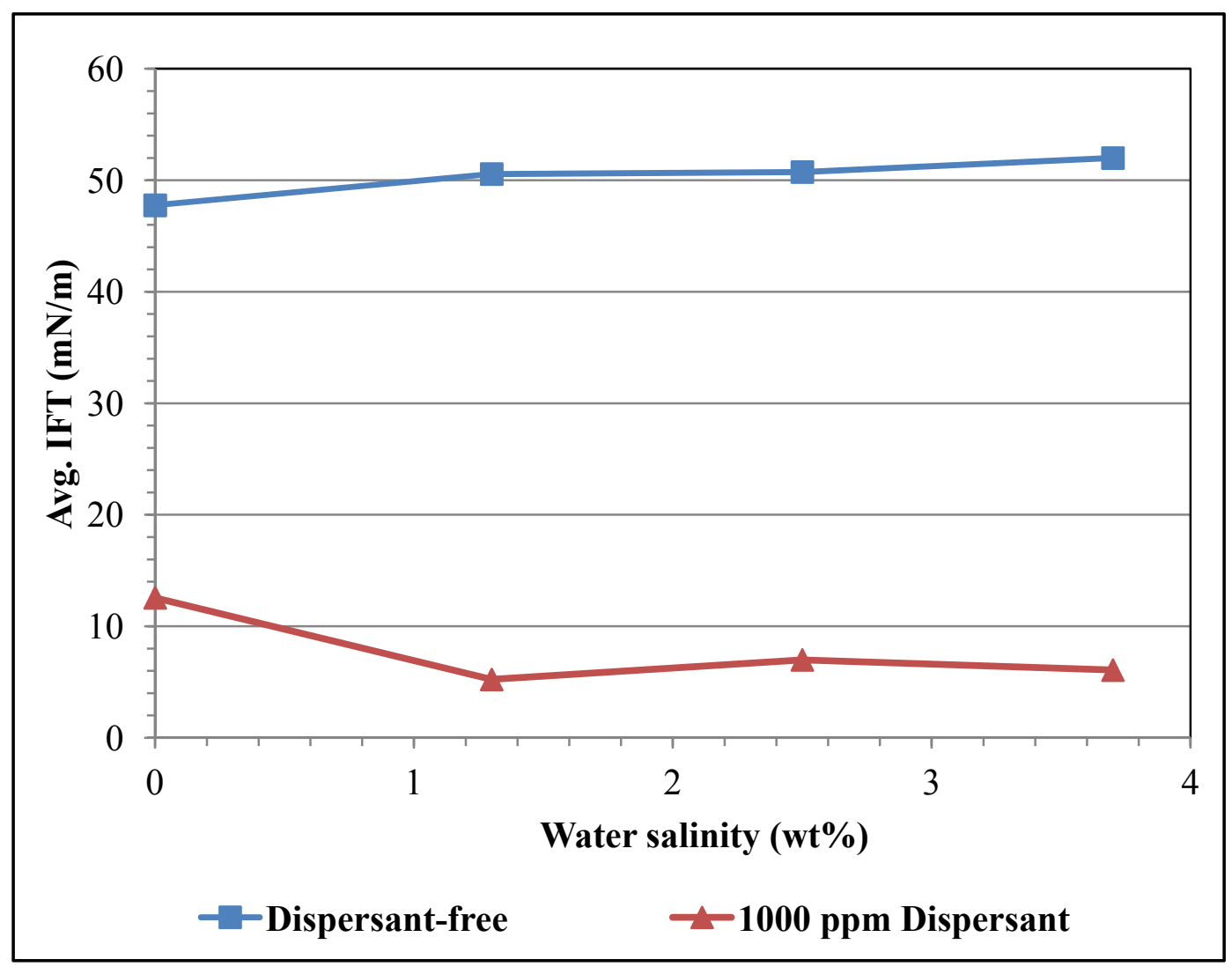

Figure 46: Average IFT between n-octane and water samples of various salinities at 2,225 psi and $40{ }^{\circ} \mathrm{F}$

\subsubsection{Crude Oil/Water/Dispersant System}

The measured densities of water samples of various salinities are compared to that of crude oil at 2,225 psi and $40{ }^{\circ} \mathrm{F}$ in Figure 47 . The density of crude oil, $0.86731 \mathrm{~g} / \mathrm{cc}$, was measured at the same conditions. The density difference between the two, $\Delta \rho$, is plotted on the right vertical axis. 
The behavior of the density difference, $\Delta \rho$, observed in Figure 47 was similar to that seen in the n-octane/water system (Figure 45) where $\Delta \rho$ increased with increased water salinity. Since the density of the crude oil was higher than that of n-octane, the magnitudes of the density difference, $\Delta \rho$, were much smaller in the crude oil/water system than in the n-octane/water system at the same conditions.

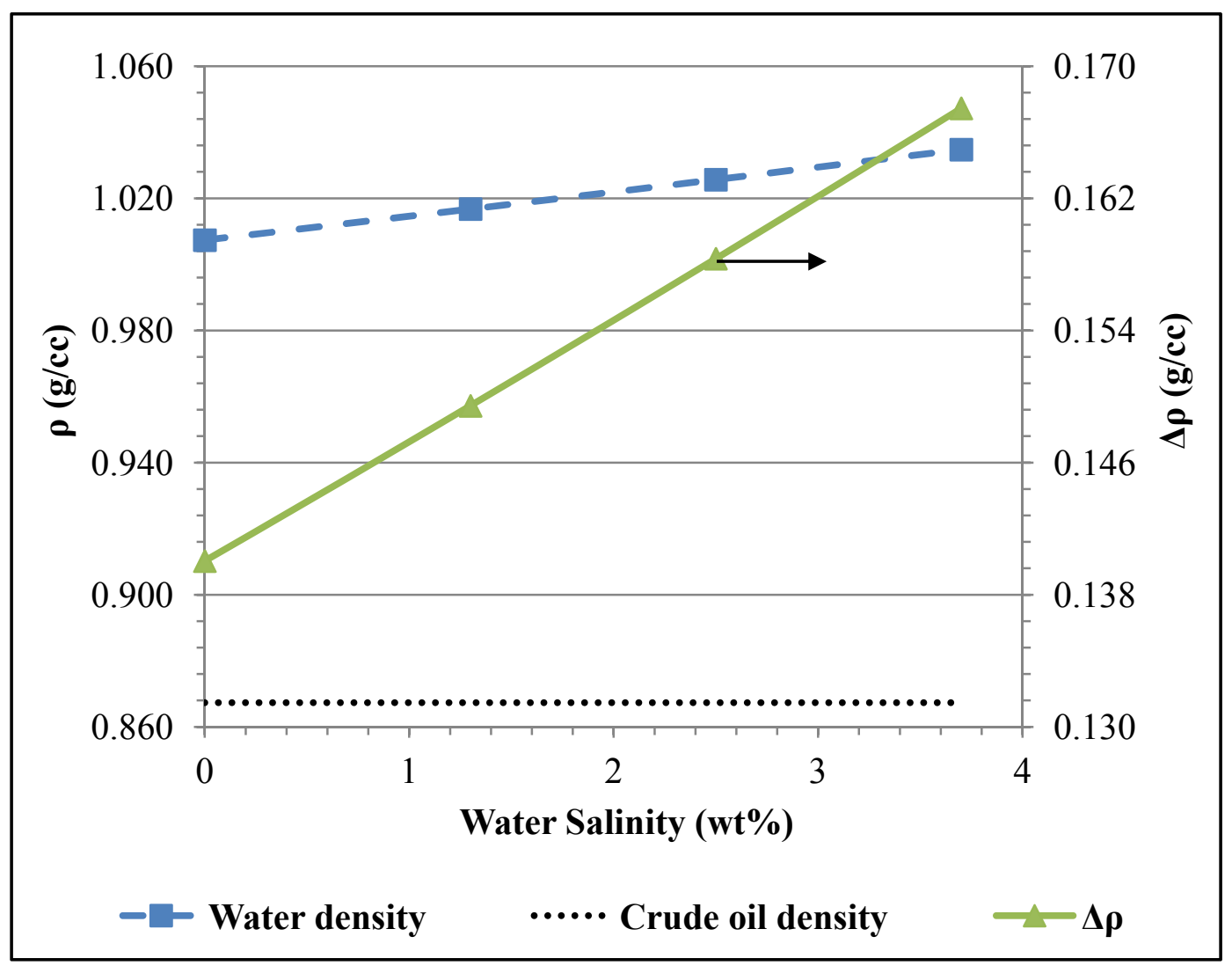

Figure 47: Crude oil and water densities at 2,225 psi and $40^{\circ} \mathrm{F}$

The average IFT between the crude oil and the various water samples was measured at 2,225 psi and $40^{\circ} \mathrm{F}$ for both the dispersant-free and dispersant-in-solution cases as illustrated in Figure 48.

It can be observed from Figure 48 that the average IFT decreased to a minimum at $2.5 \mathrm{wt} \%$ salinity and then slightly increased upon further increase of salinity for the dispersant-free case. 
On the other hand, the average IFT reached its minimum at $1.3 \mathrm{wt} \%$ salinity for the dispersantin-solution case and then also increased with increasing water salinity.

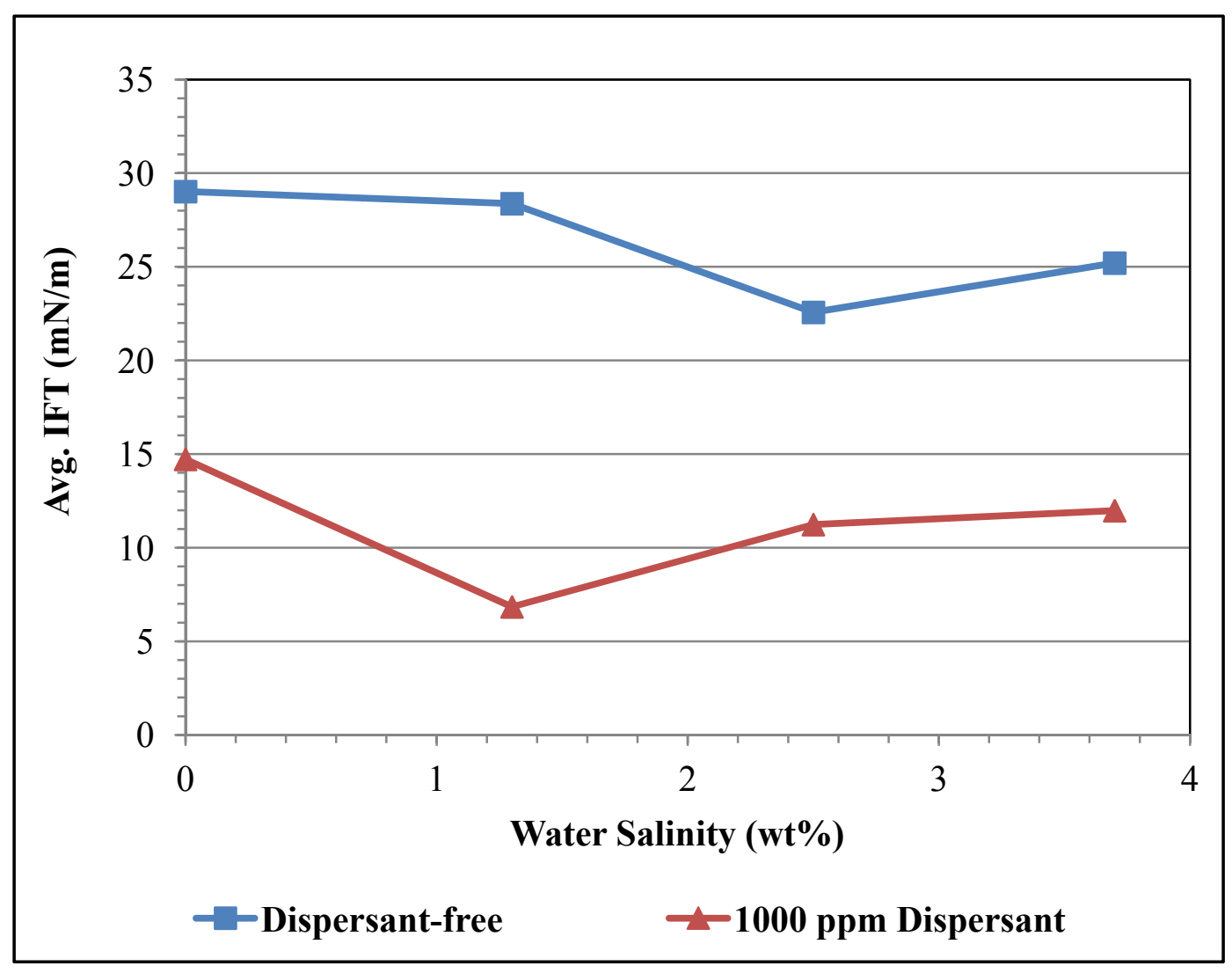

Figure 48: Average IFT between crude oil and water samples of various salinities at 2,225 psi and $40^{\circ} \mathrm{F}$

\subsubsection{Comparison of n-Octane and Crude Oil Systems}

Figure 49 shows the dispersant-induced reduction in the IFT as a percentage of the dispersant-free IFT for both the n-octane/water and crude oil/water systems at 2,225 psi, $40{ }^{\circ} \mathrm{F}$ and at various water salinities.

Figure 49 illustrates similar trends in the behavior of the magnitude of IFT reduction, $\Delta \gamma$, for both the n-octane/water and crude oil/water systems. The magnitude of the IFT reduction increased from its lowest value at $0 \mathrm{wt} \%$ salinity to its maximum value at $1.3 \mathrm{wt} \%$ salinity for both systems. It is also interesting to note that a $75 \%$ reduction in the IFT was measured at 1.3 
wt $\%$ salinity for the crude oil/water system, which is reasonably close to the reduction in the noctane/water system (90\%), and by far the greatest reduction in the crude oil/water IFT measured in this study. The magnitude in IFT reduction decreased when the salinity was increased past $1.3 \mathrm{wt} \%$ followed by a slight increase upon more addition of salt for both systems.

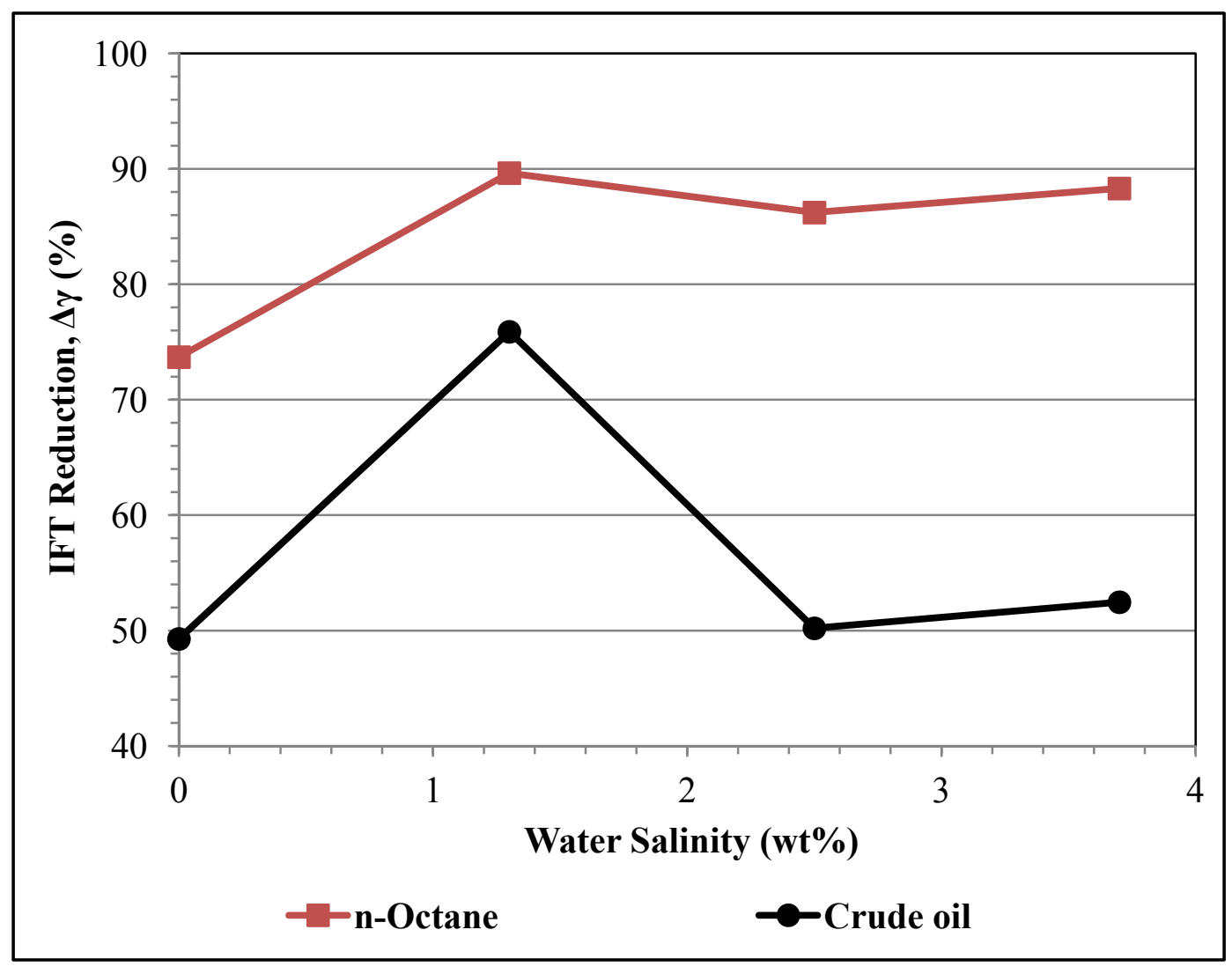

Figure 49: Dispersant-induced reduction in the hydrocarbon/water IFT as a percentage of the dispersant-fee IFT at $2,225 \mathrm{psi}$ and $40^{\circ} \mathrm{F}$ and at various water salinities

\subsection{Dispersant-in-Oil Concentration Variation}

The results of experiment set 5 in which the dispersant was dissolved in the crude oil, instead of in the water phase, at different concentrations are discussed in this section. All experiments were conducted at seafloor condition of pressure and temperature, namely $2,225 \mathrm{psi}$ and $40^{\circ} \mathrm{F}$ respectively, and using the $2.5 \mathrm{wt} \%$ salt water. Figure 50 shows the measured average IFT 
between crude oil and the $2.5 \mathrm{wt} \%$ salt water as a function of the dispersant concentration in the crude oil.

The average IFT can be observed to decrease greatly upon the addition of $1,000 \mathrm{ppm}$ of dispersant to the crude oil as is seen in Figure 50. The addition of more dispersant resulted in a progressively less pronounced reduction in the IFT which is indicative of a CMC at or below $1,000 \mathrm{ppm}$ for the crude oil/water system.

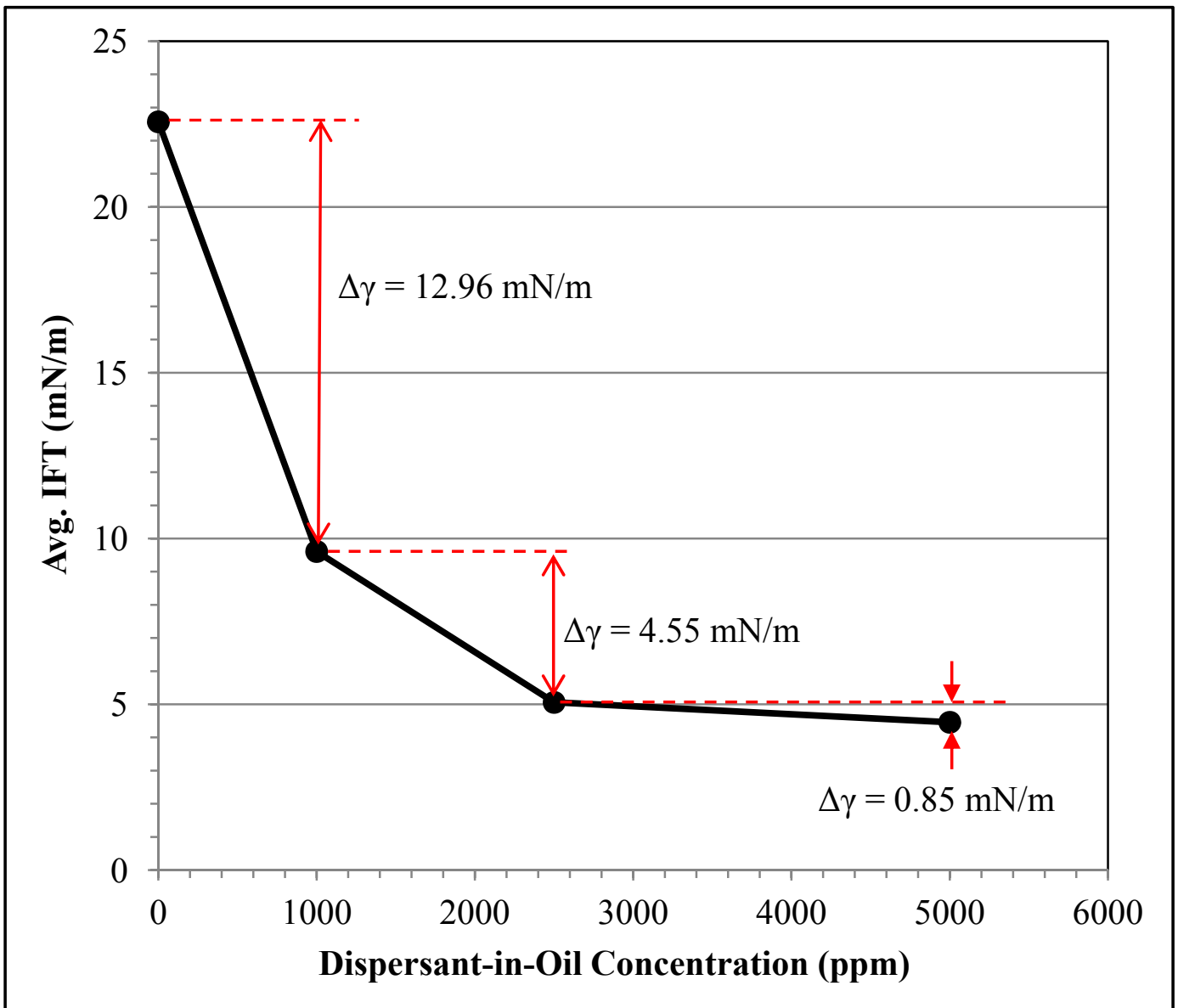

Figure 50: Average IFT between crude oil and $2.5 \mathrm{wt} \%$ salt water at 2,225 psi and $40^{\circ} \mathrm{F}$ and as a function of the dispersant concentration in the oil

It is also interesting to point out that more dispersant was dissolved in the crude oil, namely $10,000 \mathrm{ppm}$, but attempts to introduce the crude oil into the water-filled optical cell at the same conditions in the form of a pendant drop were unsuccessful. Instead of breaking up into small 
droplets, the crude oil emerged from the tip of the capillary tube in the form of a continuous stream or jet. An actual photograph of the crude oil emerging from the tip of the capillary tube at seafloor conditions and 10,000 ppm concentration of dispersant dissolved in the crude oil is shown in Figure 51.

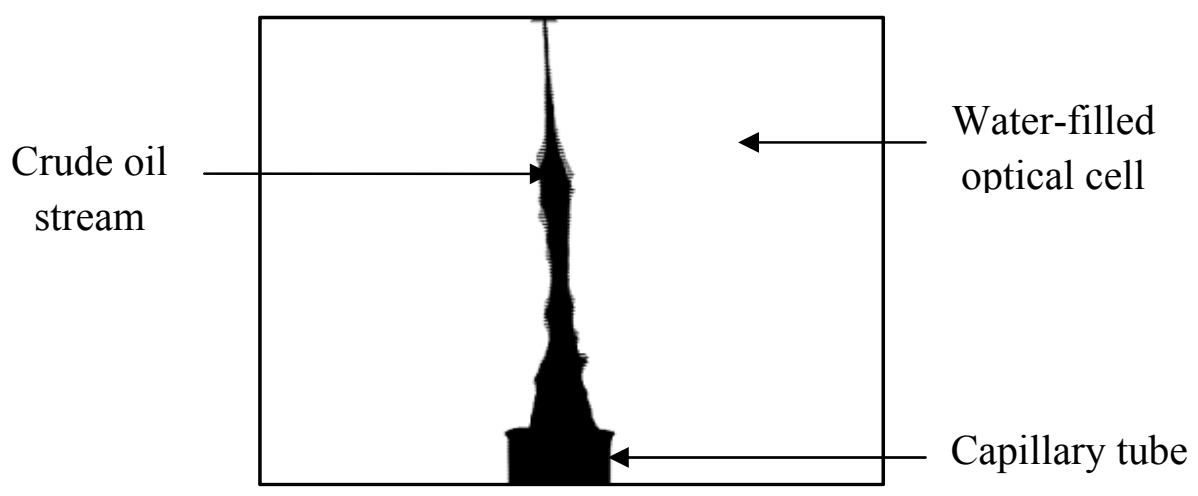

Figure 51: Photograph of the crude oil emerging from the tip of the capillary tube at 2,225 psi, $40^{\circ} \mathrm{F}$ and $10,000 \mathrm{ppm}$ dispersant-in-oil concentration

The dispersant-induced reduction in the IFT is illustrated in Figure 52 as a percentage of the dispersant-free value.

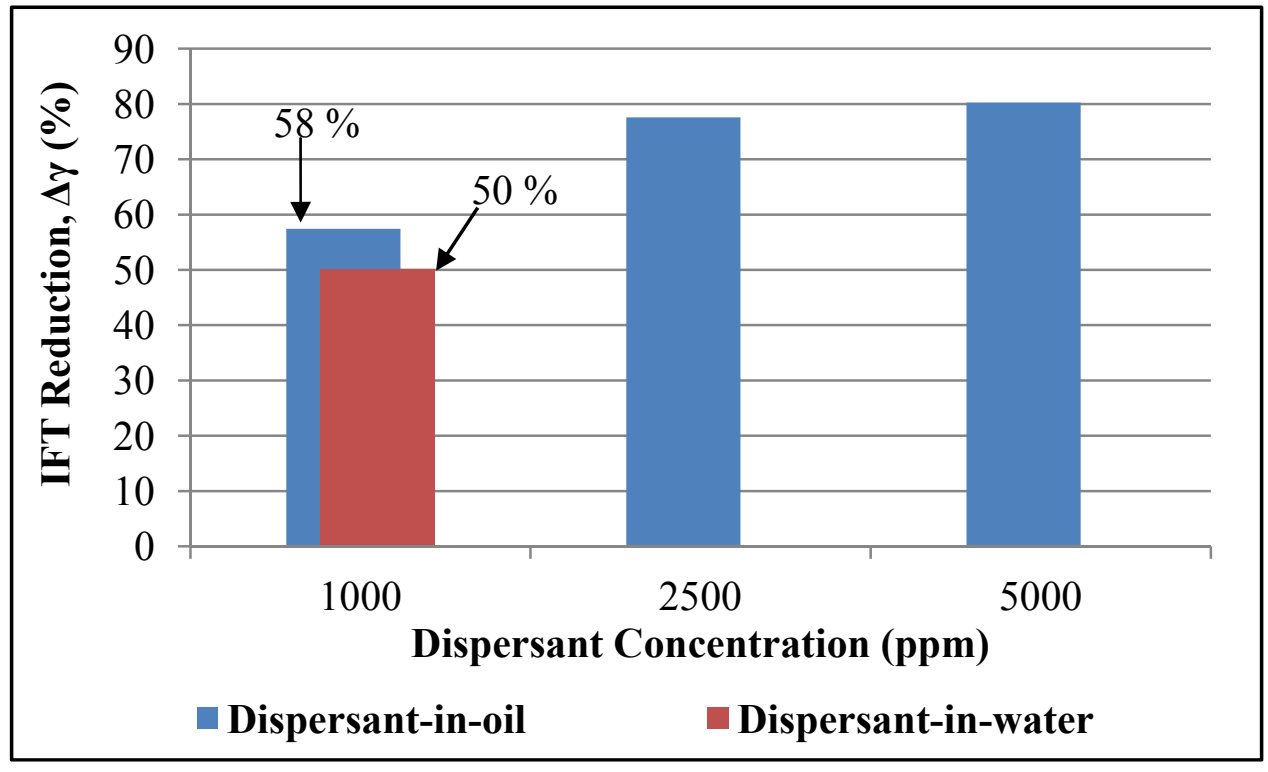

Figure 52: Dispersant-induced reduction in the crude oil/water IFT as a percentage of the dispersant-free IFT at 2,225 psi and $40^{\circ} \mathrm{F}$ 
It can be seen from Figure 52 that the IFT reduction at 1,000 ppm of dispersant was greater when the dispersant was dissolved in the crude oil as compared to when it was dissolved in the $2.5 \mathrm{wt} \%$ salt water. Accordingly, the dispersant effectiveness was higher when the dispersant agent was dissolved in the crude oil. The reason behind this improvement in dispersant effectiveness is that the surfactant molecules responsible for reducing the IFT have a more efficient accumulation at the oil/water interface when the dispersant is dissolved in the crude oil. On the other hand, when the dispersant is dissolved in the water, a relatively larger amount of surfactant molecules are lost to the bulk water and, consequently, the IFT reducing capabilities of the dispersant are significantly weakened.

The lowest measured oil/water IFT in this study was $4.46 \mathrm{mN} / \mathrm{m}$, and was recorded when $5,000 \mathrm{ppm}$ of dispersant was dissolved in the crude oil at deepwater conditions of pressure and temperature. It is noteworthy that even at such high concentrations of dispersant dissolved in the oil, ultra-low oil/water IFT $(<1.0 \mathrm{mN} / \mathrm{m})$ was not achieved. Furthermore, when the dispersant concentration was increased to $10,000 \mathrm{ppm}$ at the same conditions of pressure and temperature, the oil emerged in the form of a jet from the tip of the capillary tube. These observations clearly demonstrate that the use of such high dispersant concentrations at deepwater conditions may not be an effective remedy to breakup an oil plume into smaller droplets. 


\section{CHAPTER 5. CONCLUSIONS AND RECOMMENDATIONS}

\subsection{Summary and Conclusions}

An experimental apparatus capable of replicating the Deepwater Horizon oil spill conditions of pressure and temperature was designed and utilized to measure the densities of Macondo crude oil and water, and to measure the interfacial tension (IFT) between the two phases. The apparatus consisted of an optical cell designed to withstand deepwater conditions of pressure and temperature. A digital density meter was calibrated and used to measure the densities of the crude oil and water at the representative conditions of pressure and temperature. IFT was measured by the computerized Pendant Drop method at these conditions. The behavior of the crude oil density and the oil/water IFT were compared to those of reagent grade n-octane. The influences of pressure, temperature, water salinity and dispersant concentration on the hydrocarbon/water IFT were investigated. Additionally, the effectiveness of the dispersant, Corexit ${ }^{\circ} 9500$, was evaluated based on the magnitude of the reduction in the oil/water IFT.

The main findings of this experimental study are as follows:

- The density of crude oil was much more sensitive to changes in pressure and temperature than the density of the $2.5 \mathrm{wt} \%$ salt water. This difference in density change caused the density difference, $\Delta \rho$, between the two to decrease with increasing water depth or increasing pressure and decreasing temperature. The density difference, $\Delta \rho$, did not always follow the same trend as the measured IFT.

- The measured IFT between Macondo crude oil and $2.5 \mathrm{wt} \%$ salt water at deepwater conditions $\left(2,225 \mathrm{psi}\right.$ and $\left.40^{\circ} \mathrm{F}\right)$ ranged from 22.44 to $22.72 \mathrm{mN} / \mathrm{m}$. The dissolution of $1,000 \mathrm{ppm}$ of Corexit ${ }^{\circledR} 9500$ in the salt water reduced the average IFT to $11.24 \mathrm{mN} / \mathrm{m}$, a $50 \%$ reduction from the average dispersant-free IFT. A $58 \%$ reduction in the IFT from 
its dispersant-fee value was recorded when 1,000 ppm of the dispersant was dissolved in the crude oil at the same conditions. The average oil/water IFT decreased to $4.46 \mathrm{mN} / \mathrm{m}$, an $80 \%$ reduction from its dispersant-free value, when the concentration of dispersant in oil was increased to $5,000 \mathrm{ppm}$.

- Based on the magnitude of the IFT reduction, the effectiveness of the dispersant decreased with increasing water depth. This was mainly due to the decrease in temperature at greater water depths as the increase in pressure had a relatively smaller effect on the IFT.

- An unexpected effect of temperature was observed with the dispersant-free water at constant pressure, as the crude oil/water IFT increased from $22.57 \mathrm{mN} / \mathrm{m}$ at $40{ }^{\circ} \mathrm{F}$ to 24.52 $\mathrm{mN} / \mathrm{m}$ at $73^{\circ} \mathrm{F}$. However, the dissolution of $1,000 \mathrm{ppm}$ of dispersant in the water reversed that trend as the IFT decreased from 11.25 to $9.40 \mathrm{mN} / \mathrm{m}$ over the same temperature range. Consequently, the magnitude of IFT reduction decreased at lower temperatures indicating lower dispersant effectiveness.

- Pressure had a negligible effect on the average crude oil/water IFT when the dispersantfree salt water was used as the IFT fluctuated between 22.57 to $22.78 \mathrm{mN} / \mathrm{m}$ over the entire pressure range. A considerable increase in the IFT was observed with increasing pressure and constant temperature when $1,000 \mathrm{ppm}$ of the dispersant was dissolved in the $2.5 \mathrm{wt} \%$ salt water. The average oil/water IFT increased from $8.55 \mathrm{mN} / \mathrm{m}$ at atmospheric pressure to $11.25 \mathrm{mN} / \mathrm{m}$ at 2,225 $\mathrm{psi}$, a $31.5 \%$ increase in the IFT due to increasing pressures with the dispersant dissolved in the salt water. This in turn resulted in lower magnitudes in the IFT reduction with increasing pressures, and hence lower effectiveness at greater water depths. 
- The magnitude of IFT reduction reached a maximum of $90 \%$ in the n-octane/water system while a maximum of $70 \%$ reduction was observed in the crude oil/water system at the same conditions. This indicates that the chemical complexity and the presence of indigenous surfactants in the crude oil may lead to a different dispersion process in the crude oil/water system from the $\mathrm{n}$-octane/water system in terms of effectiveness.

- The Corexit ${ }^{\circledR} 9500$ dispersant was most effective when mixed with the $1.3 \mathrm{wt} \%$ salt water inducing the greatest magnitude in IFT reduction for both the crude oil/water and n-octane/water systems. The influence of water salinity appears to be specific to the hydrocarbon/water/dispersant system used in this study and would likely have a different effect should any of the components of the system change.

- When dissolved in the crude oil, an improvement in the effectiveness of the dispersant was observed as compared to the dissolution in the water phase. However, 1,000 ppm was noted as a concentration value beyond the CMC, since the IFT reduction was less pronounced at higher concentrations. This implies that using such high concentrations of dispersant would not be an effective solution at deepwater conditions.

- The formation of small oil droplets was not observed in this study. At the highest dispersant-in-oil concentration tested (10,000 ppm), the oil emerged from the tip of the capillary tube in the form of a continuous stream. This is indicative of an ineffective dispersion process at the deepwater conditions in which these tests were conducted.

\subsection{Practical Implications}

Based on the experimentally measured oil/water IFT values, it is evident that the low temperature associated with the seafloor was the main factor responsible for worsening the IFT reducing capabilities of the dispersant. Considering the conditions of the Deepwater Horizon oil 
spill, the seawater is at a much lower temperature than the oil gushing out of the failed wellhead. However, as the contact time between the two increases, the relatively smaller mass of oil will eventually reach a temperature as low as that of the seawater. Consequently, the oil viscosity increases and the penetration of the surfactant molecules into the oil is retarded. This in turn would result in a detrimental effect on the chemical dispersion of the spilled oil.

An effective design of a subsea dispersant injection system should therefore be able to counteract the effect of temperature and induce the greatest magnitude of interfacial tension reduction possible. To do so, the wands spraying the dispersant onto the oil stream could be equipped with heaters, with consideration of power requirements, as to delay the decline in the temperature of the spilled oil. In addition, the thermal stability of the surfactant molecules within the dispersant formulation would have to be evaluated.

The nature and time of contact between the spilled oil and the dispersant are also important factors affecting the effectiveness of the dispersion process. One of the major requirements for the formation of small oil droplets, and hence the dispersion of spilled oil, is that the surfactant molecules within the dispersant must have enough time to penetrate and mix into the oil [NRC, 1989]. Moreover, the experimentally measured oil/water IFT in this study indicated that the effectiveness of the dispersant was higher when dissolved in the oil than in water. It is also known that surfactant molecules within the dispersant are soluble in both oil and water and it is, therefore, important to minimize the loss of the dispersant to the surrounding water.

During the Deepwater Horizon spill, the oil was gushing out of the failed wellhead at such a fast rate that intimate contact between the oil and the sprayed dispersant was probably not achieved, or at least the duration of contact could have been extended. Containing the spilled oil within a closed structure for a specific amount of time while simultaneously applying the 
dispersant would have enhanced the chemical dispersion process. There was an unsuccessful attempt to contain the spilled oil using a dome, also known as a cofferdam, placed over the leak to have the oil channeled to the water surface to be collected [www.oilspillcommision.gov]. The failure was due to the fact that the methane gas escaping from the well formed slushy hydrates as it came in contact with the cold seawater and clogged the cofferdam.

The subsea application of dispersants could be improved by designing several domes that contain and inject dispersants into the spilled oil before releasing the oil back into the seawater for entrainment of the recently formed oil droplets into the water column. The period of time during which the oil is contained and the dispersant is applied could be predetermined by laboratory testing as to ensure sufficient mixing and penetration into the oil. Another potential benefit of such a design is that an adequate dispersant dosage can also be estimated since the volume of the contained oil can be approximated, given the fact that some seawater will inadvertently find its way into the dome as well. As a result, both the efficiency and effectiveness of the dispersant application process would be improved.

\subsection{Recommendations for Future Work}

The Pendant Drop method, with the ASDA technique, is a reliable way of measuring the IFT between immiscible fluids and has a great degree of reproducibility. However, one of its limitations is the inability to measure ultra-low interfacial tensions $(<1.0 \mathrm{mN} / \mathrm{m})$. The dissolution of more dispersant in the crude oil did not result in the oil breaking up into small droplets. Instead, formation of a pendant drop was not possible as the oil began to emerge as a continuous jet from the capillary tube. For this reason, the measurement of ultra-low interfacial tensions associated with small droplets was ruled out in this study. Therefore, a method capable 
of measuring ultra-low interfacial tensions such as the light scattering technique should be investigated to determine its adaptability for high pressure measurements.

The crude oil sample used in this study was collected as a 'dead' sample (without its dissolved light ends) and used as it was supplied. Although, the crude oil was pressurized, the effect of light ends in the crude oil on its composition, and ultimately on the IFT, was not accounted for due to the lack of information on the composition of the 'live' oil. The recombination of the 'dead' crude to its original 'live' oil composition to be used in the density and IFT measurements would add great value to understanding its phase behavior at deepwater conditions in which the oil spill occurred.

The nature of distribution of spilled oil on the water surface should be studied through the evaluation of the oil spreading coefficient. This could be done by the direct measurement of oil/water, water/air and air/oil interfacial tensions.

To better understand the effect of water salinity on the effectiveness of chemical dispersants, a more detailed study involving the actual composition of the seawater should be conducted. 


\section{REFERENCES}

1. http://www.noaa.gov

2. http://www.nodc.noaa.gov

3. http://www.oilspillcommission.gov

4. http://www.uscg.mil

5. http://webbook.nist.gov/chemistry/fluid

6. http://www.whoi.edu

7. Al-Shahhaf, T., Elkamel, A., Ahmed, A. S., and Khan, A. R., "The Influence of Temperature, Pressure and Surfactant Concentration on the Interfacial Tension of the n-Octane-Water System," Chem. Eng. Comm., 192: 667-684. (2005)

8. Bobra, M., "A Study of the Formation of Water-in-Oil Emulsions," Proc. Thirteenth Arctic Marine Oil Spill Program Technical Seminar, 6-8 June 1990, Edmonton, Alberta. Environment Canada, Ottawa, Ontario, pp. 87-117. (1990)

9. Bobra, M., "Water-in-Oil Emulsification: A Physiochemical Study," Proc. 1991 International Oil Spill Conference, 4-7 Mar. 1991, San Diego, CA. American Petroleum Institute, Washington, D.C., pp. 483-488. (1991)

10. Bridie, A.L., Wanders, T.H., Zegveld, W., and Van Der Heijde, H.B., "Formation, Prevention and Breaking of Sea Water in Crude Oil Emulsions 'Chocolate Mousse'," in Marine Pollution Bulletin 11, pp. 343-348. (1980)

11. Brochu, C., Pelletier, E., Caron, G., and Desnoyers, J.E., "Dispersion of Crude Oil in Seawater: The Role of Synthetic Surfactants," in Oil \& Chemical Pollution 3, pp. 257-259. (1986)

12. Buist, I.A., and Ross, S.L., "A Study of Chemicals to Inhibit Emulsification and Promote Dispersion of Oil Spills," in Oil \& Chemical Pollution 3, pp. 485-503. (1986/87)

13. Cai, B. Y., Yang, J. T., and Guo, T. M., "Interfacial Tension of Hydrocarbon + Water / Brine System Under High Pressure”, J. Chem. Eng. Data, 41, 493-496. (1996)

14. Canevari, G. P., "A Review of the Relationship between the Characteristics of Spilled Oil and Dispersant Effectiveness," in Oil Spill Chemical Dispersants: Research, Experience, and Recommendations, ASTM STP840, T.E. Allen ed., American Society for Testing and Materials, Philadelphia, PA, pp. 87-93. (1984) 
15. Canevari, G. P., "The Effect of Crude Oil Composition on Dispersant Performance," Proc. 1985 Oil Spill Conference, 25-28 Feb. 1985, Los Angeles, CA. American Petroleum Institute, Washington, D.C., pp. 441-444. (1985)

16. Canevari, G. P., "Basic Study Reveals How Different Crude Oils Influence Dispersant Performance," Proc. 1987 Oil Spill Conference. American Petroleum Institute, Washington, D.C., pp. 293-296. (1987)

17. Clayton, J. R., Payne, J. R., Farlow, J. S., "Oil Spill Dispersants: Mechanisms of Action and Laboratory Tests," illustrated edition, CRC press. (1993)

18. Cormack, D., Lynch, B.W.J., and Dowsett, B.D., "Evaluation of Dispersant Effectiveness," in Oil \& Chemical Pollution 3, pp. 87-103. (1986/87)

19. Danesh, A., "PVT and Phase behavior of Petroleum Reservoir Fluids," Elsevier Science B.V. (1998)

20. Fingas, M.F., Kolokowski, B., and Tennyson, E.J., "Study of Oil Spill Dispersants Effectiveness and Physical Studies," Proc. Thirteenth Arctic Marine Oil Spill Program Technical Conference, 6-8 June 1990, Edmonton, Alberta. Environment Canada, Ottawa, Ontario. pp., 265287. (1990)

21. Fingas, M.F., Bier, I., Bobra, M., and Callaghan, S., "Studies on the Physical and Chemical Behavior of Oil and Dispersant Mixtures," Proc. 1991 International Oil Spill Conference, 4-7 Mar. 1991, San Diego, CA. American Petroleum Institute, Washington, D.C., pp. 419-246. (1991)

22. George-Ares, A., and Clark, J.R., "Aquatic Toxicity of Two Corexit ${ }^{\circledR}$ Dispersants," in Chemosphere 40, pp. 897-906. (2000)

23. Harusawa, F., Saito, T., Nakajima, H., and Fukushima, S., "Partition Isotherms of Nonionic Surfactants in the Water Cyclohexane System and the Type of Emulsion Produced," Journal of Colloid and Interface Science 74, pp. 430-440. (1980)

24. Lehtinen, C.M. and Vesala, A-M., "Effectiveness of Oil Spill Dispersants at Low Salinities and Low Temperatures," in Oil Spill Chemical Dispersants: Research, Experience, and Recommendations, ASTM STP840, T.E. Allen ed., American Society for Testing and Materials, Philadelphia, PA, pp. 108-121. (1984)

25. Mackay, D. and Hossain, K., "Interfacial Tensions of Oil, Water, Chemical Dispersant Systems," Canadian Journal of Chemical Engineering, Vol.60, No.4, Aug. 1982, pp. 546-550. (1982)

26. Mackay, D., Chau, A., Hossain, K., and Bobra, M., "Measurement and Prediction of the Effectiveness Oil Spill Chemical Dispersants", in Oil Spill Chemical Dispersants: Research, 
Experience, and Recommendations, ASTM STP840, T.E. Allen ed., American Society for Testing and Materials, Philadelphia, PA, pp. 38-54. (1984)

27. Motomura, K., Iyota, H., Aratono, M., Yamanaka, M., and Matuura, R., "Thermodynamic Consideration of the Pressure Dependence of Interfacial Tension", Journal of Colloid and Interface Science, Vol. 93, No.1 (1983)

28. Myers, D., "Surfaces, Interfaces and Colloids: Principles and Applications," 2nd edition, John Wiley \& Sons (1999)

29. National Research Council (U.S.). Ocean Studies Board, "Using Oil Spill Dispersants on the Sea," The National Academic Press, Washington, D.C. (1989)

30. National Research Council (U.S.). Ocean Studies Board, "Oil Spill Dispersants: Efficacy and Effects," illustrated edition, The National Academic Press, Washington, D.C. (2005)

31. Nierderhauser, D., and Bartell, F., "A corrected Table for the Calculation of Boundary Tensions by the Pendent Drop Method," Research on Occurrence and Recovery of Petroleum, A Contribution from API Research Project 27, pp. 114-146 (1947)

32. Princen, H., Zia, I., and Mason, S., "Measurement of Interfacial Tension from the Shape of a Rotating Drop," Journal of Colloid and Interface Science, Vol.23, Issue 1, Jan. 1967, pp. 99-107. (1967)

33. Rao, D.N., "Fluid-Fluid and Solid-Fluid Interfacial Interactions in Petroleum Reservoirs," Petroleum Science and Technology, 19 (1\&2), 2001, pp. 157-188. (2001)

34. Rewick, R. T., Sabo, K. A., Gates, J., Smith, J. H. and McCarthy, L.T., Jr., "An Evaluation of Oil Spill Dispersant Testing Requirements," Proc. 1981 Oil Spill Conference, 2-5 Mar. 1981, Atlanta, GA. American Petroleum Institute, Washington, D.C., pp. 5-10. (1981)

35. Rewick, R. T., Sabo, K. A., and Smith, J. H., “The Drop-Weight Interfacial Tension Method for Predicting Dispersant Performance," in Oil Spill Chemical Dispersants: Research, Experience, and Recommendations, ASTM STP840, T.E. Allen ed., American Society for Testing and Materials, Philadelphia, PA, pp. 94-107. (1984)

36. Rio, del O.I. and Neumann, A.W., "Axisymmetric Drop Shape Analysis: Computational Methods for the Measurement of Interfacial Properties from the Shape and Dimensions of Pendant and Sessile Drops," Journal of Colloid and Interface Science 196, 1997, pp. 136-147. (1997)

37. Rotenberg, Y., Boruvka, L. and Neumann, A.W., "Determination of Surface Tension and Contact Angle from the Shapes of Axisymmetry Fluid Interfaces", Journal of Colloid and Interface Science, 93, 1983, pp. 169-183. (1983) 
38. Sequeira, D.S., "Compositional Effects on Gas-Oil Interfacial Tension and Miscibility at Reservoir Conditions,” Master's Thesis, Louisiana State University, Baton Rouge, LA. (2006)

39. Singer, M., Smalheer, D.L., Tjeerdema, R.S., Martin, M., "Effects of Spiked Exposure to an Oil Spill Dispersant on The Early Life Stages of Four Marine Species", Journal of Environmental Toxicology and Chemistry 10, pp. 1367-1374. (1991)

40. Vijapurapu, C.S., "The Effect of Rock and Fluids Characteristics on Reservoir Wettability," Master's Thesis, Louisiana State University, Baton Rouge, LA. (2002)

41. Wells, P.G., Abernethy, S., and Mackay, D., "Acute Toxicity of Solvents and Surfactants of Dispersants in Two Planktonic Crustaceans," Proc. Eighth Arctic and Marine Oil Spill Program Technical Seminar, 18-20 June 1985, Edmonton, Alberta, Canada. Environmental Protection Service, Environment Canada, pp. 228-240. (1985)

42. Xu, W., Ayirala, S.C. and Rao, D.N., "Measurement of Surfactant-Induced Interfacial Interactions at Reservoir Conditions," SPE Reservoir Evaluation and Engineering, Feb. 2008, pp. 83-94. (2008)

43. Anton Paar Instruction Manual, "DMA HP Density Measuring Cell for High Pressure and High Temperatures," GmbH, Graz, Austria. (2005) 


\section{VITA}

Mohamed Abdelrahim, a native of Sudan and the son of Dr. Ahmed Abdelrahim and Faiza AbuEissa, was born in Abu Dhabi, United Arab Emirates in 1985. After completing his high school studies at the International School of Choueifat in Abu Dhabi, he enrolled in the petroleum engineering undergraduate program at LSU in the Fall of 2004. Upon receiving his Bachelor of Science in May of 2008, Mohamed worked as a Mud Logger for Diversified Well Logging, Inc., before going back to LSU to work towards a graduate degree in the Fall of 2009. The degree of Master of Science in Petroleum Engineering will be conferred in May of 2012. Mohamed will then join Shell Exploration and Production Company as a Reservoir Engineer. 